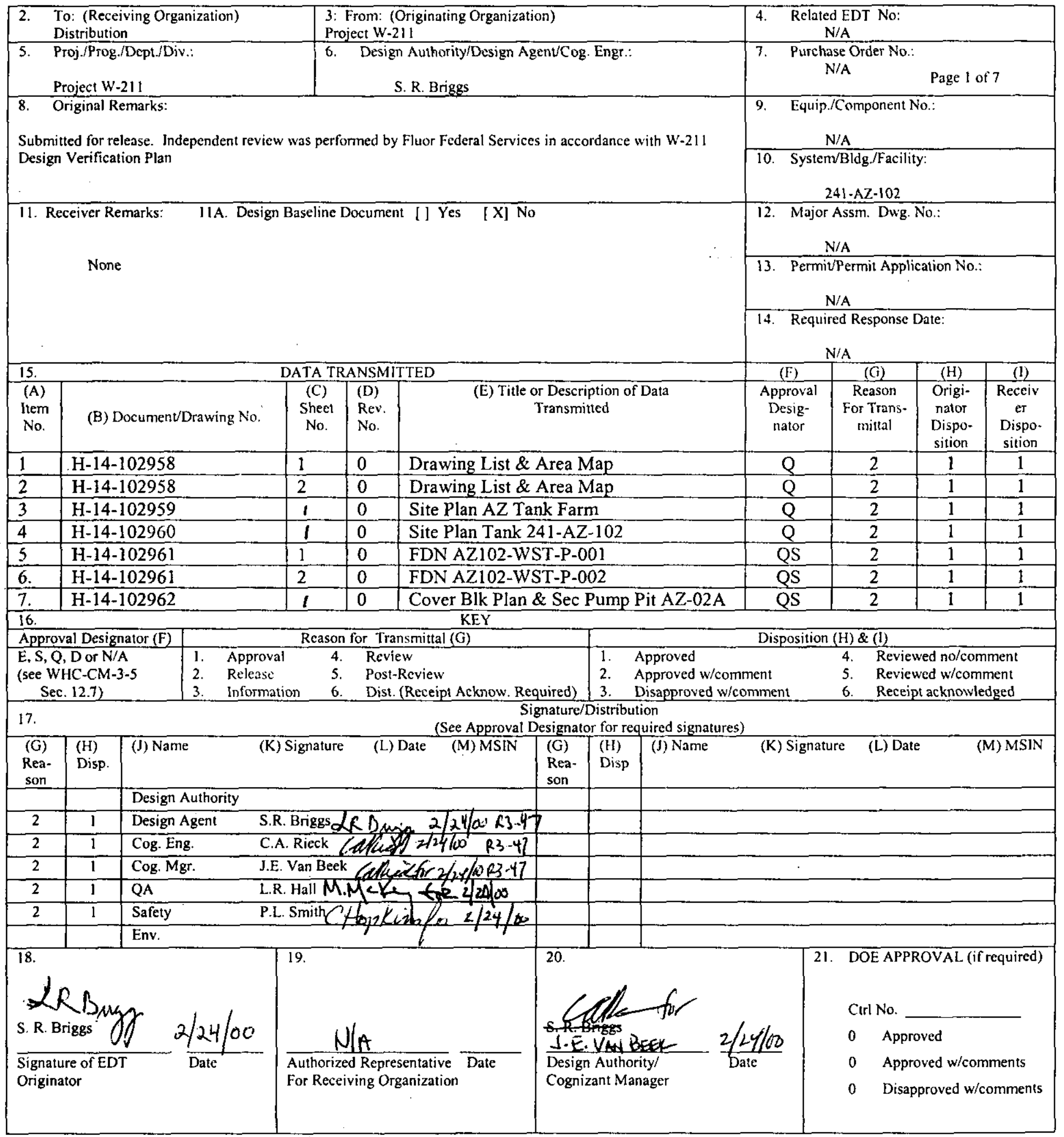




\section{ENGINEERING DATA TRANSMITTAL}

(CONTINUATION PAGE)

\begin{tabular}{|c|c|c|c|c|c|c|c|c|}
\hline \multicolumn{2}{|c|}{$\begin{aligned} & \text { 5. } \text { Proj/Prog/Dept. Div: } \\
& \text { Project W-211 }\end{aligned}$} & \multirow{2}{*}{\multicolumn{3}{|c|}{$\begin{array}{r}\text { 6. Cog. Eng. } \\
\text { S. R. Briggs } \\
\text { OATA TRANSWITTED } \\
\end{array}$}} & \multicolumn{2}{|l|}{$\begin{array}{ll}\text { 1. } & \text { EDT } \\
& 625742 \\
\end{array}$} & \multicolumn{2}{|c|}{ Page 2 of 7} \\
\hline & & & & & (F) & (G) & (H) & (1) \\
\hline $\begin{array}{l}\text { (A) } \\
\text { Item } \\
\text { No. }\end{array}$ & (B) Document/Drawing No. & $\begin{array}{l}\text { (C) } \\
\text { Sheet } \\
\text { No. }\end{array}$ & $\begin{array}{l}\text { (D) } \\
\text { Rev. } \\
\text { Noo }\end{array}$ & $\begin{array}{l}\text { (E) Title or Description of Data } \\
\text { Transmitted }\end{array}$ & $\begin{array}{c}\text { Approval } \\
\text { Designator }\end{array}$ & $\begin{array}{l}\text { Reason } \\
\text { For } \\
\text { Trans } \\
\text { mittal }\end{array}$ & $\begin{array}{l}\text { Originator } \\
\text { Disposition }\end{array}$ & $\begin{array}{c}\text { Receiver } \\
\text { Disposition }\end{array}$ \\
\hline 8 & H-14-102963 & 1 & 0 & Cover Blocks Sections \& Details & QS & 2 & 1 & 1 \\
\hline 9 & H-14-102963 & 2 & 0 & Cover Blocks Sections \& Details & QS & 2 & 1 & 1 \\
\hline 10 & H-14-102964 & 1 & 0 & Misc. Steel Frames Tank AZ-102 & $\mathrm{Q}$ & 2 & 1 & 1 \\
\hline 11 & $\mathrm{H}-14-102965$ & 1 & 0 & Mixer Pump FDN Mounting Plate & $\mathrm{Q}$ & 2 & 1 & 1 \\
\hline 12 & $\mathrm{H}-14-102968$ & 1 & 0 & Bldg 241-AZ-801A Plan, Sect \& Details & $Q$ & 2 & 1 & 1 \\
\hline 13 & $\mathrm{H}-14-102969$ & 1 & 0 & General Notes & Q & 2 & 1 & 1 \\
\hline 14 & H-14-102970 & 1 & 0 & $\begin{array}{l}\text { Process Flow Diagram } \mathrm{AZ}-102 \text { Waste } \\
\text { XFR }\end{array}$ & Q & 2 & 1 & 1 \\
\hline 15 & $\mathrm{H}-14-102971$ & $\mathrm{I}$ & 0 & P\&ID General Notes \& Legend & $\mathrm{Q}$ & 2 & 1 & 1 \\
\hline 16 & $\mathrm{H}-14-102971$ & 2 & 0 & P\&ID Interlock Schedule & $\mathrm{Q}$ & 2 & 1 & 1 \\
\hline 17 & $\mathrm{H}-14-102971$ & 3 & 0 & P\&ID Mixer Pump P-002 (WST) & Q & 2 & 1 & 1 \\
\hline 18 & $\mathrm{H}-14-102971$ & 4 & 0 & P\&ID Transfer Pump (WT) & Q & 2 & 1 & 1 \\
\hline 19 & $\mathrm{H}-14-102971$ & 5 & 0 & P\&ID Mixer Pump P-001 (WST) & $\mathrm{Q}$ & 2 & 1 & I \\
\hline 20 & $\mathrm{H}-14-102971$ & 6 & 0 & P\&ID Mixer Pumps (WST) & $\mathrm{Q}$ & 2 & 1 & 1 \\
\hline 21 & $\mathrm{H}-14-102973$ & 1 & 0 & Tank 241-AZ-102 Area Plan & Q & 2 & 1 & 1 \\
\hline 22 & $\mathrm{H}-14-102973$ & 2 & 0 & Tank 241-AZ-102 Area Plan & $Q$ & 2 & 1 & 1 \\
\hline 23 & $\mathrm{H}-14-102974$ & 1 & 0 & Tank 241-AZ-102 Sections \& Details & Q & 2 & 1 & 1 \\
\hline 24 & H-14-102974 & 2 & 0 & Tank 241-AZ-102 Sections \& Details & $\mathrm{Q}$ & 2 & 1 & 1 \\
\hline 25 & $\mathrm{H}-14-102974$ & 3 & 0 & Tank 241-AZ-102 Sections \& Details & $\mathrm{Q}$ & 2 & 1 & 1 \\
\hline 26 & H-14-102974 & 4 & 0 & Tank 241-AZ-102 Sections \& Details & $\mathrm{Q}$ & 2 & 1 & 1 \\
\hline 27 & H-14-102974 & 5 & 0 & Tank 241-AZ-102 Sections \& Details & Q & 2 & 1 & 1 \\
\hline 28 & $\mathrm{H}-14-102974$ & 6 & 0 & Tank $241-A Z-102$ Sections \& Details & $\mathrm{Q}$ & 2 & 1 & 1 \\
\hline 29 & H-14-102976 & 1 & 0 & $\begin{array}{l}\text { Pump Pit 241-AZ-02A NOZ As-Built } \\
\text { Locations }\end{array}$ & $\mathrm{Q}$ & 2 & 1 & 1 \\
\hline 30 & H-14-102977 & 1 & 0 & $\begin{array}{l}\text { Jumper Arrangement Pum Pit 241-AZ- } \\
02 \mathrm{~A}\end{array}$ & $Q$ & 2 & 1 & 1 \\
\hline 31 & H-14-102978 & 1 & 0 & $\begin{array}{l}\text { Jumper Assembly AZ02A-A-(H)-J-(K) } \\
\text { Pump Pit } 241-\mathrm{AZ}-02 \mathrm{~A}\end{array}$ & Q & 2 & 1 & 1 \\
\hline 32 & H-14-102978 & 2 & 0 & $\begin{array}{l}\text { Jumper Assembly AZ02A-A-(H)-J-(K) } \\
\text { Pump Pit 241-AZ-02A. }\end{array}$ & $Q$ & 2 & 1 & 1 \\
\hline 33 & H-14-102979 & 1 & 0 & $\begin{array}{l}\text { Jumper Assembly AZ02A-U13-(L)-K } \\
\text { Pump Pit 241-AZ-02A }\end{array}$ & $\mathrm{Q}$ & 2 & 1 & 1 \\
\hline 34 & H-14-102979 & 2 & 0 & $\begin{array}{l}\text { Jumper Assembly AZ02A-U13-(L)-K } \\
\text { Pump Pit 241-AZ-02A }\end{array}$ & $\mathrm{Q}$ & 2 & 1 & 1 \\
\hline 35 & $\mathrm{H}-14-102980$ & 1 & 0 & $\begin{array}{l}\text { Jumper Assembly AZ02A-U14-D-(J)-(N) } \\
\text { Pump Pit 241-AZ-02A }\end{array}$ & $\mathrm{Q}$ & 2 & 1 & 1 \\
\hline 36 & H-14-102980 & 2 & 0 & $\begin{array}{l}\text { Jumper Assembly AZ02A-U14-D-(J)-(N) } \\
\text { Pump Pit 241-AZ-02A }\end{array}$ & Q & 2 & 1 & 1 \\
\hline 37 & $\mathrm{H}-14-102981$ & 1 & 0 & $\begin{array}{l}\text { Jumper Assembly AZ02A-B-C-N Pump } \\
\text { Pit } 241-\mathrm{AZ}-02 \mathrm{~A}\end{array}$ & $\mathrm{Q}$ & 2 & 1 & 1 \\
\hline 38 & H-14-102982 & 1 & 0 & $\begin{array}{l}\text { Jumper Assembly AZ02A-F-H Pump Pit } \\
241-\mathrm{AZ}-02 \mathrm{~A}\end{array}$ & $\mathrm{Q}$ & 2 & 1 & 1 \\
\hline 39 & H-1 4-102983 & 1 & 0 & $\begin{array}{l}\text { Jumper Assembly AZ02A-U4-G Valve } \\
\text { Pit } 241-A Z-02 A\end{array}$ & $Q$ & 2 & 1 & 1 \\
\hline 40 & H-14-102984 & 11 & 0 & $\begin{array}{l}\text { Jumper Assembly AZ02-L-E-(M) Pump } \\
\text { Pit } 241-\mathrm{AZ}-02 \mathrm{~A}\end{array}$ & QS & 2 & 1 & 1 \\
\hline
\end{tabular}




\section{ENGINEERING DATA TRANSMITTAL}

(CONTINUATION PAGE)

\begin{tabular}{|c|c|c|c|c|c|c|c|c|}
\hline \multicolumn{2}{|c|}{$\begin{array}{cc}\text { 5. } & \text { Proj/Prog/Dept. Div: } \\
\text { Project W-211 } \\
\end{array}$} & \multirow{2}{*}{\multicolumn{3}{|c|}{$\begin{array}{r}\text { 6. Cog. Eng. } \\
\text { S.R. Briggs } \\
\text { ATA TRAYSMITTED }\end{array}$}} & \multicolumn{2}{|l|}{$\begin{array}{ll}\text { 1. } & \text { EDT } \\
& 625742 \\
\end{array}$} & \multicolumn{2}{|c|}{ Page 3 of 7} \\
\hline & & & & & (F) & (G) & (H) & (I) \\
\hline $\begin{array}{l}\text { (A) } \\
\text { Item } \\
\text { No. }\end{array}$ & (B) Document/Drawing No. & $\begin{array}{l}\text { (C) } \\
\text { Sheet } \\
\text { No. }\end{array}$ & $\begin{array}{l}\text { (D) } \\
\text { Rev. } \\
\text { No0 }\end{array}$ & $\begin{array}{l}\text { (E) Title or Description of Data } \\
\text { Transmitted }\end{array}$ & $\begin{array}{c}\text { Approval } \\
\text { Designator }\end{array}$ & $\begin{array}{c}\text { Reason } \\
\text { For } \\
\text { Trans } \\
\text { mittal } \\
\end{array}$ & $\begin{array}{c}\text { Originator } \\
\text { Disposition }\end{array}$ & $\begin{array}{c}\text { Receiver } \\
\text { Disposition }\end{array}$ \\
\hline 41 & $\mathrm{H}-14-102987$ & 1 & 0 & Valve Actuator Installation Plan & $\mathrm{Q}$ & 2 & 1 & 1 \\
\hline 42 & $\mathrm{H}-14-102987$ & 2 & 0 & Valve Actuator Installation Details & $\mathrm{Q}$ & 2 & 1 & 1 \\
\hline 43 & $\mathrm{H}-14-102988$ & 1 & 0 & Cover Black Painting Diagram & $\mathrm{Q}$ & 2 & 1 & 1 \\
\hline 44 & $\mathrm{H}-14-102989$ & 1 & 0 & Assembly Valve Actuator Components & $\mathrm{Q}$ & 2 & 1 & 1 \\
\hline 45 & $\mathrm{H}-14-102989$ & 2 & 0 & Assembly Valve Actuator Components & $Q$ & 2 & 1 & 1 \\
\hline 46 & H-14-102989 & 3 & 0 & Assembly Valve Actuator Components & $\mathrm{Q}$ & 2 & 1 & 1 \\
\hline 47 & $\mathrm{H}-14-102990$ & 1 & 0 & Assembly Bottle Rack & $Q$ & 2 & 1 & 1 \\
\hline 48 & $\mathrm{H}-14-102990$ & 2 & 0 & Assembly Bottle Rack & $\mathrm{Q}$ & 2 & 1 & 1 \\
\hline 49 & $\mathrm{H}-14-102991$ & 1 & 0 & Assembly Transfer Pump Adapter Plug & Q & 2 & 1 & 1 \\
\hline 50 & $\mathrm{H}-14-102991$ & 2 & 0 & Assembly Transfer Pump Adapter Plug & $\mathrm{Q}$ & 2 & 1 & 1 \\
\hline 51 & $\mathrm{H}-14-102991$ & 3 & 0 & Assembly Transfer Pump Adapter Plug & $\mathrm{Q}$ & 2 & 1 & 1 \\
\hline 52 & $\mathrm{H}-14-102992$ & 1 & 0 & Assembly Transfer Pump Restraint & $\mathrm{Q}$ & 2 & 1 & 1 \\
\hline 53 & H-14-102993 & 1 & 0 & $\begin{array}{l}\text { Assembly Mixer Pump Spray Wash Riser } \\
\text { Extension }\end{array}$ & Q & 2 & 1 & 1 \\
\hline 54 & $\mathrm{H}-14-102995$ & 1 & 0 & Assembly Camera Riser Adapter & Q & 2 & 1 & 1 \\
\hline 55 & $\mathrm{H}-14-103008$ & 1 & 0 & Block Diagram PLC System Network & Q & 2 & 1 & 1 \\
\hline 56 & $\mathrm{H}-14-103008$ & 2 & 0 & Block Diagram Control System Cabling & $\mathrm{Q}$ & 2 & 1 & 1 \\
\hline 57 & $\mathrm{H}-14-103008$ & 3 & 0 & Block Diagram Control System Cabling & $Q$ & 2 & 1 & $\mathrm{I}$ \\
\hline 58 & $\mathrm{H}-14-103008$ & 4 & 0 & Block Diagram Control System Cabling & $Q$ & 2 & 1 & 1 \\
\hline 59 & $\mathrm{H}-14-103009$ & 1 & 0 & Logic Diagram Drawings List \& Notes & Q & 2 & 1 & 1 \\
\hline 60 & $\mathrm{H}-14-103009$ & 2 & 0 & Logic Diagram DIL Mode & Q & 2 & 1 & 1 \\
\hline 61 & H-14-103009 & 3 & 0 & Logic Diagram ITR Mode & Q & 2 & 1 & 1 \\
\hline 62 & $\mathrm{H}-14-103009$ & 4 & 0 & Logic Diagram ITF Mode & $\mathrm{Q}$ & 2 & 1 & 1 \\
\hline 63 & $\mathrm{H}-14-103009$ & 5 & 0 & Logic Diagram WT Mode & $\mathrm{Q}$ & 2 & 1 & 1 \\
\hline 64 & $\mathrm{H}-14-103009$ & 6 & 0 & Logic Diagram ILD Modc & Q & 2 & 1 & 1 \\
\hline 65 & $\mathrm{H}-14-103009$ & 7 & 0 & Logic Diagram PTF Mode & Q & 2 & 1 & 1 \\
\hline 66 & $\mathrm{H}-14-103009$ & 8 & 0 & Logic Diagram PFD Mode & Q & 2 & 1 & 1 \\
\hline 67 & H-14-103009 & 9 & 0 & Logic Diagram SSD Mode & $Q$ & 2 & 1 & 1 \\
\hline 68 & $\mathrm{H}-14-103010$ & 1 & 0 & Logic Diagram Mode Select $1 \mathrm{~A}$ & $\mathrm{Q}$ & 2 & 1 & 1 \\
\hline 69 & $\mathrm{H}-14-103010$ & 2 & 0 & Logic Diagram Mode Select 1B & $\mathrm{Q}$ & 2 & 1 & 1 \\
\hline 70 & $\mathrm{H}-14-103010$ & 3 & 0 & Logic Diagram Mode Select 2 & $\mathrm{Q}$ & 2 & 1 & 1 \\
\hline 71 & $\mathrm{H}-14-103011$ & 1 & 0 & Logic Diagram AZ012-ST-MOV-608 & $Q$ & 2 & 1 & 1 \\
\hline 72 & $\mathrm{H}-14-103011$ & 2 & 0 & Logic Diagram AZ012-WT-MOV-609 & $\mathrm{Q}$ & 2 & 1 & 1 \\
\hline 73 & $\mathrm{H}-14-103011$ & 3 & 0 & Logic Diagram AZ012-WT-FCV-610 & Q & 2 & 1 & 1 \\
\hline 74 & $\mathrm{H}-14-103011$ & 4 & 0 & Logic Diagram AZ012-WT-MOV-611 & $Q$ & 2 & 1 & 1 \\
\hline 75 & $\mathrm{H}-14-103011$ & 5 & 0 & Logic Diagram AZ012-WT-MOV-612 & $\mathrm{Q}$ & 2 & 1 & 1 \\
\hline 76 & $\mathrm{H}-14-103011$ & 6 & 0 & Logic Diagram AZ012-WT-MOV-613 & Q & 2 & 1 & 1 \\
\hline 77 & $\mathrm{H}-14-103011$ & 7 & 0 & Logic Diagram AZ012-WT-MOV-614 & Q & 2 & 1 & 1 \\
\hline 78 & $\mathrm{H}-14-103011$ & 8 & 0 & Logic Diagram MOV Position Alarms & $Q$ & 2 & 1 & 1 \\
\hline 79 & H-14-103011 & 9 & 0 & $\begin{array}{l}\text { Logic Diagram MOV Position Alarms } \\
\text { Mode Sht DN }\end{array}$ & $\mathrm{Q}$ & 2 & 1 & 1 \\
\hline 80 & $\mathrm{H}-14-103012$ & 1 & 0 & $\begin{array}{l}\text { Logic Diagram AZ102 Analog } \\
\text { Alarms/Interlocks }\end{array}$ & $\mathrm{Q}$ & 2 & 1 & 1 \\
\hline
\end{tabular}




\section{ENGINEERING DATA TRANSMITTAL}

(CONTINUATION PAGE)

\begin{tabular}{|c|c|c|c|c|c|c|c|c|}
\hline \multicolumn{2}{|c|}{$\begin{array}{cc}5 . & \text { Proj/Prog/Dept. Div: } \\
\text { Project W-211 }\end{array}$} & \multirow{2}{*}{\multicolumn{3}{|c|}{\begin{tabular}{|}
$6 . \quad$ Cog. Eng. \\
S. R. Briggs \\
DATA TRANSMITTEED
\end{tabular}}} & \multirow{2}{*}{\multicolumn{2}{|c|}{$\begin{array}{ll}\text { 1. } & \text { EDT } \\
& 625742 \\
\end{array}$}} & \multicolumn{2}{|c|}{ Page 4 of 7} \\
\hline & & & & & (F) & & (H) & (I) \\
\hline $\begin{array}{l}\text { (A) } \\
\text { Item } \\
\text { No. }\end{array}$ & (B) Document/Drawing No. & $\begin{array}{l}\text { (C) } \\
\text { Sheet } \\
\text { No. }\end{array}$ & $\begin{array}{l}\text { (D) } \\
\text { Rev. } \\
\text { No0 }\end{array}$ & $\begin{array}{l}\text { (E) Titic or Description of Data } \\
\text { Transmitted }\end{array}$ & $\begin{array}{c}\text { Approval } \\
\text { Designator }\end{array}$ & $\begin{array}{l}\text { Reason } \\
\text { For } \\
\text { Trans } \\
\text { mittal }\end{array}$ & $\begin{array}{l}\text { Originator } \\
\text { Disposition }\end{array}$ & $\begin{array}{c}\text { Receiver } \\
\text { Disposition }\end{array}$ \\
\hline 81 & H-14-103012 & 2 & 0 & $\begin{array}{l}\text { Logic Diagram AZ102 Mixer Pump 001 } \\
\text { Control }\end{array}$ & $\mathrm{Q}$ & 2 & 1 & 1 \\
\hline 82 & $\mathrm{H}-14-103012$ & 3 & 0 & $\begin{array}{l}\text { Logic Diagram AZ102 Mixer Pump } 001 \\
\text { Turntable }\end{array}$ & $\mathrm{Q}$ & 2 & 1 & 1 \\
\hline 83 & $\mathrm{H}-14-103012$ & 4 & 0 & $\begin{array}{l}\text { Logic Diagram AZ102 Mixer Pump } 002 \\
\text { Control }\end{array}$ & Q & 2 & 1 & 1 \\
\hline 84 & $\mathrm{H}-14-103012$ & 5 & 0 & $\begin{array}{l}\text { Logic Diagram AZ102 Mixer Pump } 002 \\
\text { Turntable }\end{array}$ & $Q$ & 2 & 1 & 1 \\
\hline 85 & H-14-103012 & 6 & 0 & $\begin{array}{l}\text { Logic Diagram AZ102 Mixer Pump } \\
\text { P-022 Control }\end{array}$ & $\mathrm{Q}$ & 2 & 1 & 1 \\
\hline 86 & H-14-103012 & 7 & 0 & $\begin{array}{l}\text { Logic Diagram AZ102 Riser } 15 \mathrm{~A} \text { Temp } \\
\text { Probe }\end{array}$ & $\mathrm{Q}$ & 2 & 1 & 1 \\
\hline 87 & $\mathrm{H}-14-103012$ & 8 & 0 & $\begin{array}{l}\text { Logic Diagram AZ102 Riser } 15 \text { C Temp } \\
\text { Probe }\end{array}$ & $\mathrm{Q}$ & 2 & 1 & 1 \\
\hline 88 & H-14-103012 & 9 & 0 & $\begin{array}{l}\text { Logic Diagram AZ102 Riser 15G Temp } \\
\text { Probe }\end{array}$ & $\mathrm{Q}$ & 2 & 1 & 1 \\
\hline 89 & H-14-103012 & 10 & 0 & $\begin{array}{l}\text { Logic Diagram A 102 Riser 15I Temp } \\
\text { Probe }\end{array}$ & $\mathrm{Q}$ & 2 & 1 & 1 \\
\hline 90 & $\mathrm{H}-14-103013$ & 1 & 0 & $\begin{array}{l}\text { Logic Diagram AZ102 Analog } \\
\text { Ams/Interlocks }\end{array}$ & $Q$ & 2 & 1 & 1 \\
\hline 91 & $\mathrm{H}-14-103013$ & 2 & 0 & $\begin{array}{l}\text { Logic Diagram AZ101 Mixer Pump 001 } \\
\text { Control }\end{array}$ & $\mathrm{Q}$ & 2 & 1 & 1 \\
\hline 92 & H-14-103013 & 3 & 0 & $\begin{array}{l}\text { Logic Diagram AZ101 Mixer Pump } 001 \\
\text { Trntbl }\end{array}$ & $\mathrm{Q}$ & 2 & 1 & 1 \\
\hline 93 & $\mathrm{H}-14-103013$ & 4 & 0 & $\begin{array}{l}\text { Logic Diagram AZ101 Mixer Pump } 002 \\
\text { Control }\end{array}$ & Q & 2 & 1 & 1 \\
\hline 94 & $\mathrm{H}-14-103013$ & 5 & 0 & $\begin{array}{l}\text { Logic Diagram AZ101 Mixer Pump } 002 \\
\text { Trntbl }\end{array}$ & $\mathrm{Q}$ & 2 & 1 & 1 \\
\hline 95 & $\mathrm{H}-14-103014$ & 1 & 0 & $\begin{array}{l}\text { Central Pump Pit 02A TBS-103/Encl - } \\
105 \text { Assy }\end{array}$ & Q & 2 & 1 & 1 \\
\hline 96 & $\mathrm{H}-14-103014$ & 2 & 0 & $\begin{array}{l}\text { Central Pump Pit 02A AZ02A-WT-TBX- } \\
103 \text { Assy }\end{array}$ & Q & 2 & 1 & 1 \\
\hline 97 & $\mathrm{H}-14-103014$ & 3 & 0 & $\begin{array}{l}\text { Central Pump Pit 02A WT-TBX-103 } \\
\text { Conn Diagram }\end{array}$ & Q & 2 & 1 & 1 \\
\hline 98 & H-14-103014 & 4 & 0 & Central Pump Pit 02A Encl-015 Assy & $\mathrm{Q}$ & 2 & 1 & 1 \\
\hline 99 & H-14-103014 & 5 & 0 & $\begin{array}{l}\text { Central Pump Pit 02A Encl-015 Conn } \\
\text { Diag }\end{array}$ & $\mathrm{Q}$ & 2 & 1 & 1 \\
\hline 100 & H-14-103015 & 1 & 0 & $\begin{array}{l}\text { Mixer Pump } 001 \& 002 \text { Terminal Box } \\
\text { Assy's }\end{array}$ & Q & 2 & 1 & 1 \\
\hline 101 & $\mathrm{H}-14-103015$ & 2 & 0 & $\begin{array}{l}\text { Mixer Pump } 001 \& 002 \text { TBS Connection } \\
\text { Diagrams }\end{array}$ & $\mathrm{Q}$ & 2 & 1 & 1 \\
\hline 102 & $\mathrm{H}-14-103015$ & 3 & 0 & $\begin{array}{l}\text { Mixer Pump } 001 \& 002 \text { Connection } \\
\text { Diagrams }\end{array}$ & $\mathrm{Q}$ & 2 & 1 & 1 \\
\hline 103 & H-14-103015 & 4 & 0 & $\begin{array}{l}\text { Mixer Pump } 001 \& 002 \text { VFD Connection } \\
\text { Diagrams }\end{array}$ & Q & 2 & 1 & 1 \\
\hline 104 & H-14-103016 & 6 & 0 & Density Transmitter AZ156-WT-UT-161 & $\mathrm{Q}$ & 2 & 1 & 1 \\
\hline 105 & H-14-103017 & 1 & 0 & $\begin{array}{l}\text { AZ801A-WT-ENCL-104 Inst. Encl } \\
\text { Assembly }\end{array}$ & Q & 2 & 1 & 1 \\
\hline 106 & $\mathrm{H}-14-103017$ & 2 & 0 & $\begin{array}{l}\text { AZ801A-WT-ENCL-104 Inst. Enct } \\
\text { Assembly }\end{array}$ & Q & 2 & 1 & 1 \\
\hline
\end{tabular}




\section{ENGINEERING DATA TRANSMITTAL}

(CONTINUATION PAGE)

\begin{tabular}{|c|c|c|c|c|c|c|c|c|}
\hline 5. $\mathbf{P}$ & $\begin{array}{l}\text { oj/Prog/Dept. Div: } \\
\text { Project W-211 }\end{array}$ & 6. $\mathrm{C}$ & $\begin{array}{l}\text { Eng. } \\
\text { S. R. }\end{array}$ & Briggs & $\begin{array}{ll}\text { EDT } \\
& \text { 625742 } \\
\end{array}$ & & Page 5 & \\
\hline & & ATA TI & ANSM & TTED & (F) & (G) & (H) & (1) \\
\hline $\begin{array}{l}\text { (A) } \\
\text { Item } \\
\text { No. }\end{array}$ & (B) Document/Drawing No. & $\begin{array}{l}\text { (C) } \\
\text { Sheet } \\
\text { No. }\end{array}$ & $\begin{array}{l}\text { (D) } \\
\text { Rev. } \\
\text { No0 }\end{array}$ & $\begin{array}{l}\text { (E) Title or Description of Data } \\
\text { Transmitted }\end{array}$ & $\begin{array}{c}\text { Approval } \\
\text { Designator }\end{array}$ & $\begin{array}{l}\text { Reason } \\
\text { For } \\
\text { Trans } \\
\text { mittal }\end{array}$ & $\begin{array}{l}\text { Originator } \\
\text { Disposition }\end{array}$ & $\begin{array}{c}\text { Receiver } \\
\text { Disposition }\end{array}$ \\
\hline 107 & $\mathrm{H}-14-103017$ & 3 & 0 & $\begin{array}{l}\text { AZ801A-WT-ENCL-104 Connection } \\
\text { Diagram }\end{array}$ & Q & 2 & 1 & 1 \\
\hline 108 & $\mathrm{H}-14-103017$ & 4 & 0 & $\begin{array}{l}\text { AZ801A-WT-ENCL-104 Connection } \\
\text { Diagram }\end{array}$ & Q & 2 & 1 & 1 \\
\hline 109 & $\mathrm{H}-14-103017$ & 5 & 0 & $\begin{array}{l}\text { AZ801A-WT-ENCL-104 Connection } \\
\text { Diagram }\end{array}$ & Q & 2 & 1 & 1 \\
\hline 111 & $\mathrm{H}-14-103017$ & 6 & 0 & $\begin{array}{l}\text { AZ801A-WT-ENCL-104 Connection } \\
\text { Diagram }\end{array}$ & Q & 2 & 1 & 1 \\
\hline 112 & H-14-103017 & 7 & 0 & $\begin{array}{l}\text { AZ801A-WT-ENCL-104 Connection } \\
\text { Diagram }\end{array}$ & $\mathrm{Q}$ & 2 & 1 & 1 \\
\hline 113 & $\mathrm{H}-14-103018$ & 1 & 0 & $\begin{array}{l}\text { Interconnection Diagram Mixer AZ101- } \\
\text { WST-P-001 }\end{array}$ & $\mathrm{Q}$ & 2 & 1 & 1 \\
\hline 114 & H-14-103018 & 2 & 0 & $\begin{array}{l}\text { Interconnection Diagram Mixer AZ101- } \\
\text { WST-P-002 }\end{array}$ & Q & 2 & 1 & 1 \\
\hline 115 & $\mathrm{H}-14-103019$ & 1 & 0 & $\begin{array}{l}\text { Interconnection Diagram Mixer AZ012- } \\
\text { WST-P-001 }\end{array}$ & Q & 2 & 1 & 1 \\
\hline 116 & H-14-103019 & 2 & 0 & $\begin{array}{l}\text { Interconnection Diagram Mixer AZ012- } \\
\text { WST-P-002 }\end{array}$ & $\mathrm{Q}$ & 2 & 1 & 1 \\
\hline 117 & $\mathrm{H}-14-103020$ & 1 & 0 & $\begin{array}{l}\text { Interconnection Diagram Service Water } \\
\text { Pressure }\end{array}$ & $\mathrm{Q}$ & 2 & 1 & 1 \\
\hline 118 & H-14-103021 & 1 & 0 & $\begin{array}{l}\text { Interconnection Diagram Central Pump } \\
\text { Pit }\end{array}$ & $\mathrm{Q}$ & 2 & 1 & 1 \\
\hline 119 & H-14-103021 & 2 & 0 & $\begin{array}{l}\text { Interconnection Diagram Central Pump } \\
\text { Pit }\end{array}$ & $Q$ & 2 & 1 & 1 \\
\hline 120 & H-14-103021 & 3 & 0 & $\begin{array}{l}\text { Interconnection Diagram Central Pump } \\
\text { Pit }\end{array}$ & $\mathrm{Q}$ & 2 & 1 & 1 \\
\hline 121 & $\mathrm{H}-14-103022$ & 1 & 0 & $\begin{array}{l}\text { In-Tank Temp Probe Notes \& Material } \\
\text { List }\end{array}$ & $Q$ & 2 & 1 & 1 \\
\hline 122 & $\mathrm{H}-14-103022$ & 2 & 0 & In-Tank Temp Probe Assy & QS & 2 & 1 & 1 \\
\hline 123 & $\mathrm{H}-14-103022$ & 3 & 0 & In-Tank Temp Probe Assy & QS & 2 & 1 & 1 \\
\hline 124 & $\mathrm{H}-14-103022$ & 4 & 0 & In-Tank Temp Probe Sections \& Details & QS & 2 & 1 & 1 \\
\hline 125 & $\mathrm{H}-14-103022$ & 5 & 0 & In-Tank Temp Probe Sections \& Details & QS & 2 & 1 & 1 \\
\hline 126 & H-14-103022 & 6 & 0 & In-Tank Temp Probe Details & QS & 2 & 1 & 1 \\
\hline 127 & $\mathrm{H}-14-103022$ & 7 & 0 & In-Tank Temp Probe Details & QS & 2 & 1 & 1 \\
\hline 128 & H-14-103022 & 8 & 0 & In-Tank Temp Probe View \& Section & QS & 2 & 1 & 1 \\
\hline 129 & H-14-103022 & 9 & 0 & $\begin{array}{l}\text { In-Tank Temp Probe Connection } \\
\text { Diagram }\end{array}$ & QS & 2 & 1 & 1 \\
\hline 130 & $\mathrm{H}-14-103023$ & 1 & 0 & $\begin{array}{l}\text { Drywell Temp Probe Notes \& Material } \\
\text { List }\end{array}$ & QS & 2 & 1 & 1 \\
\hline 131 & H-14-103023 & 2 & 0 & Drywell Temp Probe Section Details & QS & 2 & 1 & 1 \\
\hline 132 & H-14-103023 & 3 & 0 & Drywell Temp Probe Section Details & QS & 2 & 1 & 1 \\
\hline 133 & H-14-103023 & 4 & 0 & $\begin{array}{l}\text { Drywell Temp Probe Connection } \\
\text { Diagram }\end{array}$ & QS & 2 & 1 & 1 \\
\hline 134 & $\mathrm{H}-14-103025$ & 1 & 0 & Central Pump Pit 02A Plan & QS & 2 & 1 & 1 \\
\hline 135 & H-14-103025 & 2 & 0 & $\begin{array}{l}\text { Central Pump Pit 02A Elev. Views \& } \\
\text { Details }\end{array}$ & QS & 2 & 1 & 1 \\
\hline 136 & H-14-103025 & 3 & 0 & $\begin{array}{l}\text { Central Pump Pit 02A Connection } \\
\text { Diagrams }\end{array}$ & QS & 2 & 1 & 1 \\
\hline 137 & $\mathrm{H}-14-103026$ & 1 & 0 & Central Pump Pit 02A Cable Assemblies & QS & 2 & 1 & $\mathrm{l}$ \\
\hline 138 & $\mathrm{H}-14-103027$ & 1 & 0 & Plan, Sections \& Connection Diagram & Q & 2 & 1 & 1 \\
\hline
\end{tabular}




\section{ENGINEERING DATA TRANSMITTÁL}

(CONTINUATION PAGE)

\begin{tabular}{|c|c|c|c|c|c|c|c|c|}
\hline 5. & $\begin{array}{l}\text { oj/Prog/Dept. Div: } \\
\text { Project W-211 }\end{array}$ & 6. C & $\begin{array}{l}\text { g. Eng } \\
\text { S. R }\end{array}$ & Briggs & $\begin{array}{ll}\text { 1. } & \text { EDT } \\
& 625742\end{array}$ & & Page 6 & \\
\hline & & DATA T & ANSI & TTED & (F) & (G) & (H) & (1) \\
\hline $\begin{array}{l}\text { (A) } \\
\text { lem } \\
\text { No. }\end{array}$ & (B) Document/Drawing No. & $\begin{array}{l}\text { (C) } \\
\text { Sheet } \\
\text { No. }\end{array}$ & $\begin{array}{l}\text { (D) } \\
\text { Rev. } \\
\text { No0 }\end{array}$ & $\begin{array}{l}\text { (E) Title or Description of Data } \\
\text { Transmitted }\end{array}$ & $\begin{array}{c}\text { Approval } \\
\text { Designator }\end{array}$ & $\begin{array}{c}\text { Reason } \\
\text { For } \\
\text { Trans } \\
\text { mittal }\end{array}$ & $\begin{array}{l}\text { Originator } \\
\text { Disposition }\end{array}$ & $\begin{array}{c}\text { Receiver } \\
\text { Disposition }\end{array}$ \\
\hline 139 & H-14-103028 & 1 & 0 & $\begin{array}{l}\text { AZ801A-RW-ENCL-220 Alarm Panel } \\
\text { Assembly }\end{array}$ & Q & 2 & 1 & 1 \\
\hline 140 & H-14-103028 & 2 & 0 & $\begin{array}{l}\text { AZ801A-RW-ENCL-220 Connection } \\
\text { Diagram }\end{array}$ & Q & 2 & 1 & 1 \\
\hline 141 & H-14-103029 & 1 & 0 & $\begin{array}{l}\text { Central Pump Pit 02A TBX-101/ } \\
\text { MTS-222 }\end{array}$ & Q & 2 & 1 & 1 \\
\hline 142 & H-14-103029 & 2 & 0 & $\begin{array}{l}\text { Central Pump Pit 02A TBX-101/ } \\
\text { MTS-222 }\end{array}$ & Q & 2 & 1 & 1 \\
\hline 143 & $\mathrm{H}-14-103030$ & 1 & 0 & In-Tank Imaging (CCTV) Block Diagram & Q & 2 & 1 & 1 \\
\hline 144 & $\mathrm{H}-14-103031$ & 1 & 0 & In-Tank Imaging (CCTV) FCU Rack & Q & 2 & 1 & 1 \\
\hline 145 & H-14-103032 & 1 & 0 & $\begin{array}{l}\text { In-Tank Imaging (CCTV) HLPC } \\
\text { Enclosure }\end{array}$ & Q & 2 & 1 & 1 \\
\hline 146 & $\mathrm{H}-14-103033$ & 1 & 0 & $\begin{array}{l}\text { TBS-104/ZS016B Assembly \& } \\
\text { Connection Diagram }\end{array}$ & Q & 2 & 1 & 1 \\
\hline 147 & $\mathrm{H}-14-103035$ & 1 & 0 & 241-AZ-102 One Line Diagram & $\mathrm{Q}$ & 2 & 1 & 1 \\
\hline 148 & $\mathrm{H}-14-103035$ & 2 & 0 & 241-AZ-102 One Line Diagram & Q & 2 & 1 & 1 \\
\hline 149 & $\mathrm{H}-14-103036$ & $\mathbf{I}$ & 0 & AZ Tank Farm Site Plan & $\mathrm{Q}$ & 2 & 1 & 1 \\
\hline 150 & $\mathrm{H}-14-103037$ & $t$ & 0 & 241-AZ-156 Area Plan & Q & 2 & 1 & 1 \\
\hline 151 & $\mathrm{H}-14-103038$ & 1 & 0 & Tank-AZ-102 Plan \& Sections & $Q$ & 2 & 1 & 1 \\
\hline 152 & H-14-103038 & 2 & 0 & $\begin{array}{l}\text { Tank-AZ-102 Instrument Bldg Plan \& } \\
\text { Section }\end{array}$ & Q & 2 & 1 & 1 \\
\hline 153 & $\mathrm{H}-14-103038$ & 3 & 0 & Tank-AZ-102 Sections & $\mathrm{Q}$ & 2 & 1 & 1 \\
\hline 154 & $\mathrm{H}-14-103039$ & 1 & 0 & Tank-AZ-101 Plan & Q & 2 & 1 & 1 \\
\hline 155 & H-14-103040 & 1 & 0 & 241-AZ-156 Conduit Layout & $Q$ & 2 & 1 & 1 \\
\hline 156 & $\mathrm{H}-14-103040$ & 2 & 0 & 241-AZ-156 Sections \& Schedule & Q & 2 & 1 & 1 \\
\hline 157 & $\mathrm{H}-14-103041$ & & 0 & 241-AZ-156 Equipment Layout & $Q$ & 2 & 1 & 1 \\
\hline 158 & $\mathrm{H}-14-103042$ & 1 & 0 & AZ101-WST-M-001 Plan & $\mathrm{Q}$ & 2 & 1 & 1 \\
\hline 159 & $\mathrm{H}-14-103042$ & 2 & 0 & AZ101-WST-M-001 View & Q & 2 & 1 & 1 \\
\hline 160 & $\mathrm{H}-14-103043$ & 1 & 0 & AZ101-WST-M-002 Plan & $\mathrm{Q}$ & 2 & 1 & 1 \\
\hline 161 & $\mathrm{H}-14-103043$ & 2 & 0 & AZ101-WST-M-002 View & Q & 2 & 1 & 1 \\
\hline 162 & $\mathrm{H}-14-103044$ & 1 & 0 & AZ102-WST-M-001 Plan \& Diagrams & $\mathrm{Q}$ & 2 & 1 & 1 \\
\hline 163 & $\mathrm{H}-14-103044$ & 2 & 0 & AZ102-WST-M-001 Sections \& Detail & $\mathrm{Q}$ & 2 & 1 & 1 \\
\hline 164 & H-14-103045 & 1 & 0 & AZ02A-WT-M-022 Plan & $\mathrm{Q}$ & 2 & 1 & 1 \\
\hline 165 & $\mathrm{H}-14-103045$ & 2 & 0 & AZ02A-WT-M-022 Sections \& Detail & $Q$ & 2 & 1 & 1 \\
\hline 166 & H-14-103046 & 1 & 0 & AZ102-WST-M-002 Plan \& Diagrams & Q & 2 & 1 & 1 \\
\hline 167 & $\mathrm{H}-14-103046$ & 2 & 0 & AZ102-WST-M-002 Sections \& Detail & Q & 2 & 1 & 1 \\
\hline 168 & $\mathrm{H}-14-103047$ & 1 & 0 & AZ101-WST-MTS-203 Assembly & Q & 2 & 1 & 1 \\
\hline 169 & $\mathrm{H}-14-103047$ & 2 & 0 & $\begin{array}{l}\text { AZ101-WST-MTS- } 203 \text { Connection } \\
\text { Diagrams }\end{array}$ & Q & 2 & 1 & 1 \\
\hline 170 & $\mathrm{H}-14-103048$ & 1 & 0 & AZ101-WST-MTS-204 Assembly & $Q$ & 2 & 1 & 1 \\
\hline 171 & H-14-103048 & 2 & 0 & $\begin{array}{l}\text { AZ101-WST-MTS-204 Connection } \\
\text { Diagram }\end{array}$ & Q & 2 & 1 & 1 \\
\hline 172 & $\mathrm{H}-14-103049$ & 1 & 0 & AZ-102 Heat Trace Plan and Section & $\mathrm{Q}$ & 2 & 1 & 1 \\
\hline 173 & H-14-103049 & 2 & 0 & AZ-102 Heat Trace Plan and Section & $\mathrm{Q}$ & 2 & 1 & 1 \\
\hline 174 & $\mathrm{H}-14-103049$ & 3 & 0 & AZ-102 Heat Trace Plan and Sections & Q & 2 & 1 & 1 \\
\hline 175 & $\mathrm{H}-14-103050$ & 1 & 0 & $\begin{array}{l}\text { AZ102-WST-M-001 \& } 003 \text { Connection } \\
\text { Diagrams }\end{array}$ & Q & 2 & 1 & 1 \\
\hline 176 & H-14-103051 & 1 & 0 & $\begin{array}{l}\text { AZ102-WST-M-002 \& } 004 \text { Connection } \\
\text { Diagrams }\end{array}$ & $Q$ & 2 & 1 & 1 \\
\hline
\end{tabular}




\section{ENGINEERING DATA TRANSMITTAL}

(CONTINUATION PAGE)

\begin{tabular}{|c|c|c|c|c|c|c|c|c|}
\hline 5. & $\begin{array}{l}\text { oj/Prog/Dept. Div: } \\
\text { Project W-21l }\end{array}$ & 6.8 & $\begin{array}{l}\text { g. Eng } \\
\text { S. R }\end{array}$ & Briggs & $\begin{array}{ll}\text { 1. } & \text { EDT } \\
& 62574\end{array}$ & & Page 7 & \\
\hline & & ATA T & ANSM & TTED & (F) & (G) & (H) & (I) \\
\hline $\begin{array}{l}\text { (A) } \\
\text { Item } \\
\text { No. }\end{array}$ & (B) Document/Drawing No. & $\begin{array}{l}\text { (C) } \\
\text { Shcet } \\
\text { No. }\end{array}$ & $\begin{array}{l}\text { (D) } \\
\text { Rev. } \\
\text { Noo }\end{array}$ & $\begin{array}{l}\text { (E) Title or Description of Data } \\
\text { Transmitted }\end{array}$ & $\begin{array}{c}\text { Approval } \\
\text { Designator }\end{array}$ & $\begin{array}{c}\text { Reason } \\
\text { For } \\
\text { Trans } \\
\text { mittal }\end{array}$ & $\begin{array}{l}\text { Originator } \\
\text { Disposition }\end{array}$ & $\begin{array}{c}\text { Recejver } \\
\text { Disposition }\end{array}$ \\
\hline 177 & $\mathrm{H}-14-103052$ & 1 & 0 & AZ02A-WT-M-022 Connection Diagram & $Q$ & 2 & 1 & 1 \\
\hline 178 & H-14-103053 & 1 & 0 & $\begin{array}{l}\text { AZ801A-EDS-DP-121 Panelboard } \\
\text { Schedule }\end{array}$ & $Q$ & 2 & 1 & 1 \\
\hline 179 & H-14-103054 & 1 & 0 & Power Cable Schedule & $Q$ & 2 & 1 & 1 \\
\hline 180 & H-14-103055 & 1 & 0 & Control Cable Schedule & $Q$ & 2 & 1 & 1 \\
\hline 181 & $\mathrm{H}-14-103056$ & 1 & 0 & Instrument Cable Schedule & $\mathrm{Q}$ & 2 & 1 & 1 \\
\hline 182 & $\mathrm{H}-14-103057$ & 1 & 0 & Raceway Conduit Schedule & $\vec{Q}$ & 2 & 1 & 1 \\
\hline 183 & W-211-AZ2-Cl & & 0 & $241-A Z-102$ Construction Specification & QS & 2 & 1 & 1 \\
\hline 184 & HNF-3695 & & 0 & $\begin{array}{l}\text { Descriptions of Operations for } \\
24\}-A Z-102\end{array}$ & $Q$ & 2 & 1 & 1 \\
\hline 185 & HNF-3836 & & 0 & $\begin{array}{l}\text { Descriptions of Operations for } \\
241-\mathrm{AN}-105\end{array}$ & $\mathrm{Q}$ & 2 & ] & 1 \\
\hline 186 & $\mathrm{~W}-211-\mathrm{AZ2} 2 \mathrm{Pl}$ & & 0 & Proc. Specification Slurry Transfer Pump & $Q$ & 2 & 1 & 1 \\
\hline 187 & W-211-AZ2-P6 & & 0 & $\begin{array}{l}\text { Proc. Specification Waste Mobilization } \\
\text { Mixer Pump }\end{array}$ & $\mathrm{Q}$ & 2 & 1 & 1 \\
\hline & & & & & & & & \\
\hline & & & & & & & & \\
\hline & & & & & & & & \\
\hline & & & & & & & & \\
\hline & & & & & & & & \\
\hline & & & & & & & & \\
\hline & & & & & & & & \\
\hline & & & & & & & & \\
\hline & & & & & & & & \\
\hline & & & & & & & & \\
\hline & & & & & & & & \\
\hline & & & & & & & & \\
\hline & & & & & & & & \\
\hline & & & & & & & & \\
\hline & & & & & & & & \\
\hline & & & & & & & & \\
\hline & & & & & & & & \\
\hline & & & & & & & & \\
\hline & & & & & & & & \\
\hline & & & & & & & & \\
\hline & & & & & & & & \\
\hline & & & & & & & & \\
\hline & & & & & & & & \\
\hline & & & & & & & & \\
\hline & & & & & & & & \\
\hline & & & & & & & & \\
\hline & & & & & & & & \\
\hline & & & & & & & & \\
\hline & & & & & & & & \\
\hline
\end{tabular}


DISTRIBUTION SHEET

To

Distribution

Project Title/Work Order

Project $\mathrm{W}-211$, Initial Tank Retrieval systems
Page 1 of 1
Date $02 / 24 / 00$
EDT No. 625742
ECN No.

\begin{tabular}{c|c|c|c|} 
MSIN & $\begin{array}{c}\text { Text } \\
\text { With All } \\
\text { Attach. }\end{array}$ & Text Only & $\begin{array}{c}\text { Attach. } \\
\text { Appendix } \\
\text { Only }\end{array}$ \\
\hline
\end{tabular}

EDT/ECN Only

S. R. Briggs Dwgs $3-1 / 2$ Specs 1

C. A. Rieck

J.. E. Van Beek

L. R. $\mathrm{Hall}$

P. L. Smith

M. E. Mckinney Dwgs $3-1 / 2$ Specs 2

Project Files

R3 - 47

R3-47

R3 -47

A3-04

S5-12

R3-47

Project $W-211$ Files Dwgs $1-11 / 17$ Specs 1

R1-29

C. Chinery Dwgs $1-11 / 17$

J. J. Davis Dwgs 1 - $11 / 17$ Specs - 1

L. L. Penn Dwgs $1-1 / 2$ Specs 1

E. M. Koellermeier Dwgs $4-1 / 2$ Specs 4

M. D. Long Dwgs. $1-1 / 2$ Specs 1

W. E. Eischens Dwgs $2-1 / 2$ Specs 2

2

|

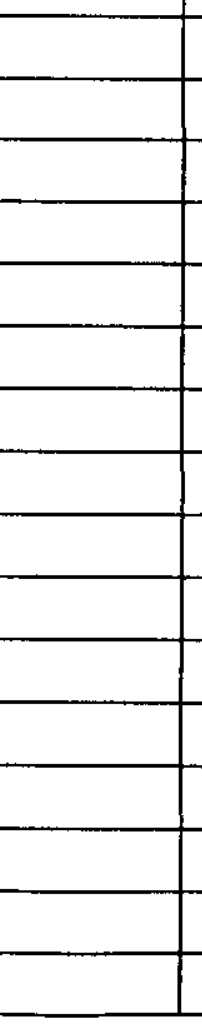

$\mathbf{x}$

(2)

- 


\title{
PROJECT W-211, INITIAL TANK RETRIEVAL SYSTEMS, DESCRIPTION OF OPERATIONS FOR 241-AZ-102
}

\author{
s. R. Brigge \\ Numatec Hanford Company \\ Richland, WA 09352 \\ U.S. Department of Energy Contract DE-AC06-99RL14047 \\ EDT/ECN: 625742 \\ UC: 2030 \\ Cost Center: 83200 \\ Charge Code: 102070 \\ BeR Code: 39EW02J10 \\ Total Pages: 75
}

\section{Key Words:}

Retrieval Control Syatem, Description of Operations, Project w-211, Inltial Tank Retrieval syatems

Abstract:

This document provides a basic description of the instrumentation, equipment, general operation, application sofware, and how the software will control the various retrieval operations for tank 241-AZ-102

TRADEMARK DISCLAMER. Rolerences hereln b emy apecilse commercial product, proceese, or service by trade name.

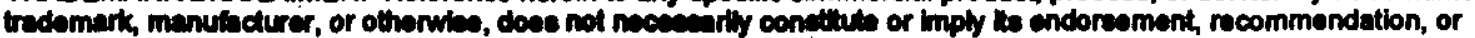
favoring by the Unitad states Government or any agency thereof or its contractors or aubcontrectors.

Printed in the Uniled states of Amertes. To obtein copies of this document, contact: Document Control Services, P.O. Box 950, Malletop H6-08, Rlctiand WA ses52, Phone (500) 372-2420; Fax (500) 376-4989.
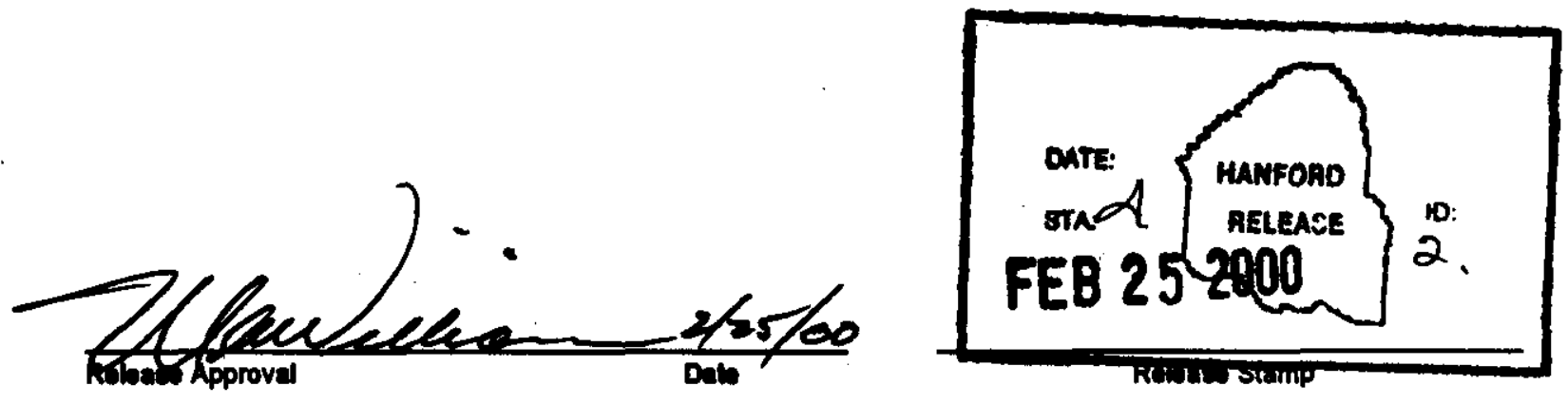

Approved For Public Release 


\section{PROJECT W-211}

\section{RETRIEVAL CONTROL SYSTEM}

\section{DESCRIPTION OF OPERATION}

FOR

241-AZ-102

Prepared for

Numatec Hanford Corporation

December 16, 1999

Prepared by

Fluor Daniel Northwest, Inc. Richland, Washington

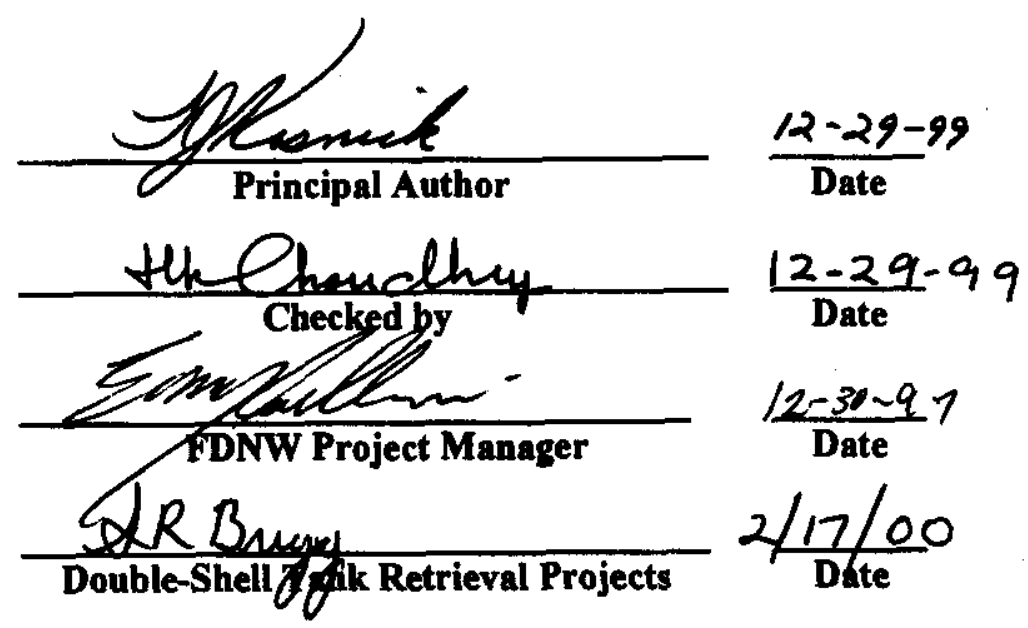


Table of Revisions

\begin{tabular}{|c|c|l|l|}
\hline Rev. & $\begin{array}{c}\text { Date of } \\
\text { Issue }\end{array}$ & \multicolumn{1}{|c|}{ Description } & Remarks \\
\hline 0 & & Initial Issue & \\
\hline & & & \\
\hline & & & \\
\hline & & & \\
\hline & & & \\
\hline & & & \\
\hline & & & \\
\hline & & & \\
\hline & & & \\
\hline
\end{tabular}




\section{TABLE OF CONTENTS}

I. INTRODUCTION

A. PURPOSE

B. SCOPE

C. PROCESS OVERVIEW

D. DEFINITIONS

II. GENERAL DESCRIPTION

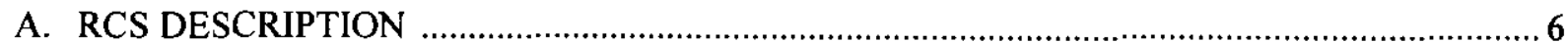

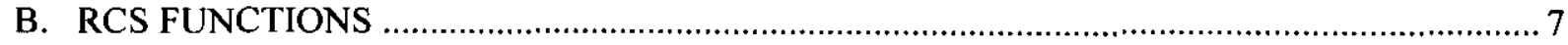

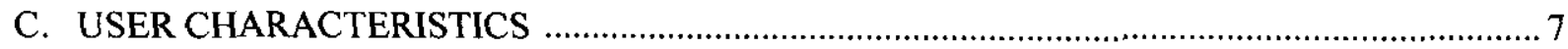

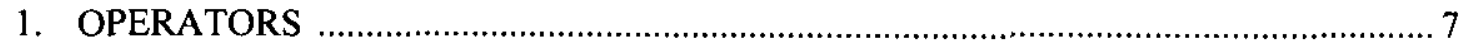

2. SYSTEM ENGINEERS …................................................................................. 7

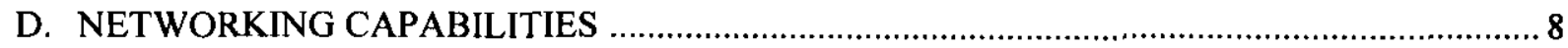

III. GENERAL FUNCTIONAL REQUIREMENTS …...................................................................

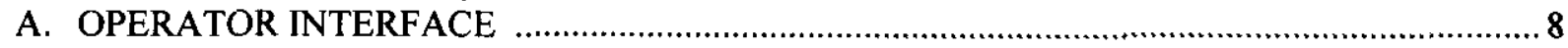

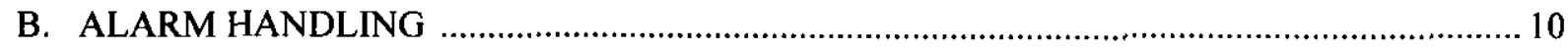

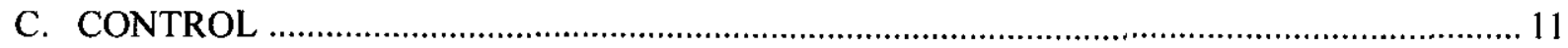

IV. MODE OF OPERATION - FUNCTIONAL REQUIREMENTS ….............................................. 13

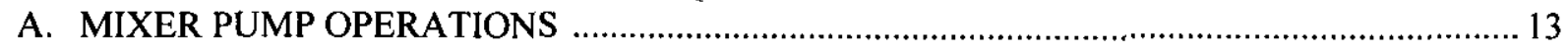

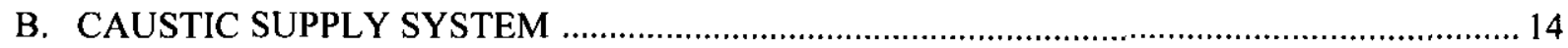

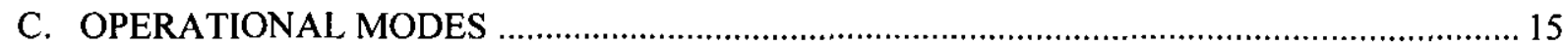

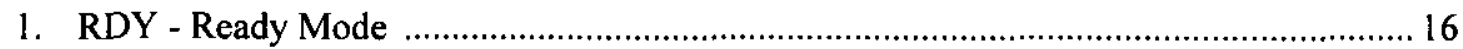

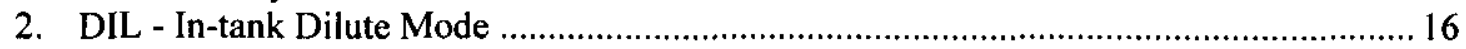

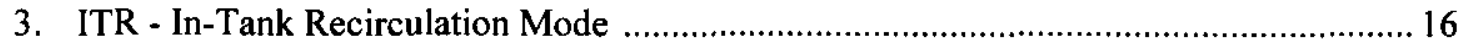

4. ITF - Back flush after In-Tank Recirculation Mode ITR............................................. 16

5. WT - Transfer waste from tank AZ-102 to Valve Pit 241-AZ-02A .............................. 17

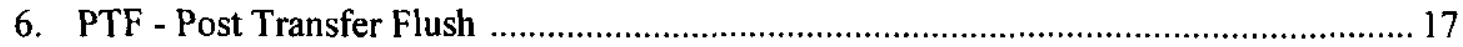

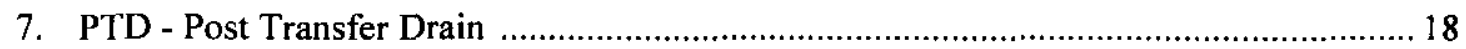

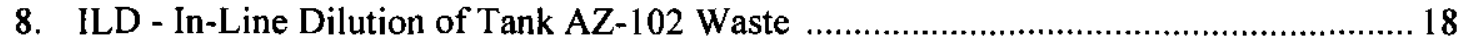

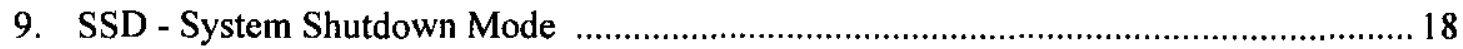

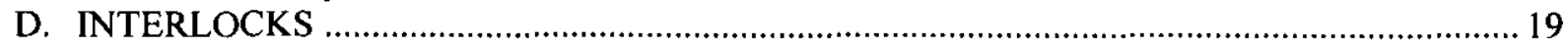

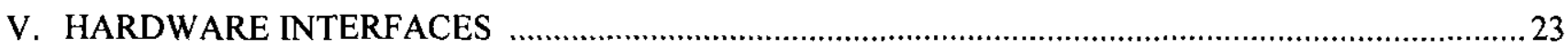

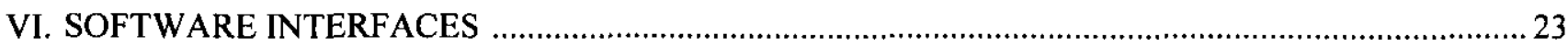

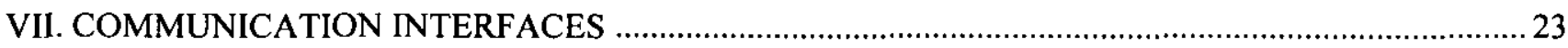

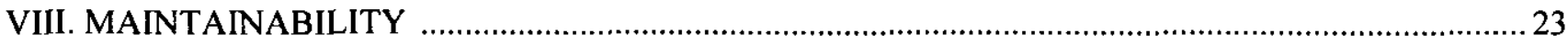

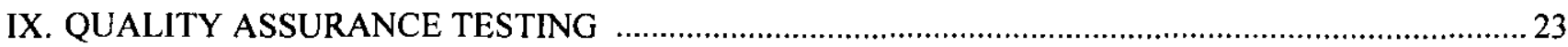

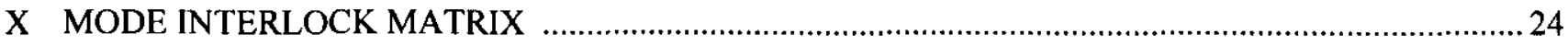


XI. MODE FLOW DIAGRAMS

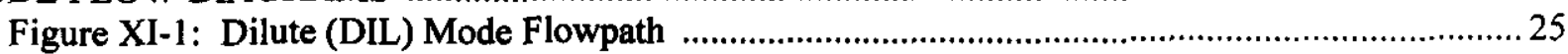

Figure XI-2: In-Tank Recirculation (ITR) Mode Flowpath .................................................... 26

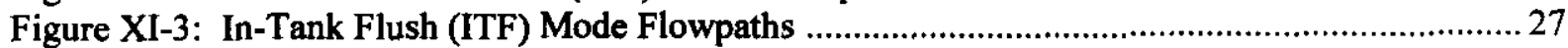

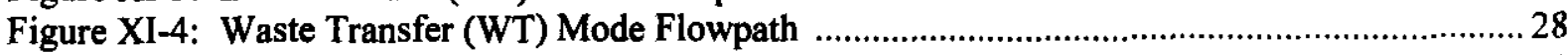

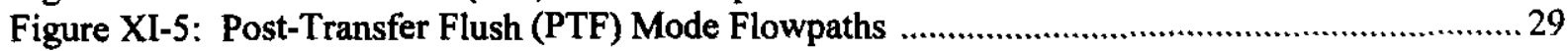

Figure XI-6: Post Flush Drain (PFD) Mode Flowpath ............................................................. 30

Figure XI-7: In-Line Dilution (ILD) Mode Flowpath ............................................................. 31

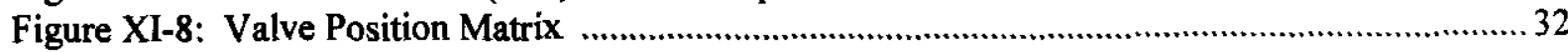

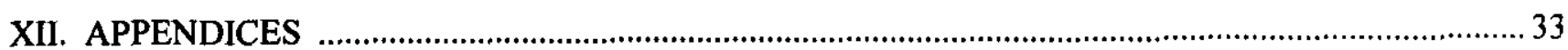

APPENDIX A - KEYBOARD ASSIGNMENTS …......................................................... A-1

APPENDIX B - PARAMETERS FOR TRENDING, ALARMS, CONTROLS \& INDICATIONS B-1

APPENDIX C - CAUSTIC SUPPLY SYSTEM ….........................................................

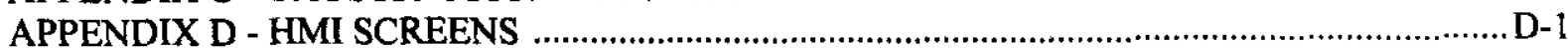




\section{INTRODUCTION}

\section{A. PURPOSE}

The primary purpose of the Initial Tank Retrieval Systems (ITRS) is to provide systems for retrieval of radioactive wastes stored in underground double-shell tanks (DSTs) for transfer to alternate storage, evaporation, pretreatment or treatment, while concurrently reducing risks associated with safety watch list and other DSTs. This Description of Operation (DOO) defines the control philosophy for the waste retrieval system for Tank 241-AZ-102 (AZ-102). This DOO provides a basis for the detailed design of the Project W-211 Retrieval Control System (RCS) for AZ-102 and also establishes test criteria for the RCS.

B. SCOPE

The DOO provides a basic description of the instrumentation, equipment, general operations, applications software, and how the software will control the necessary operations for AZ-102. The functional requirements for the operation of the ITRS using the RCS are included. Graphic display screens convey the manner in which the RCS will be used to control the retrieval process (see Appendix D).

\section{PROCESS OVERVIEW}

The retrieval process for AZ-102 will provide radioactive waste feed to other River Protection Program (RPP) processes by mixing waste contained in AZ-102, diluting it if required, and pumping it to the AZ-02A pit for further routing.

The Retrieval Control System (RCS) will have the following general capabilities; the retrieval process will be accomplished using a combination of these capabilities dependent on the specific mission profile. An exact listing and description of the specific modes is provided in section IV.

1. Upon equipment turn-on, the computer will default to the Ready Mode. This will be the default mode with no automatic actions taken and will be the only mode where remote manual control, as well as local manual (handwheel) pre-positioning of all the valves is possible.

2. The RCS will be able to control the Caustic Supply System, including the service water system, the raw water system, and the oil-fired water-heating boiler.

3. The RCS will be able to control the mixing of waste in AZ-102.

4. The Variable Frequency Drives (VFDs) that drive the previously installed Tank 241-AZ-101 (AZ-101) mixer pumps will be replaced. These replacement VFDs will be able to drive either the AZ-102 mixer pumps or the AZ-101 mixer pumps. Control of the VFDs will be from the RCS. Consequently, the RCS will control the AZ-102 mixer pumps and turntables for the retrieval process, and will also provide manual start/stop capability of the AZ-101 mixer pumps and turntables.

5. The RCS will be able to establish routing, and control the addition of diluent from the Caustic Supply System (CSS) to tank AZ-102, either through the tank return line, or to the suction of the transfer pump, to achieve in-line dilution. 
6. The RCS will be able to establish routing, and control the recirculation of waste in the tank, from the transfer pump, through an instrumented pipeline back to the tank to measure hydraulic characteristics prior to transfer to another tank, and to flush the lines and pump after recirculation is complete.

7. The RCS will be able to establish routing and control the pumping of waste from AZ-102 (pump pit 241-AZ-02A) through pump pit 241-AZ-01A, and then on to other selected tanks via a new valve pit 241-AZ-XXX (future installation by Project W-314), and to flush the lines and pump after the transfer is complete.

8. The Retrieval System equipment can be safely shutdown either automatically upon detection of a system or equipment fault, or manually under procedural response to an administrative control.

9. The RCS operations inside AZ-102 may be monitored using a closed-circuit television (CCTV) system.

\section{DEFINITIONS}

\section{ALARA: As Low As Reasonably Achievable}

Application Software: Application software is the general term applied to the software that will be developed based on the operational requirements set forth in this document. The application software performs or supports the performance of the primary functions of the RCS as described herein.

ATP: Acceptance Test Procedure is used to demonstrate that a system has been properly installed according to the approved design.

Auto: Refers to the automatic operation of equipment and/or control sequences in response to inputs from sensors and outputs to actuators by the process control software of the RCS, without operator intervention. (See Manual for comparison.)

\section{CASS: Computer Aided Surveillance System}

\section{CCTV: closed-circuit television}

Control Room: One ITRS Operator Interface Station (OIS), will be located in the 241-AZ-156 (AZ-156) building, with provisions to interface with a similar workstation installed by project W-314 in the existing W-030 control room. A second computer will be installed in the AZ-156 building for use as an Engineering workstation (EWS). The EWS will be able to operate in parallel with any OIS in buildings AZ-156 and 241-AZ-271 (AZ-271), and will be able to operate the ITRS if either OIS becomes unavailable. The OIS and EWS computers will also be used to service AN and AY Farm tanks during ITRS retrieval. All of the electrical power distribution equipment such as panelboards and MCC's necessary to support AZ-102 retrieval will be located in the AZ-156 building.

It is intended that the ITRS OIS and EWS interface with the OIS and EWS installed in the AZ-271 building by project W-314. The AZ-271 computers service the Master Pump Shutdown (MPS) portion of the Tank Farm Restoration and Safe Operations (TFRASO) project. The ITRS control room will house two OISs (one for the AZ farm and one for the AN farm), one shared EWS, and two in-tank CCTV monitors. The CCTV monitor and controls are mounted near the operator control stations. 
The PLC controller module for the ITRS, including local $\mathrm{I} / \mathrm{O}$, is located in the PLC panel in the AZ-156 building. Any necessary local instrumentation for monitoring and controlling the various pump and motor drives are also located in the AZ-156 building.

CPU: Central Processing Unit (e.g., the 486 or Pentium chip)

Critical Alarms: Alarms deemed sufficiently important to be communicated to a central monitoring station (TMACS). These are any alarms signaling immediate safety hazards, critical equipment failures, etc.

\section{CSS: Caustic Supply System}

DST: Double-shell tank

EWS: Engineering Workstation (PC with HMI software)

FCV: Flow Control Valve - FCVs are special purpose motor operated ball valves with linearized trim, that include analog position feedback in addition to end-travel limit switches. FCVs may be manually operated by use of a handwheel.

HMI Software: An HMI (Human-Machine Interface) software package, used to create the operator interface portion of the RCS.

I/O: Inputs and Outputs - The PLC provides the hardware interface for all field inputs and outputs which are typically divided into Discrete (On/Off) and Analog (Process Variable) inputs and outputs. Discrete Inputs and Outputs (DI and DO) are from and to devices such as switches and motor starters, respectively. Analog Inputs and Outputs ( $\mathrm{AI}$ and $\mathrm{AO})$ are from and to devices such as process variable transmitters, and VFDs, respectively.

ITRS: Initial Tank Retrieval Systems. ITRS is a project that provides for retrieval of radioactive wastes stored in DST's 241-SY-102; AN-103,-104, -105; AP-102 and 104; AY-102; AZ-102 and TBD.

Local: Refers to the control capabilities provided at or near the equipment, that do not depend on the RCS/PLC or central control console. Local control generally applies to items such as variable frequency motor drive cabinets, that can operate the motor or pump by manipulating buttons or key pads on the face of the cabinet.

Local/Manual: Refers to physical operation/control of a device such as a valve actuator handwheel.

Manual: Refers to control of a component or process from the graphic screen by the direct selection and action of the operator, in contrast to "Automatic", which requires no specific operator action. Hardwired interlocks are not bypassed in the remote/manual environment; however, software interlocks active under Auto mode may be bypassed. (See Auto for comparison.)

\section{MCC: Motor Control Center}

Menu List: A software list displayed on the graphic display screen that provides the various programmed actions available to the operator. For example, a menu list might contain selections for In-Tank Recirc Mode, Flush Mode, Transfer Mode, and the desired routing for the transfer, etc. Each menu item has prerequisites and conditions tables associated with them. 
MOV: Motor Operated Valve - These are typically 2-way and 3-way ball valves that are equipped with 120VAC actuators. Limit switches are provided for position indication.

MPS: Master Pump Shutdown - The system, that upon the detection of any pipe leak or misrouting, shuts down any pump capable of transferring waste.

OIS: Operator Interface Station (PC with HMI software)

Operating System: Operating System software directly manages the physical computer resources on behalf of the application software. For the RCS, this will be Windows NTß from Microsoft $\$$ providing multi-windowing and multi-tasking capability. (See HMI Software).

PC: Personal Computer used with HMI software to provide the OIS.

PID: Proportional / Integral / Derivative (Relational aspects between process control error and output.)

PLC: The Programmable Logic Controller is the microprocessor-based industrial controller capable of real-time control. The PLC provides all of the discrete and process control logic required for controlling the process. Once the PLC program has been loaded into the PLC controller module, the PLC will execute all control functions even if connection to the Operator Interface computer is severed or interrupted.

QTP: Qualification Test Procedure is used to validate the software logic.

RAM: Random Access Memory is the location where the computer's CPU temporarily stores data as it executes the programs it is running. Generally, the more RAM a computer has the faster it can run any of its programs, since access to data in RAM is much faster than access to data on a hard disk.

RCS: Retrieval Control System refers to the Industrial IBM compatible PC with its operator interface software, all peripherals such as modems and printers, the PLC system and all field instrumentation. The operator interface will consist of screens with graphics depicting the ITRS. The RCS provides monitoring and control capabilities to the Operations group.

Remote: Refers to the operation of any device and process control from the RCS either in Auto or Manual Mode.

Sensor: Refers to any instrument or device that detects and inputs signals to provide indication and/or status to the RCS. It may provide an Analog Input (AI) or a Discrete Input (DI).

TCP/IP: Transport Control Protocol / Internet Protocol (De facto standard for Unix and Microsoft Windows $\$$ communications)

TFRASO: Tank Farm Restoration and Safe Operation (Project W-314)

TMACS: Tank Monitoring and Control System

VFD: Variable Frequency Drive which modulates the speed of the motor it controls by changing the frequency of its power supply.

Window: Term used to describe a part or all of a complete screen display. 


\section{GENERAL DESCRIPTION}

The retrieval system for AZ-102 will provide for the retrieval of radioactive wastes stored in the tank. The following major equipment and subsystems will make up the ITRS for AZ-102:

- Two Mixer pumps, motors and associated instrumentation.

- One Transfer pump, motor and associated instrumentation.

- Transfer piping, including new jumpers.

- RCS consisting of one OIS, one EWS, one central (Caustic System) PLC-I/O enclosure located in building AZ-156, one remote (AZ-102) PLC-I/O enclosure located in building 241-AZ-801A (AZ-801A), and various field-mounted instrument devices.

- One shared CSS; refer to HNF-3836.

- Nitrogen bottle station.

- One CCTV camera system and associated compressed air system.

- Four new in-tank temperature probes with 14 sensors each, and two new dry-well temperature sensors; dry-well temperatures are used for indication only.

- Westronics temperature indicator/controller.

The W-211 RCS will also monitor and control the two mixer pumps and turntables installed in AZ-101 by project W-151.

Dilution with a $\mathrm{NaOH}$ diluent, from the existing shared CSS, will be used to adjust the fluid properties of the waste. AZ-102 will have a transfer pump with in-line diluent injection capability at the low-pressure side of the first impeller of the multi-stage pump. The CSS will provide diluent to the tank either at the transfer pump suction for in-line dilution or through a different inlet pipe for in-tank dilution. In-line dilution may be required during transfer if parameters, such as apparent viscosity or density, approach the upper limits for fluid pumpability. In-line sensing instruments located in pump pit 241-AZ-02A will measure density, flow, pressure and temperature during transfer.

The CSS will also be used to flush the system piping and transfer line after the completion of a transfer campaign, or upon system shutdown.

The RCS will consist of two industrial PCs with video monitors, an AZ-102 PLC, a Caustic System PLC, printer(s), and the field instrumentation and control devices. The PCs will have identical versions of the operator interface software application loaded and running thus increasing availability. One of the PCs will be nominally dedicated as an OIS, and one PC will be dedicated as an EWS. Graphic display screens will be designed to allow ease of operation and will provide the monitoring and control functions necessary for proper operation.

AZ-102 and AZ-101 instrument inputs and outputs required for the RCS will be connected to the AZ-102 PLC unless stated otherwise. Instrumentation will provide the following monitoring and control functions for the ITRS:

- Mixer pumps (For both AZ-101 and AZ-102): Motor speed and amperage, upper and lower motor bearing vibration and temperature, motor winding temperature, turntable orientation and rotation, and seal water flow and pressure.

- Transfer pump: Motor speed and amperage, seal gas flow and pressure, and motor winding temperature. 
- Transfer Pump Pit 241-AZ-02A: MOV Positions, pump pressure, waste density, flow, temperature and pressure, waste backflow detection, and rupture disk failure.

- Inside tank: Tank level, waste temperature and dome pressure.

- CSS: Refer to HNF-3836 for monitoring and control functions for the CSS.

- AZ-156 building: All pump VFDs and motor starter monitoring and control signals, including pump speeds and motor loads via the ModBus Plus link between the PLC controller module and the VFDs.

\section{A. RCS DESCRIPTION}

One uninterruptable power supply (UPS) will be provided to keep the Caustic System PLC, associated V/O racks, and EWS operating during short (approximately one hour) power outages. The UPS is in the RCS enclosure in the AZ-156 building. Another UPS will be provided for the AZ-102 PLC and associated I/O rack. These UPSs will provide AC power to retain the RCS "memory" for a quick restart after normal power is restored, and to provide power to two MOVs in the Caustic system required to be moved to the CLOSED position upon a general loss of normal $\mathrm{AC}$ power.

Custom application software for the ITRS will be developed using the Control Plus $B$ PLC programming software for the Modicon Quantum $\otimes P L C$, and the Ci Technology Citect $\$$ operator interface software for the PC. The requirements for external system interfaces include communication links with TMACS, the VFDs, the TFRASO project, HLAN, the CSS and the packaged boiler (part of the CSS).

The design of the RCS will allow Manual (and local/manual) operation of all MOVs in the Ready mode. When in a Mode other than Ready, the RCS will allow manual operation of only those MOVs not part of the current routing arrangement. All valves may be locally operated with a handwheel; however, handwheel operation cannot conflict with electric operation. To place a valve in a position not allowed by the PLC logic, will require supervisor approval to disable the electrical supply to the valve. This administrative control is necessary to avoid defeating the misrouting prevention features of the RCS without proper authority. All pump starts are manually initiated by operator action; there is no provision for automatic pump starts. The RCS is configured to allow the transfer of operational control to a future central location (e.g., 241-AZ-271), and may be shared with the Tank Farms Restoration and Safe Operations MPS OIS (Project W-314).

The RCS software will provide a process system report when requested by the operator. This report will contain the current status of all significant process equipment and alarms.

The RCS will provide a display of any caution or warning messages while in the process of startup. All alarms, controls and indications will be available to the operator when in the mode indicated in Appendix B.

All screens on the OIS will be available for selection by two methods: by using the SCREEN LIST pop-up menu or by clicking on the appropriate screen target.

All screen and equipment controls will be executed in either one of two ways: clicking on screen targets with the mouse or keyboard commands. 


\section{B. RCS FUNCTIONS}

The RCS will monitor the process via the instrumentation, control the process via the equipment connected as outputs from the PLC, display status information and accept operator input. The applications software (Citect) will include all of the tools necessary to provide the required functions. The RCS will be designed and programmed to implement the following process functions:

- Provide monitoring, and display the status and performance of each selected ITRS process subsection and/or component group.

- Provide a signal interface to HLAN for remote monitoring.

- Provide for adjustment of control setpoints by the operator during operation (e.g., adjust the speed of a pump).

- Provide indication of all monitored process parameters.

- Provide audible and visual annunciation for all alarm conditions.

- Provide ability to change alarm setpoints by Operations Supervisor or System Engineer.

- Allow Auto/Manual control of system processes and equipment.

- Include Proportional-Integral-Derivative (PID) loop controls.

- Provide on-line historical and real-time trending of process parameters with report capability for a period of one week. After one week, data will be downloaded to an appropriate archive, either removable storage media or an as-yet-to-be-defined HLAN/TMACS/network data repository.

- Provide prioritized, grouped, and time/date stamped Alarm Summary screen and event log on the RCS. All alarms may be automatically printed out on the RCS alarm printer. Alarms and operator actions on the RCS will be automatically logged to the hard drive for periodic archival to off-line storage media.

\section{USER CHARACTERISTICS}

\section{OPERATORS \& SUPERVISORS}

The RCS application software will be designed for use by process operators. All computer displays and windows will be representative of the process flow and components. All persons who operate this equipment will receive training on the RCS OIS.

\section{SYSTEM ENGINEERS}

System Engineers will be RPP engineers trained to provide support for the ITRS. The System Engineers will be familiar with the RCS operating system, Windows NT®. The System Engineers will also be familiar with the Modicon Quantum $\otimes$ PLCs, the Control Plus $\otimes$ PLC programming software, and the Citect $\$$ operator interface software. The System Engineers will have access to all of the process control documentation, software and keys required to 
build/rebuild/modify PLC logic, communications drivers, graphic screens, databases, and any other software components of the system.

\section{NETWORKING CAPABILITIES}

1. The W-211 OIS and EWS, plus the related RCS/PLC, will be in permanent communication with the W-314 PLC system, including all the W-314 OISs and EWSs via the W-314 Ethernet Tank Farm LAN (TFLAN). This feature allows W-211 to access W-314 waste routing and Master Pump Shutdown information, and allows W-314 to access similar W-211 information. This feature also eliminates the necessity to "hardwire" this information between projects.

2. The W-211 OIS and EWS, including the RCS/PLC will also be in permanent communication with TMACS over the HLAN; TMACS is expected to be upgraded (by others) to communicate via HLAN. This feature allows TMACS to access any W-211 information that Operations may want to see, such as Tank Waste Temperature probes (TI-101 through TI-156 on drawing H-14-102971), nitrogen bottle low pressure alarms, etc. This assumption also allows W-211 to access information already collected on TMACS. It is planned to retrieve the following information from TMACS via HLAN, rather than routing the signal wires directly to the RCS/PLC:

\section{Tank AZ-102 Waste Level \\ LI-101 on drawing H-14-102971}

3. Any safety-class devices installed by $\mathrm{W}-211$ will deliver their output (safety-class function) via a hard-wired circuit to the related safety-class actuation system (e.g., MPS, W-314 mis-routing prevention system), without going through the W-211 RCS/PLC.

\section{GENERAL FUNCTIONAL REQUIREMENTS}

\section{A. OPERATOR INTERFACE}

The following are the system general functional requirements:

1. All RCS graphical display screens, designed to be operator friendly, will be graphically oriented. There will be two modes of selection: with the mouse or with keyboard key combinations. Menu-driven operations will be used to control the system (operator selects from an on-screen "menu" as opposed to having to "spell out" commands from a keyboard). Menu selections will be provided as keyboard key combinations, such as Ctrl-F1, and lists of commands and/or command symbols, which can be selected with the mouse. The RCS screens will allow the user the capability of going from one screen to another by clicking the designated area (e.g., a Pump symbol). All screens will be standardized for key assignments, color assignments, etc. (e.g., Fl is the Help key). See Appendix A for list of standard key assignments.

2. The RCS will provide data storage capabilities to an ASCII or common spreadsheet format, e.g., Microsoft ${ }^{\mathbb{0}}$ Excel.

3. The RCS will provide historical trending capabilities. All important process parameters will be trended. See Appendix B for the list of parameters which will initially be configured for trending. 
4. Loss of PLC communications, as well as other PLC diagnostics, will be annunciated with the screen indicator flashing red and an audible alarm. In addition, all values displayed on the OIS PCs from the PLC will show as ???? upon loss of communications between the PLC and the HMI running on the OIS PCs. The I/O modules monitor their own inputs, and report to the PLC on any loss of signal, the PLC then reports the problem to the HMI screen. The loss of the incoming 480 volt feeder to the ITRS will also be annunciated.

5. All required software will load automatically any time the RCS is started or reset. This includes restart after a power outage. The operator must, however, log-in again into Windows ${ }^{\circledR} \mathrm{NT}$ and the RCS (see Appendix D, Figure D-1). The RCS will already be in communications with the PLC, gathering data, etc.

6. All remotely operated pumps and valves will have running and position indications displayed on the RCS display monitors.

7. All operator initiated actions will be logged, e.g., if any remotely operated device or equipment is placed in Manual control.

8. The alarms and indications will be displayed on the RCS monitors. Any logic that is used for interlocks or control will be programmed into the PLC, instead of the HMI software. The PLC will set a separate bit for each alarm associated with the triggering of an interlock (e.g., Hi-Hi Tank Temperature will cause the pumps to stop). The RCS PC operator interface (HMI) software will log, display, and annunciate all alarms, as well as providing alarm logic for some of the less critical alarms.

9. Graphic Screen Color Coding

a. Process lines on the screens will be color-coded as follows:

\section{Line Color Code}

White

Dark Gray

Green with white diamonds

\section{Condition}

General piping arrangement - not selected Correct configuration for selected mode Flow

b. Valve Operation Indication

Each open valve port will be green. A closed port will be white. Valve symbols will always indicate current position whether they are in the auto or manual mode. When in transition, the valve symbols will be yellow. There will be a valve transition delay for each valve which if exceeded will cause the failure alarm for that valve to be annunciated, and will cause the entire valve symbol to flash alternately red and white.

c. Pump Operation Indication

Pumps not running will be light gray in color. When pumps are started, and a confirmation of running is received from the related MCC or VFD, the pump symbol will turn green.

If a pump fails to start, an alarm will sound after an adjustable time delay, and the pump symbol will flash alternately red and white. 


\section{Security - User Access to Displays and Functions}

In order to use the operator interface software application to control the retrieval operation, the user must be in the log-in group that will allow access to perform the desired functions. In some cases, a user from the Operations Supervisor group must be logged in to enable or execute a particular function. In other cases, a user from the Operator group will be able to enable and execute the function. Supervisor and Operator groups are just for operations, while the Systems Engineer may make changes to the application programming as well. The table below lists the user group and its access to the different types of functions.

\begin{tabular}{|c|l|}
\hline User Group & \multicolumn{1}{|c|}{ Accessible Functions } \\
\hline Operator & $\begin{array}{l}\text { May perform resets, input operating parameters, start and stop equipment, } \\
\text { change auto/manual modes for specific pieces of equipment, sort alarms, } \\
\text { and initiate all operational modes. }\end{array}$ \\
\hline Operations Supervisor & $\begin{array}{l}\text { May override software interlocks, and disable alarms, instruments or } \\
\text { equipment, change alarm setpoints, and perform all of the operator } \\
\text { functions. }\end{array}$ \\
\hline Systems Engineer & $\begin{array}{l}\text { May override all functions, make software changes to all of the system } \\
\text { software, and perform all of the operator and operations supervisor group } \\
\text { functions. Works with instrument technicians to upgrade and repair RCS. }\end{array}$ \\
\hline
\end{tabular}

\section{B. ALARM HANDLING}

The following section defines the alarm handling requirements. See Appendix B for a list of alarms and their setpoints.

1. Alarm sequence of operation:

a. An alarm condition will produce a red flashing alarm indication on the RCS monitors and audible beeps from the PC speakers.

b. In addition, if the alarming device or parameter is shown on a sub-screen, the sub-screen will display with the appropriate symbol or display box flashing. Refer to color schemes below.

c. The alarm page may be displayed by clicking on the flashing alarm symbol (upper right of a full page screen), by clicking the alarm icon button on the navigation bar (left side of a full page screen) or by pressing the "F5" key. From the alarm page any active alarm can be acknowledged by clicking on the alarm text. Each alarm displays the following information, tag name, time and date of activation, name, a brief description, value, and the state. Refer to color schemes below.

d. The alarm summary screen may be displayed by clicking on the alarm summary button on the navigation bar or by pressing the "F6" key. This page will display a history of alarms giving alarm name, brief description of alarm, time alarm became active, time alarm became inactive, and operator comments. Operator comments can be added to any alarm on the alarm summary screen by right clicking on the text of the alarm that is in focus (text outlined by white). 
e. The alarm summary screen will display (on multiple pages) up to 1,000 alarms. Alarms will stay on the summary page for 60 minutes after they become active.

2. Color Schemes:

Symbols and display boxes flash red/white for critical alarms (e.g. High High level or Low Low level) and yellow/black for non-critical alarms (e.g. High level, Low level, or valve fail). The symbols and display boxes stay flashing until the alarm becomes inactive, not after acknowledgment.

Alarm and summary alarm pages text flashes red, yellow, or blue (critical, non-critical, and misc.) for alarms that are unacknowledged and active. The colors go steady when the alarm is acknowledged but still active. When the alarm is no longer active but not acknowledged, the text colors invert (e.g. red on gray goes to gray on red). When the alarm is acknowledged and inactive, it disappears from the alarm page and turns light blue on the alarm summary page. Any disabled alarms will be white.

3. Set Alarm Points:

The Operations Supervisor or Systems Engineer can change the setpoint of certain analog alarms via the alarm setpoint screen.

4. Remote Alarms:

All alarms will be individually available to TMACS over a serial data link.

\section{CONTROL}

1. The RCS will be designed and programmed to operate either in a manual or automatic mode of operation. The manual mode of operation occurs when the RCS is in the READY Mode, and the automatic mode of operation is in effect when any other "Mode" listed in section IV.C is in effect. The RCS includes a valve position interlock permissive provision that prevents the transfer pump from being operated unless the selected waste transfer route is verified. The computer verifies the route by automatically comparing actual valve positions against the required valve positions. This feature requires that the transfer pump be prevented from being started when the system is in the "READY" mode, because no valve position checks are made in the READY Mode. This preventive interlock will be able to be bypassed under administrative control. All MOVs will be able to be controlled manually in the Ready mode. For all other modes, all MOVs related to that mode must be in Auto in order to activate the mode. MOVs not related to the active mode may be individually placed in the RCS Manual Mode of operation, and manually operated for maintenance or other reasons. Valves that could interfere with operation of any currently active mode will be prevented from being individually placed in the RCS Manual Mode.

The RCS will maintain the process variables with a PID algorithm (where appropriate) at the setpoints set by the operator. Process (analog) control and on-off (discrete) control of equipment will be in accordance with those control sequences described herein and the logic diagrams done in Control Plus format. See Appendix B for list of controls for the retrieval equipment and processes. 
2. The operator will be able to place the retrieval system in a safe shutdown condition in case of failures or unusual operating circumstances.

3. All L/O control (analog and discrete) will be programmed into the PLC. The operator interface to the PLC will be via color graphic display screens on the OIS monitor. The redundant PCs (OIS and EWS) will be capable of independent action. For example, one PC could be used to monitor alarms the majority of the time while the other PC could be used to show the current area of interest. The graphic displays will be hierarchical with the Overview screen depicting the basic overall arrangement and common elements. If the operator selects any of the major blocks on the screen, the screen will change to a more detailed screen of that process block, e.g., Tank 241-AZ-102 (see Appendix D, Figure D-9). The detailed process screens will indicate individual components, the status of the component (On/Off, Auto/Manual, etc.) and the control mode for the component or process. See Appendix D for a depiction of the screens.

4. Equipment symbols on the screens, that provide further detail or control, will be signified with black text.

5. Operator actions that will be subject to interlocking will be programmed into the PLC logic (software interlocks) to protect equipment and personnel, and to prevent any undesired process action.

6. Monitoring and control of all analog $\mathrm{I} / \mathrm{O}$ will be programmed into the $\mathrm{PLC}$, including PID algorithms. The process variable signal from an analog instrument, e.g., the transfer pump discharge pressure, will be displayed on the RCS as a digital readout with the engineering units displayed next to the reading. In some cases, an additional analog indication, such as a bar graph, will also be displayed.

7. The Operations Supervisor or Systems Engineer will enter various process setpoints into the RCS. Provisions will be made to enter these settings into the program in an operator friendly manner. All setpoints will have minimum and maximum limits to prevent entering setpoints outside these limits. If a user attempts to enter an out-of-range setpoint, the invalid setpoint will be rejected and the user will be notified immediately with the appropriate message. Setpoint ranges will be only adjustable at an Operations Supervisor or Systems Engineer security level. (See Appendix D, Figure D-4.)

8. All pump auto/manual, on/off and start/stop selections and indications will be provided at the RCS. The appropriate "buttons" will be located in a pop-up window showing a pump control faceplate (one for mixer pumps and turntable control, and one for transfer pump control) triggered by selecting the pump symbol. (See Appendix D, Figures D-10 and D-11.)

9. All remote controlled valve auto/manual and position selections and indications will be provided at the RCS. The appropriate "buttons" will be located in a pop-up window showing a standard valve control faceplate triggered by selecting the valve symbol. (See Appendix D, Figures D-17, D-19 and D-20.)

10. It is intended that this ITRS be used in conjunction with the TFRASO system to depict the entire waste transfer route on one or more graphic computer screens.

11. Provisions will be programmed into the RCS to allow the operator to print in color any screen that is displayed. This will capture the alarms (shown in red), as well as the normal states.

12. The CCTV system will be used to view inside AZ-102 for support of ITRS operations. 


\section{MODE OF OPERATION - FUNCTIONAL REQUIREMENTS}

Note: The following description of mixer pump and turntable operation applies to mixer pumps in both AZ-101 and AZ-102.

The purpose of this section is to define the sequence of operations for the ITRS. Initial startup and commissioning of the ITRS after installation will be addressed in the Acceptance Test Procedure (ATP) document. The final objective of the procedures described herein is to obtain safe, automatic operation, by describing key operator interactions required, such as starting pumps and manipulating valves.

\section{A. MIXER PUMP OPERATIONS}

The four (4) VFDs previously installed for mixer pumps and turntables for AZ-101 will be replaced and shared with the mixer pumps and turntables being installed for AZ-102. The output of each VFD will be routed through a transfer switch. The manually operated transfer switches will connect (for example) a common VFD to either pump 1 in AZ-101, or pump I in AZ-102. The position of the transfer switch will be sent to the RCS computer. The RCS computer will display on the computer graphic screens, the appropriate EINs of the instruments and controls related to the selected pump (or turntable), based on the position of the transfer switch. Because the pumps (and turntables) use common VFDs, the graphic screen controls will be identical except for EINs.

Any AZ-102 mixer pump will be able to be operated independent of the operational mode. A mixer pump will be able to be run any time that the tank level is above 66" (approximately 48" above pump suction), the waste temperature (from the four AZ-102 in-tank temperature probes) is below $195^{\circ} \mathrm{F}$, and tank vapor space vacuum is greater than 0.25 " W.G. When in AUTO, the mixer pump speed will be automatically controlled by the PLC, as a function of pump nozzle rotation angle to minimize impingement on other in-tank components. The mixer pumps in AZ-102 will be automatically shutdown in either the AUTO or MANUAL mode if any of the interlocks listed in Table IV-3 are in effect. The mixer pumps in AZ-101 will be operated manually under procedural control (no operational modes apply), and will only have interlock 5 described in Table IV-3 for mixer pump motor vibration, motor current and bearing temperature; shutdown of the mixer pumps in AZ-101 will occur due to mixer pump motor parameters and will depend on operator action for all other parameters.

1. Initial Startup

On the initial startup of the mixer pump or after a long idle period, when the mixer pump intake may be immersed in a layer of sludge, adding diluent at the intake is desirable in order to dilute the sludge and enable the mixer pump to start and operate. The mixer pump will be able to be flushed and started with either the intake-mounted sparge ring piping, or the casing flush piping, connected to the flexible hose from the Retrieval Service Water Enclosure.

2. Normal Startup and Operations

The operator will prepare to operate a mixer pump by placing it in either Auto or Manual Mode, depending upon operational requirements. This will require a series of steps as given below:

a. Select tank "241-AZ-101" or "241-AZ-102" on the Retrieval System Overview screen. This will display the appropriate tank overview screen. 
b. Select the "Mixer Pump" symbol, and the Mixer Pump faceplate for the desired mixer pump and related turntable drive controls will pop-up.

c. On the mixer pump faceplate, enter the desired speed setpoint in percent $(60 \%$ minimum allowable and $100 \%$ maximum allowable) or adjust it up or down using the speed up or down buttons. Initial value for mixer pump speed upon PLC power-up will be $60 \%$.

d. The faceplate will also allow the operator to put the mixer pump into AUTO or MANUAL mode, as well as START and STOP it. In AUTO mode, the mixer pump speed will be controlled in accordance with the speed versus position profile (see Appendix D, Figure D-12). The mixer pump will also be stopped if any of the automatic shutdown conditions occur, or if stopped by the operator.

e. Select the mixer pump START button. If the mixer pump does not start, the mixer pump failure alarm will be annunciated after an adjustable delay.

f. Using the faceplate controller for the turntable drive, enter the desired speed setpoint for the turntable drive in percent or adjust it up or down using the speed up or down buttons. Initial value for turntable drive speed upon PLC power up will be 100\%.

g. There will also be a faceplate for the turntable that allows the operator to put the mixer turntable drive into AUTO or MANUAL mode, as well as, START and STOP it. In AUTO mode, the mixer turntable drive will oscillate between pre-established rotational limits with $0^{\circ}$ indicating North. It will automatically stop at the end of each oscillation and reverse direction. In MANUAL, the turntable will move the mixer pump to the position desired by the operator who will use the $\mathrm{CW}$ (clockwise) and $\mathrm{CCW}$ (counter-clockwise) buttons to position the mixer pump. The position of the mixer pump nozzles will be displayed by the NOZZLE ORIENTATION symbol.

h. Select the mixer turntable drive START button. If the mixer turntable does not start, the mixer turntable drive failure alarm will be annunciated after an adjustable delay.

\section{B. CAUSTIC SUPPLY SYSTEM}

Refer to HNF-3836, Project W-211 Initial Tank Retrieval Systems Description of Operations for 241-AN-105. A generic description of Caustic Supply System operation is in Appendix C.

\section{OPERATIONAL MODES}

Specific control parameters such as pump speed settings, etc., are given in Appendix B. Actuation of the MPS will shut down or prevent startup of the transfer pump under any operational mode. The CSS is shutdown by actuation of the MPS. 
The operational modes for the Transfer System will be as follows: (Refer to Section XI, MODE FLOW DIAGRAMS, Figures XI-1 to XI-7, and Valve Position Matrix, Figure XI-8).

- RDY Ready Mode (No flow diagram.)

- DIL In-Tank Dilute Mode

- ITR In-Tank Recirculation Mode

- ITF In-Tank Flush Mode (After ITR)

- WT Waste Transfer Mode (from AZ-102)

- PTF Post Transfer Flush Mode

- PFD Post Flush Drain Mode

- ILD In-Line Dilution Mode

- SSD Safe Shutdown Mode (No flow diagram.)

Operation of the CSS and the mixer pumps will be independent of any mode.

The transfer pump will always be started manually. In the following operations descriptions, if the transfer pump has not been set up, the following procedure will have to be performed to set up the pump prior to clicking on the "Press Start When Ready" button:

a) Select tank "241-AZ-102" on the Retrieval System Overview screen. This will display the Tank 241-AZ-102 Screen (Appendix D, Figure D-9).

b) Select the "Transfer Pump" symbol and the Transfer Pump Faceplate (Appendix D, Figure D-11) will pop-up.

c) Enter the desired speed setpoint in percent (minimum allowable to maximum allowable) or adjust it up or down using the speed up or down buttons.

d) The faceplate window will allow the operator to put the transfer pump into AUTO or MANUAL mode, as well as START and STOP it. In AUTO mode, the transfer pump speed will be controlled in a PID loop to maintain the flow setpoint through FE-156. This setpoint will be available on the Retrieval Setup screen (Appendix D, Figure D-4). In the MANUAL mode, the pump will run at the speed selected. The transfer pump will be stopped if any of the automatic shutdown conditions occur, by a Master Pump Shutdown System trip, or if stopped by the operator.

When a mode is selected (except the READY mode), the RCS will check the status of all prerequisites (valve status, pump status, other mode status, etc.). The RCS will provide an on-screen display of control system pre-requisites not met. Examples of required operator actions might be to place a local control in the remote mode (e.g., VFD), or change a valve control from manual to automatic. When all pre-requisites have been met, the system will display a message that the selected mode is confirmed ready for "activation." The operator can then mouse click on an "ACTIVATE" button causing the actions described below. The mode steps below will be under the control of the RCS except where noted otherwise, e.g., "(administratively controlled)". Refer to Appendix D, Figure D-2, for valve location information. Note that only the numeric portion of the number is displayed on the screen.

When the phrase, "All valves in Auto mode" or similar is used, it means that all valves required for the selected MODE have been put in the AUTO mode by selecting AUTO on each specific valve pop-up face-plate. 
In the following operational MODE descriptions that utilize the CSS, valves CHEMB-V-112 and CHEMB-V-175 will be verified open, and valves CHEMB-V-174, 176, 177 will be verified closed. These manifold valve positions do not change unless retrieval activities are transferred to a different tank farm, in which case that system will demand and monitor the new (but static) positions.

1. RDY: Ready Mode

When the RCS system is in the Ready mode, all pump status and valve positions will be monitored and displayed, but no commands will be given automatically to change valve positions or start and stop pumps except for safety related interlocks. Mixer pumps may be run in AUTO or MANUAL. The transfer pump cannot be run in AUTO in the READY Mode, but may be run in MANUAL in the READY Mode if the interlock is bypassed by proper authority. The MPS interlock is not bypassable. The CSS may be run in this mode in AUTO or MANUAL.

2. DIL: In-Tank Dilute Mode (refer to Figure XI-1)

The DIL mode can be activated if all valves are in Auto mode and the CSS is ready (administratively controlled). Upon activation, the following events will occur:

Step 1: Align Valves: the RCS will position (or will confirm position of CHEMB-FCV-129, CHEMB-V-178, WT-MOV-609 and WT-MOV 614.

Step 2: Open Caustic: Once the above valves are in the correct alignment, open valve CHEMB-FCV-129. Add diluent to AZ-102 until the desired total has been reached and equals the setpoint as indicated on status screen (Diluent Addition to Tank: \#\#, \#\# gal.). Diluent flow control valve CHEMB-FCV-129 will modulate around a flow setpoint to control flow of diluent into AZ-102.

Step 3: Recirculate Caustic: When the Preset Amount has been reached (entered on Retrieval Setup screen), the RCS program will automatically close CHEMB-FCV-129, resulting in automatic CSS recirculation through FIT-128. (The diluent supply to the flush tank will be automatically terminated at this point.)

3. ITR: In-Tank Recirculation Mode (refer to Figure XI-2)

The operator selects the ITR Mode from the Mode Selection pop-up window. If all of the prerequisite conditions have been met for this operation (e.g., operator will not be allowed to go into this mode if a waste transfer is in progress), the operator can then activate this mode via the controls on the RCS monitor. Activation is by clicking on the Activate Mode ITR button or by pressing the correct key combination on the keyboard. This mode can be used to establish wastespecific pump curves for the transfer pump. Upon Activation, the following events will occur:

Step 1: Align Valves: the RCS positions (or confirms position of) WT-MOV-608, 609, 612, and 613 , and confirms that WT-FCV-610 is at least $50 \%$ open.

Press Start when ready. Operator activates the transfer pump START button. If the transfer pump does not start, the transfer pump failure alarm will annunciate after an adjustable delay. The RCS will stay in the ITR mode until the objectives of that mode (e.g., waste hydraulic characterization) have been met. The operator may then shut down the pump and go to another mode. 
4. ITF: In-Tank Flush Mode (After ITR) (refer to Figure XI-3)

The optimum time to flush the central pump pit jumper is immediately after in-tank recirculation. ITF consists of several steps to: backflush the pump seals, backflush the pump itself, and backflush the appropriate pipe sections.

The ITF mode can be activated if all valves are in Auto mode and the CSS is ready (administratively controlled). Check ready status of CSS (in recirculation and at the correct temperature, pressure and $\mathrm{pH}$ for flushing; see Retrieval Setup screen, Appendix D, Figure D-4). Upon activation, the following events will occur: (Note: each step will reconfirm proper valve positioning.)

Step 1: Stop (or confirm stopped) Transfer Pump.

Step 2: Align Valves: the RCS will position (or will confirm the position of CHEMB-FCV-129, CHEMB-V-178, and WT-MOV-608, 609, 611,612, 613, and 614, and forces WT-FCV-610 to full open.

Step 3: Flush Pump Seals: Open CHEMB-FCV-129 and backflush the pump seals for the preset gallons previously entered on the Retrieval Setup screen.

Step 4: Flush Pump: When preset gallons have flushed per step 3, the RCS will reposition WT-MOV-609 to redirect the flush fluid through the pump and part of the transfer piping for the preset gallons previously entered on the Retrieval Setup Screen.

Step 5: Flush Transfer Pipe: When the preset gallons have flushed per step 4, the RCS will reposition WT-MOV-608 to flush the remainder of the transfer piping for the preset gallons previously entered on the Retrieval Setup Screen.

Step 6: Recirculate Caustic: When preset gallons have flushed per step 5, the RCS will put the CSS into recirculation by closing CHEMB-FCV-129.

5. WT: Waste Transfer Mode (from AZ-102 to Valve Pit 241-AZ-01A) (refer to Figure XI-4)

Upon activation of the WT mode, the following events will occur:

Step 1: Align Valves: the RCS will position (or will confirm the position of) WT-MOV-608, 609,611 , and 613 .

Press Start when ready. Operator activates the transfer pump START button to turn on transfer pump at preset speed. If the transfer pump does not start, the transfer pump failure alarm will annunciate after an adjustable delay. When transfer is complete, operator stops the transfer pump. (Note: Post Transfer Flush (PTF) should be performed immediately after WT.

6. PTF: Post Transfer Flush (refer to Figure XI-5)

The optimum time to flush the waste transfer lines is immediately after waste transfer (WT).

Check ready status of CSS (in recirculation and at the correct temperature, pressure and $\mathrm{pH}$ for flushing; see Retrieval Setup screen, Appendix D, Figure D-4). Upon activation, the following events will occur: 
Step 1: Stop (or confirm stopped) Transfer Pump.

Step 2: Align Valves: the RCS will position (or will confirm the position of CHEMB-FCV-129, CHEMB-V-178, and WT-MOV-608, 609, 611, 613, and 614.

Step 3: Flush Pump Seals: Open CHEMB-FCV-129 and backflush the pump seals through WT-MOV-611 and 614 for the preset gallons previously entered on the Retrieval Setup screen.

Step 4: Flush Pump: When the preset gallons have flushed per step 3, the RCS will reposition WT-MOV-609 to redirect the flush fluid through the pump and part of the transfer piping through WT-MOV-608 for the preset gallons previously entered on the Retrieval Setup screen.

Step 5: Flush Transfer Pipe: When the preset gallons have flushed per step 4, the RCS will reposition WT-MOV-608 to flush the remainder of the transfer piping through WT-MOV-613 for the preset gallons previously entered on the Retrieval Setup Screen.

Step 6: Recirculate Caustic: When preset gallons have flushed per step 5, the RCS will put the CSS into recirculation by closing CHEMB-FCV-129.

7. PFD: Post Flush Drain (refer to Figure XI-6)

Upon completion of the PTF Mode, the piping system should be drained of flush fluid. Upon activation of the PFD Mode, the following events will occur:

Step 1: Drain Transfer and Flush Piping: the RCS positions (or confirms the position of) CHEMB-FCV-129, and WT-MOV-608, 609, 612, 613, 614, and forces WT-FCV-610 to full open.

Step 2: Drain In-Pit Piping A: After a pre-set time, realign WT-MOV-609 to drain a portion of the in-pit piping.

Step 3: Drain In-Pit Piping B and Upper Transfer Pump Piping: After a pre-set time, realign WT-MOV-608 to drain a portion of the in-pit piping and the upper piping of the transfer pump. Valves remain in these positions until a different MODE is selected and activated.

8. ILD: In-Line Dilution of AZ-102 Waste (refer to Figure XI-7)

Provisions will be made to allow in-line dilution of waste being pumped by the transfer pump by introducing diluent into the suction bowl of the operating pump. This feature can be performed whenever the pump is running, and the flush system is not being used in some other mode. The mode will be "grayed out" on the mode list if it is not available; otherwise, this mode can be activated while another mode is in progress in the same tank.

Check ready status of CSS (in recirculation and at the correct temperature, pressure and $\mathrm{pH}$ for dilution). Upon activation, the following events will occur:

Step 1: Align Valves: the RCS will position (or will confirm the position of CHEMB-FCV-129, CHEMB-V-178, and WT-MOV-609, 611 and 614. 
Step 2: Open Caustic: Once the above valves are in the correct alignment, open CHEMB-FCV-129 to a pre-set flowrate.

Step 3: Recirculate Caustic: Continue until the need for in-line dilution is satisfied, then the operator manually closes CHEMB-FCV-129, which places the CSS in the recirculation mode.

9. SSD: System Shutdown Mode(s)

A SSD mode will be able to be actuated by the operator, or automatically upon loss of $120 \mathrm{Vac}$ power to the PLC UPS or a MPS event. The exact sequence of events following activation of the SSD mode will be different depending upon which mode of operation is being shutdown. In general, the SSD mode will be used only when there is a problem and the current mode must be suspended or stopped. Usually, when a mode is complete, the operator selects the next mode to be implemented, or returns to the Ready mode.

Unplanned shutdowns, due to power failures, will cause all valves except CHEMB-FCV-129 and CHEMB-MOV-117 (fail closed) to fail in place and all pumps to stop pumping. There will be no danger to the environment or to personnel resulting from such an unplanned shutdown. When power is restored, the RCS will come up in the Ready mode with valve positions maintained, and it will be an operator decision to reposition failed closed valves if necessary, reselect the mode, and restart the pumps to resume the mode.

Other types of shutdowns may be caused by a leak being detected and causing a Master Pump Shutdown (MPS) to stop all transfer pumps, or by an abnormal event that procedurally requires the operator to perform an administrative shutdown. Automatic shutdowns will sound an alarm to alert the operator. An MPS actuation will stop the transfer pump if it is running, or prevent it from being started. The electric actuators for valves CHEMB-FCV-129 and MOV-117 are powered from the same UPS that supports the RCS, so the valves will drive to the closed position upon system failure. CHEMB-FCV-129 must close to prevent gravity drain of the flush tank to the waste tank if control is lost, and closure of CHEMB-MOV-117 is necessary to prevent flush tank overfill from the raw water system if system control is lost.

The following list describes the automatic shutdown actions. Other shutdown sequences will be covered by written procedures based on a decision matrix.

a. Loss of 120 Vac power to the AZ-102 PLC UPS: All motors stop, all valves fail in place except CHEMB-FCV-129 and CHEMB-MOV-117, which fail closed because they are powered from the Caustic System PLC UPS, and the RCS goes into the Ready mode.

b. MPS Shutdown: Transfer pump stops, and RCS goes into Ready mode, ready for flush if appropriate.

c. Operator-Initiated Shutdown: Stops all pumps and closes valves CHEMB-FCV-129 and CHEMB-MOV-117.

If an RCS Failure occurs, then the operators must procedurally stop all pumps at the VFDs, and visually verify CHEMB-FCV-129 and CHEMB-MOV-117 have moved to the CLOSED position. If not, an operator must manually close them. 


\section{INTERLOCKS}

Interlocks in the RCS will be provided to prevent equipment damage or harm to the environment or personnel. Any of the interlocks listed below will take the appropriate action (stop the appropriate pump or place the valves in the correct positions) in all modes, unless the interlock is bypassed. If an interlock condition exists, the appropriate alarm will be annunciated, and a warning message displayed to the operator, whether the interlock is bypassed or not. There will be two types of interlocks: one via the PLC and one hard-wired. Interlocks for safety class items such as MPS will be hard-wired interlocks, and will not be dependent on the RCS or PLC to take action (See Table IV-2). Non-safety class alarms and/or interlocks may be either hard-wired or PLC implemented. There will be two types of PLC interlocks: those that can be bypassed and those that cannot. PLC interlocks will only be able to be bypassed at a Supervisor or higher level access. All PLC interlocks are listed in Table IV-3. See Appendix D, Figure D-8 for the PLC Bypassable Interlocks Table screen and Figure D-18 for the PLC AZ-102 Active Interlocks Table screen.

All software interlocks are processed in the PLC, and remain in effect even if the operator station is turned off or malfunctions. If the last operator station is turned off, any bypasses in effect will be reset, so that no bypasses can be in effect unless at least one operator station is active.

The two hard-wired interlocks are MPS, which shuts down the transfer pump, and loss of electric power, which shuts down all equipment except the RCS computers and PLC. Inputs that cause an MPS actuation include leaks detected in the AZ tank farm pits, waste backflow to the CSS system, or leaks detected in the transfer pipe encasements.

Table IV-2

Hardwired Interlocks for Tank 241-AZ-102 (Not AZ-101)

\begin{tabular}{|c|c|c|l|}
\hline $\begin{array}{c}\text { Intl'k } \\
\text { No. }\end{array}$ & \multicolumn{1}{|c|}{ Event } & $\begin{array}{c}\text { Bypass } \\
\text { Avail }\end{array}$ & Action(s) \\
\hline \multirow{2}{*}{3} & $\begin{array}{c}\text { Leak detected from transfer line to flush } \\
\text { line through WT-MOV-608 } \\
\text { (WT-PSH-250 or WT-PSH-251 pressure } \\
\text { high) }\end{array}$ & No & Input to Master Pump Shutdown System \\
\cline { 2 - 4 } & Master Pump Shutdown Actuation & No & $\begin{array}{c}\text { Shutdown of Transfer Pump AZ02A-WT-P-022 via } \\
\text { shunt trip of power supply circuit breaker }\end{array}$ \\
\hline
\end{tabular}


Table IV-3

PLC Interlocks for Tank 241-AZ-102 (Not AZ-101)

\begin{tabular}{|c|c|c|c|}
\hline $\begin{array}{l}\text { Intl'k } \\
\text { No. }\end{array}$ & Event & $\begin{array}{l}\text { Bypass } \\
\text { Avail }\end{array}$ & Action(s) \\
\hline 1 & $\begin{array}{l}\text { Valve positions for: } \\
\text { WT-MOV-608 } \\
\text { WT-MOV-609 } \\
\text { WT-FCV-610 } \\
\text { WT-MOV-611 } \\
\text { WT-MOV-612 } \\
\text { WT-MOV-613 } \\
\text { WT-MOV-614 } \\
\text { CHEMB-V-178 }\end{array}$ & No & $\begin{array}{l}\text { Interlock permissive for mode of operation: } \\
\text { In-Tank Dilution (DIL) } \\
\text { In-Tank Recirculation (ITR) } \\
\text { In-Tank Flush (ITF) } \\
\text { In-Line Dilution (ILD) } \\
\text { Post Flush Drain (PFD) } \\
\text { Post Transfer Flush (PTF) } \\
\text { Waste Transfer (WT) } \\
\text { Safe Shutdown (SSD) } \\
\text { Valve positions required are dependent on MODE } \\
\text { chosen (see Figure XI-8) }\end{array}$ \\
\hline \multirow[t]{3}{*}{2} & $\begin{array}{l}\text { Tank AZ-102 Waste Temp High-High } \\
\text { Tank AZ-102 Waste Level Low-Low } \\
\text { (LALL1) } \\
\text { Tank AZ-102 Waste Level High-High } \\
\text { Tank AZ-102 Dome Press (Vacuum) } \\
\text { Low-Low [Loss of Tank Ventilation] } \\
\text { Loss of AC Input Power to UPS for PLC } \\
\text { AZ801A-WT-YYC-104 }\end{array}$ & $\begin{array}{l}\text { No } \\
\text { Yes } \\
\text { No } \\
\text { No } \\
\text { No }\end{array}$ & $\begin{array}{l}\text { Shutdown of Mixer Pumps AZ102-WST-P-001 and } \\
\text { AZ102-WST-P-002 }\end{array}$ \\
\hline & $\begin{array}{l}\text { Mixer Pump AZ102-WST-P-001 Motor: } \\
\text { Vibration High-High (upper or lower) } \\
\text { Motor Current High-High } \\
\text { Motor Winding Temp High-High } \\
\text { Bearing Temp High-High (upper or } \\
\text { lower) }\end{array}$ & $\begin{array}{l}\text { No } \\
\text { Yes } \\
\text { No } \\
\text { No }\end{array}$ & Shutdown of Mixer Pump AZ102-WST-P-001 \\
\hline & $\begin{array}{l}\text { Mixer Pump AZ102-WST-P-002 Motor: } \\
\text { Vibration High-High (upper or lower) } \\
\text { Motor Current High-High } \\
\text { Motor Winding Temp High-High } \\
\text { Bearing Temp High-High (upper or } \\
\text { lower) }\end{array}$ & $\begin{array}{l}\text { No } \\
\text { Yes } \\
\text { No } \\
\text { No }\end{array}$ & Shutdown of Mixer Pump AZ102-WST-P-002. \\
\hline \multirow[t]{2}{*}{4} & Tank AZ-102 Waste Level High-High & No & $\begin{array}{l}\text { Close Caustic Supply System diluent outlet valve } \\
\text { CHEMB-FCV-129 }\end{array}$ \\
\hline & $\begin{array}{l}\text { Loss of AC Input Power to UPS for PLC } \\
\text { AZ801A-WT-YYC-104 }\end{array}$ & No & $\begin{array}{l}\text { Shutdown of Caustic Supply System if lined up to } \\
\text { Tank AZ-102 }\end{array}$ \\
\hline
\end{tabular}




\begin{tabular}{|c|c|c|c|}
\hline $\begin{array}{l}\text { Intl'k } \\
\text { No. }\end{array}$ & Event & $\begin{array}{l}\text { Bypass } \\
\text { Avail }\end{array}$ & Action(s) \\
\hline \multirow[t]{2}{*}{5} & $\begin{array}{l}\text { Mixer Pump AZ101-WST-P-001 Motor: } \\
\text { Vibration Detected (upper or lower) } \\
\text { Motor Current High-High } \\
\text { Bearing Temp High-High (upper or } \\
\text { lower) }\end{array}$ & $\begin{array}{l}\text { No } \\
\text { No } \\
\text { No }\end{array}$ & Shutdown of Mixer Pump AZ101-WST-P-001 \\
\hline & $\begin{array}{l}\text { Mixer Pump AZ101-WST-P-002 Motor: } \\
\text { Vibration Detected (upper or lower) } \\
\text { Motor Current High-High } \\
\text { Bearing Temp High-High (upper or } \\
\text { lower) }\end{array}$ & $\begin{array}{l}\text { No } \\
\text { No } \\
\text { No }\end{array}$ & Shutdown of Mixer Pump AZ101-WST-P-002 \\
\hline 6 & Not Used & & \\
\hline 7 & $\begin{array}{l}\text { Transfer Pump AZ02A-WT-P-022 } \\
\text { Discharge Pressure High-High } \\
\text { Tank AZ-102 Waste Level Low-Low } \\
\text { (LALL2) } \\
\text { Tank AZ-102 Waste Level High-High } \\
\text { Tank AZ-102 Waste Temp High-High } \\
\text { Transfer Pump AZ02A-WT-P-022 Motor } \\
\text { Current High-High } \\
\text { Transfer Pump AZ02A-WT-P-022 Motor } \\
\text { Winding Temp High-High } \\
\text { Tank AZ-102 Dome Press (Vacuum) } \\
\text { Low-Low [Loss of Tank Ventilation] } \\
\text { Transfer Pump AZ02A-WT-P-022 } \\
\text { Discharge Relief Valve Rupture Disc } \\
\text { Failure/Actuation } \\
\text { Transfer Pump AZ02A-WT-P-022 } \\
\text { Discharge Flow Low-Low } \\
\text { Discharge Valve WT-MOV-608 Not in } \\
\text { Position C } \\
\text { Master Pump Shutdown Event } \\
\text { Loss of AC Input Power to UPS for PLC } \\
\text { AZ801A-WT-YYC-104 }\end{array}$ & $\begin{array}{l}\text { Yes } \\
\text { Yes } \\
\text { Yes } \\
\text { No } \\
\text { Yes } \\
\text { No } \\
\text { No } \\
\text { Yes } \\
\text { No } \\
\text { No } \\
\text { No } \\
\text { No }\end{array}$ & $\begin{array}{l}\text { Shutdown of Transfer Pump AZ02A-WT-P-022 } \\
\text { (by PLC) }\end{array}$ \\
\hline 8 & $\begin{array}{l}\text { Mixer Pump P-001 Manual Transfer Switch } \\
\text { AZ101-WST-MTS-201 or } 203 \text { Position } \\
\text { Mixer Pump P-002 Manual Transfer Switch } \\
\text { AZ101-WST-MTS-202 or } 204 \text { Position }\end{array}$ & No & $\begin{array}{l}\text { Non-Selected Mixer Pump(s)/Turnable(s) are } \\
\text { Inoperable }\end{array}$ \\
\hline 9 & $\begin{array}{l}\text { Transfer Pump Manual Transfer Switch } \\
\text { AZ02A-WST-MTS-222 Position }\end{array}$ & No & Non-Selected Transfer Punp is Inoperable \\
\hline
\end{tabular}

See drawing H-14-102971, sheet 2, for interlock schedule 


\section{HARDWARE INTERFACES}

Communications between the computers and the PLC will be via Modbus Plus links so that the PLC communicates with both PC's directly. See drawing H-14-103008 for PLC System Cabling diagram.

\section{SOFTWARE INTERFACES}

The OIS software will be capable of communicating directly with data handling programs running on the OIS PC, such as Microsoft Excel.

\section{COMMUNICATION INTERFACES}

The RCS inter-system communication equipment will use TCP/IP protocol. Between the RCS and TMACS, for example, the HLAN physical layer will be used as the TMACS workstations gather data directly from the PLC via an Ethernet to Modbus Plus communications link.

\section{MAINTAINABILITY}

The RCS PLC software will be capable of being changed on-line should the need arise. The PLC code is modularized by function and a function module may be altered and down-loaded while the system is online and operational. The flexibility of the system hardware and software thereby allows on-line fixes of operational functions if necessary.

\section{QUALITY ASSURANCE TESTING}

The software will undergo testing to ensure that all functional requirements have been met. The RCS is considered a General Service class of design. An acceptance test document, and a functional test document, will be prepared and approved prior to final operation to verify system operations. All software documentation will be prepared in accordance with appropriate procedures. 


\section{OPERATIONAL MODE INTERLOCK MATRIX}

\begin{tabular}{|c|c|c|c|c|c|c|c|c|c|}
\hline \multicolumn{10}{|c|}{ Tank AZ-102 } \\
\hline $\begin{array}{c}\text { MODE To } \\
\text { From }\end{array}$ & RDY & DIL & ITR & ITF & WT & PTF & PFD & ILD & SSD \\
\hline RDY & $\mathrm{X}$ & & & & & & & & \\
\hline DIL & & $\mathrm{X}$ & $\mathrm{I}$ & & 1 & & & & \\
\hline ITR & & 1 & $\mathrm{X}$ & & & & & 1 & \\
\hline ITF & & & & $\mathrm{X}$ & & & & & \\
\hline WT & & 1 & & & $\mathrm{X}$ & & & 1 & \\
\hline PTF & & & & & & $\mathrm{X}$ & & & \\
\hline PFD & & & & & & & $\mathrm{X}$ & & \\
\hline ILD & & & 1 & & 1 & & & $\mathrm{X}$ & \\
\hline SSD & & & & & & & & & $\mathrm{X}$ \\
\hline
\end{tabular}

Example: Choose two desired modes of operation and determine if the intersection has a "l" or not. Intersections with a "l" can be operated simultaneously. The control system allows simultaneous operation if Manually selected, and prevents simultaneous operation based on this matrix. For MODES and Interlock Details, refer to Logic Diagrams. 


\section{OPERATIONAL MODE FLOW DIAGRAMS}

The following Mode Flow Diagrams represent the paths and sequences described in Section IV.C
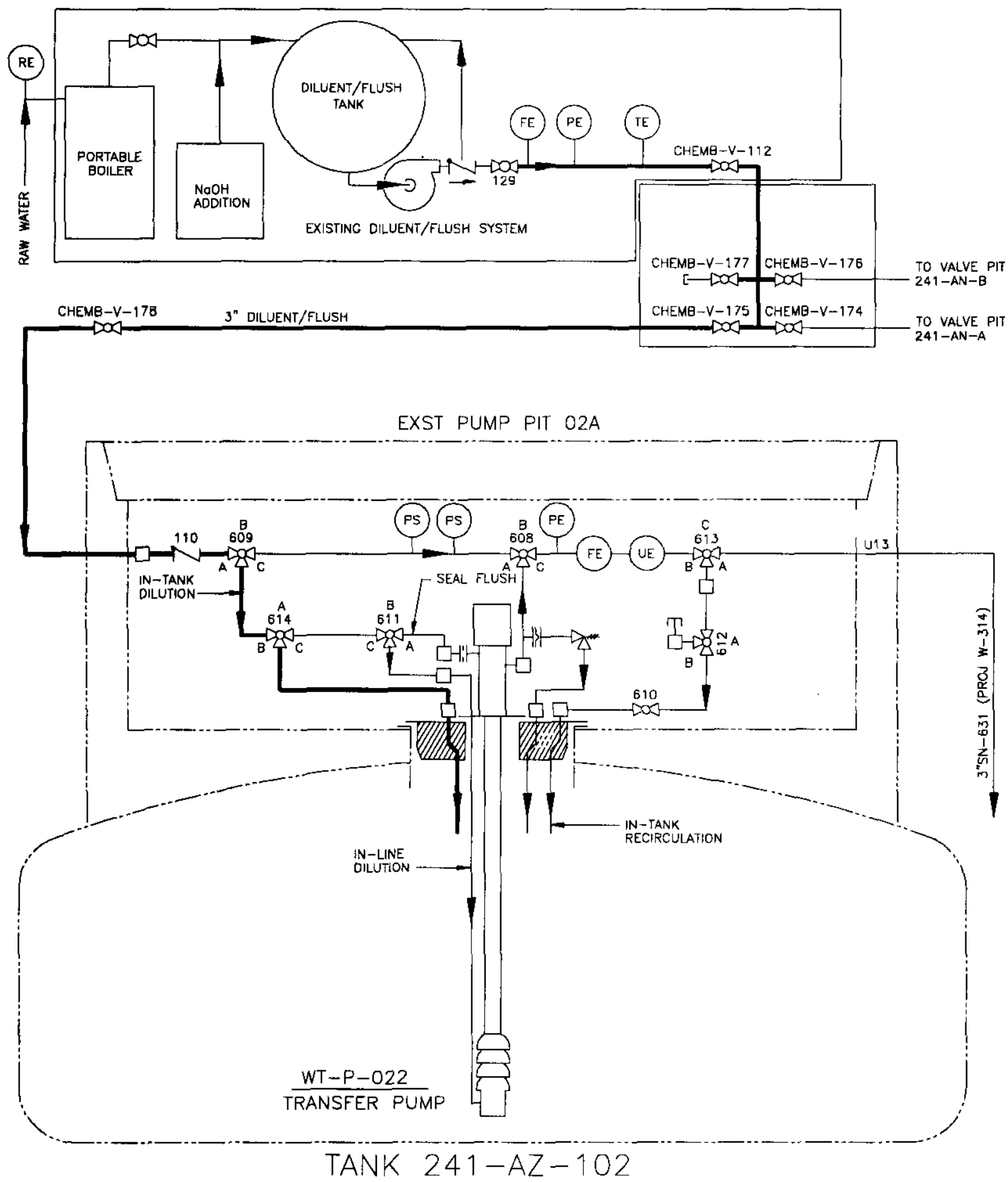

Dilute (DIL) Mode Flowpath

Figure XI-1 

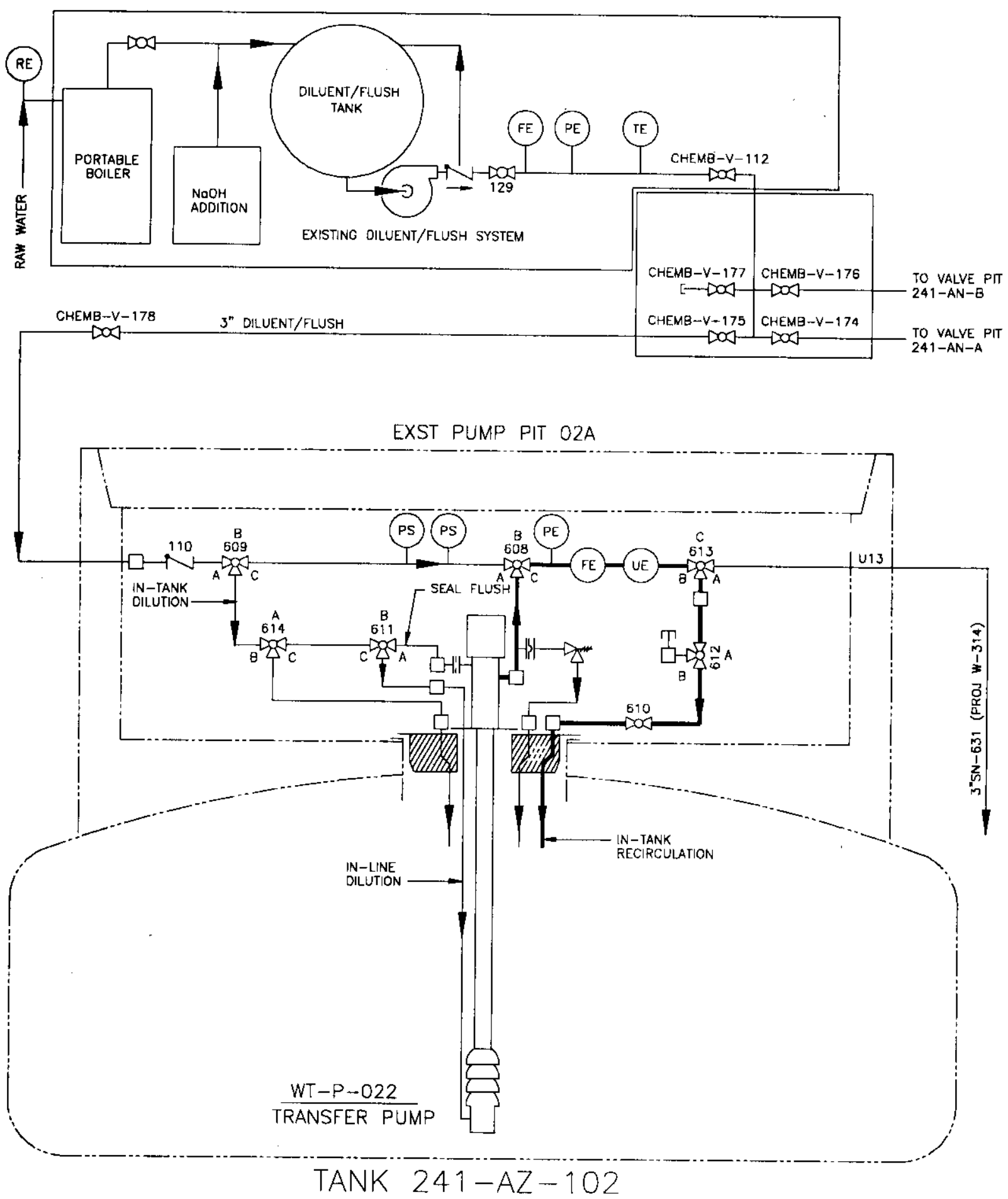

In-Tank Recirculaion (ITR) Mode Flowpath

Figure XI-2 

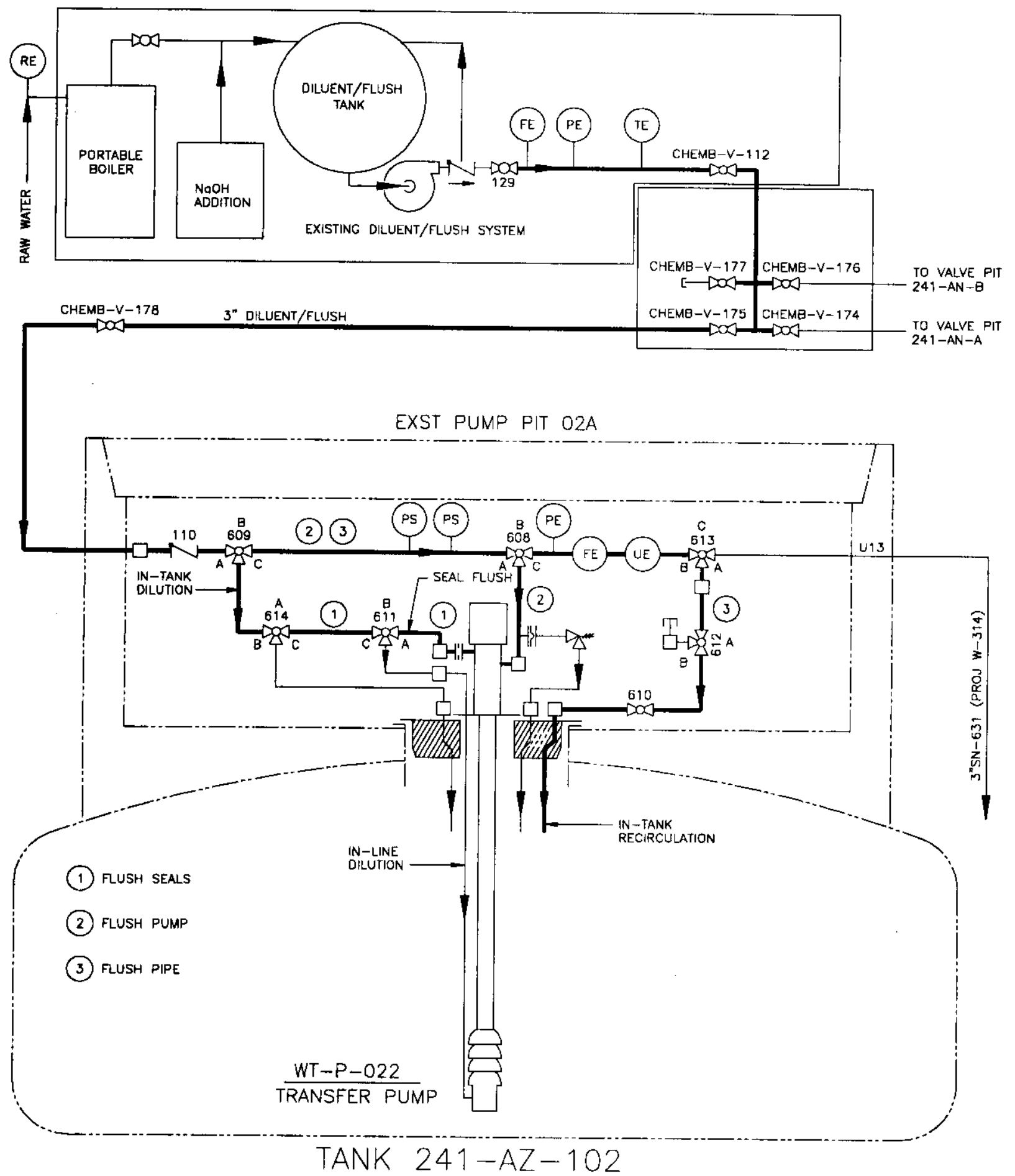

In-Tank Flush (ITF) Mode Flowpaths

Figure XI-3 

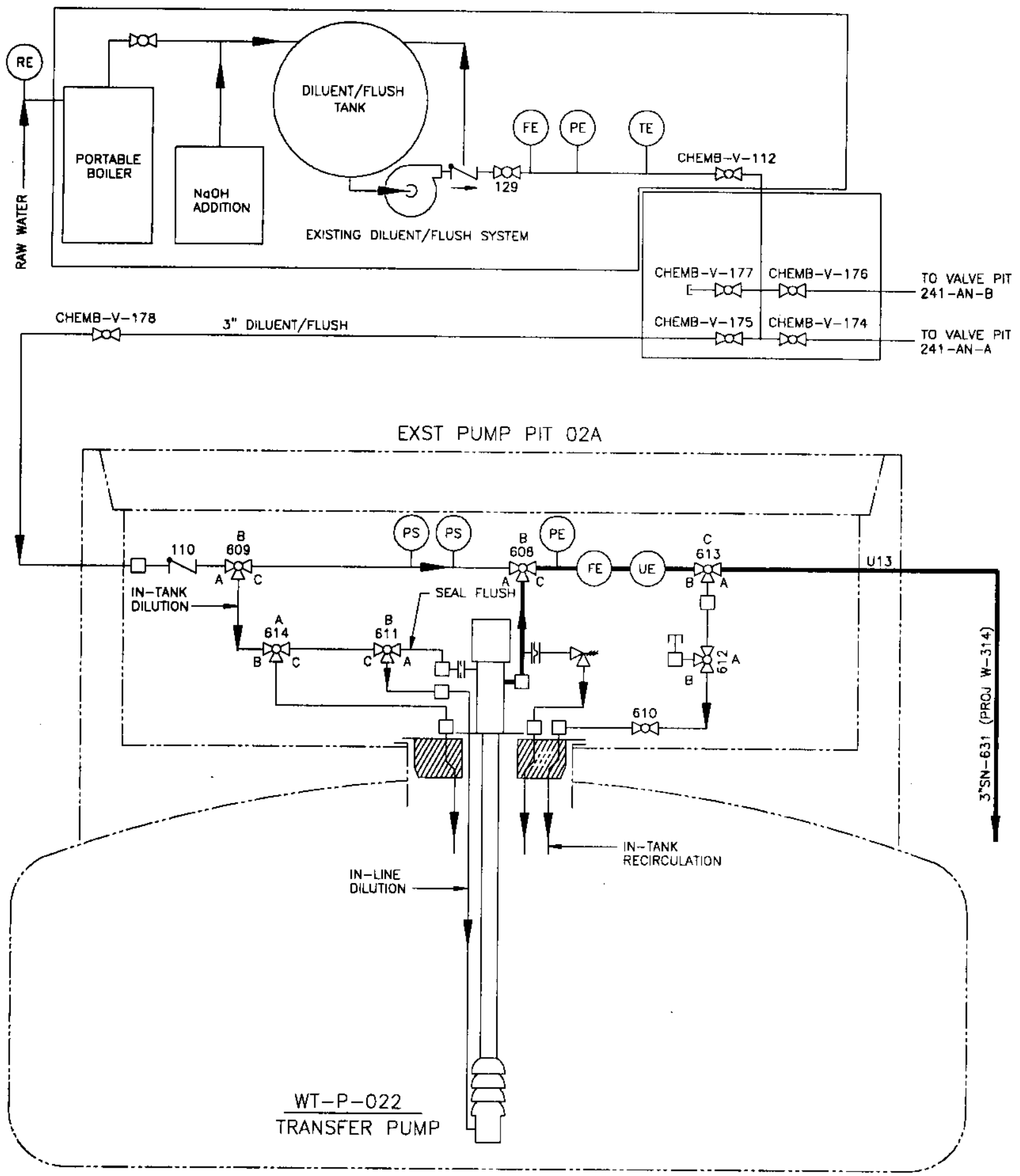

TANK 241-AZ-102

\section{Waste Transfer (WT) Mode Flowpath}

Figure XI-4 
RCS Description of Operation for DST 241-AZ-102

HNF-3695, Revision 0

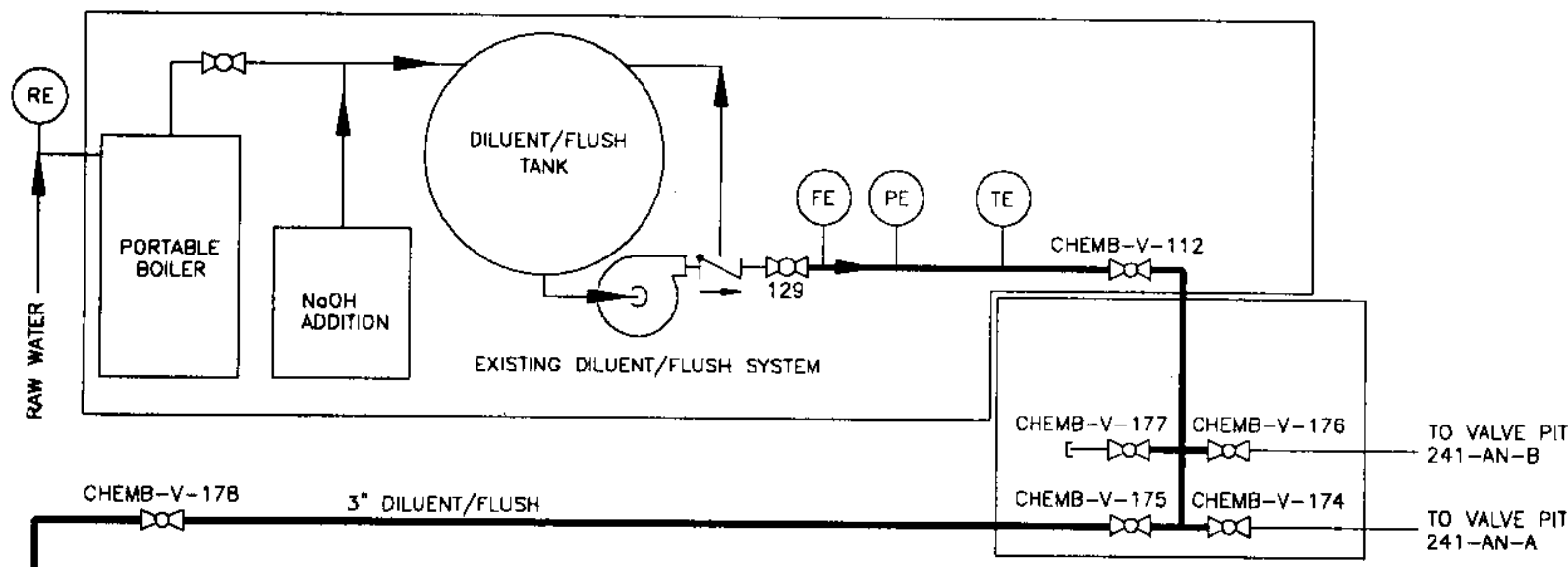

EXST PUMP PIT O2A

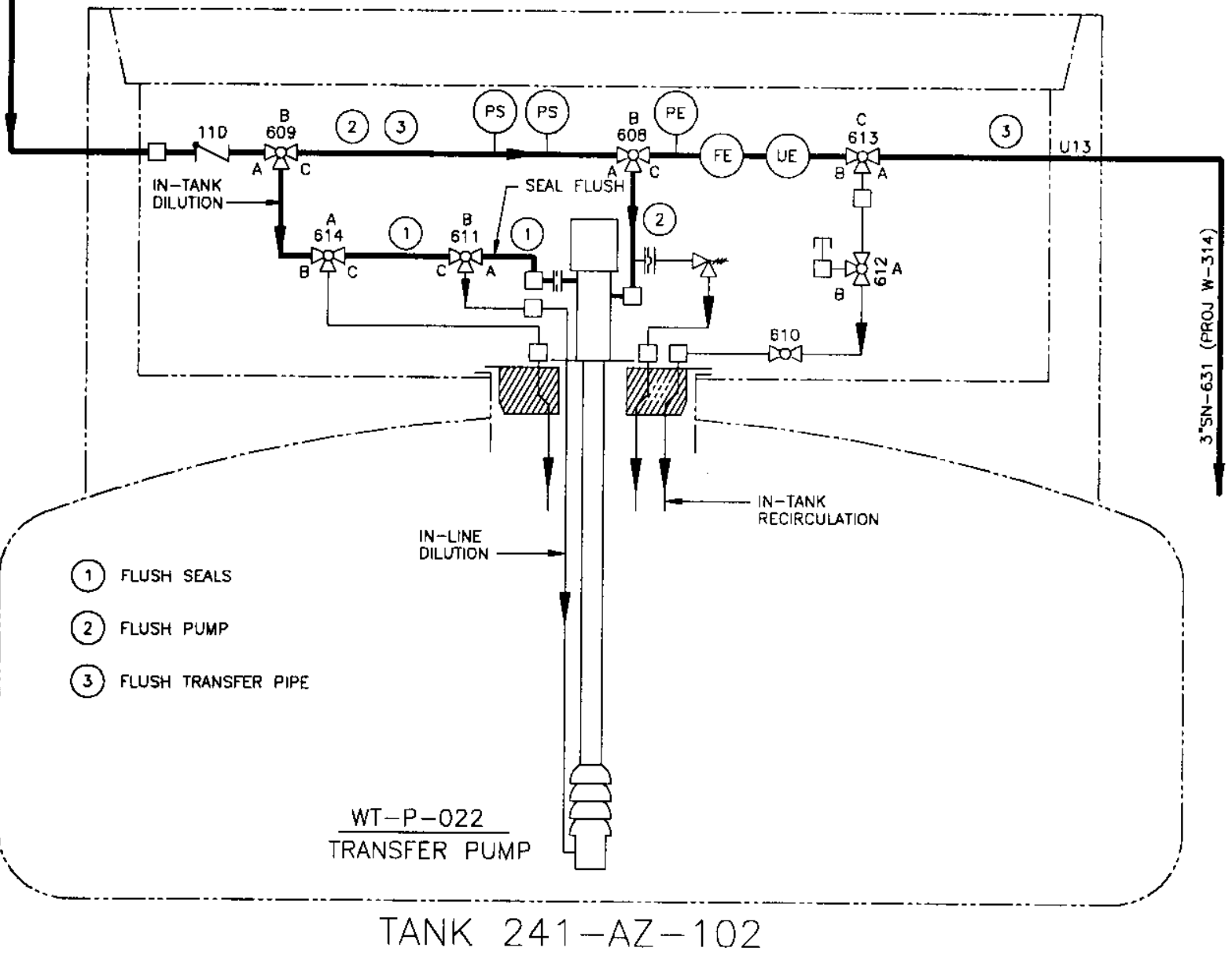

Post-Transfer Flush (PTF) Mode Flowpaths

Figure XI-5 


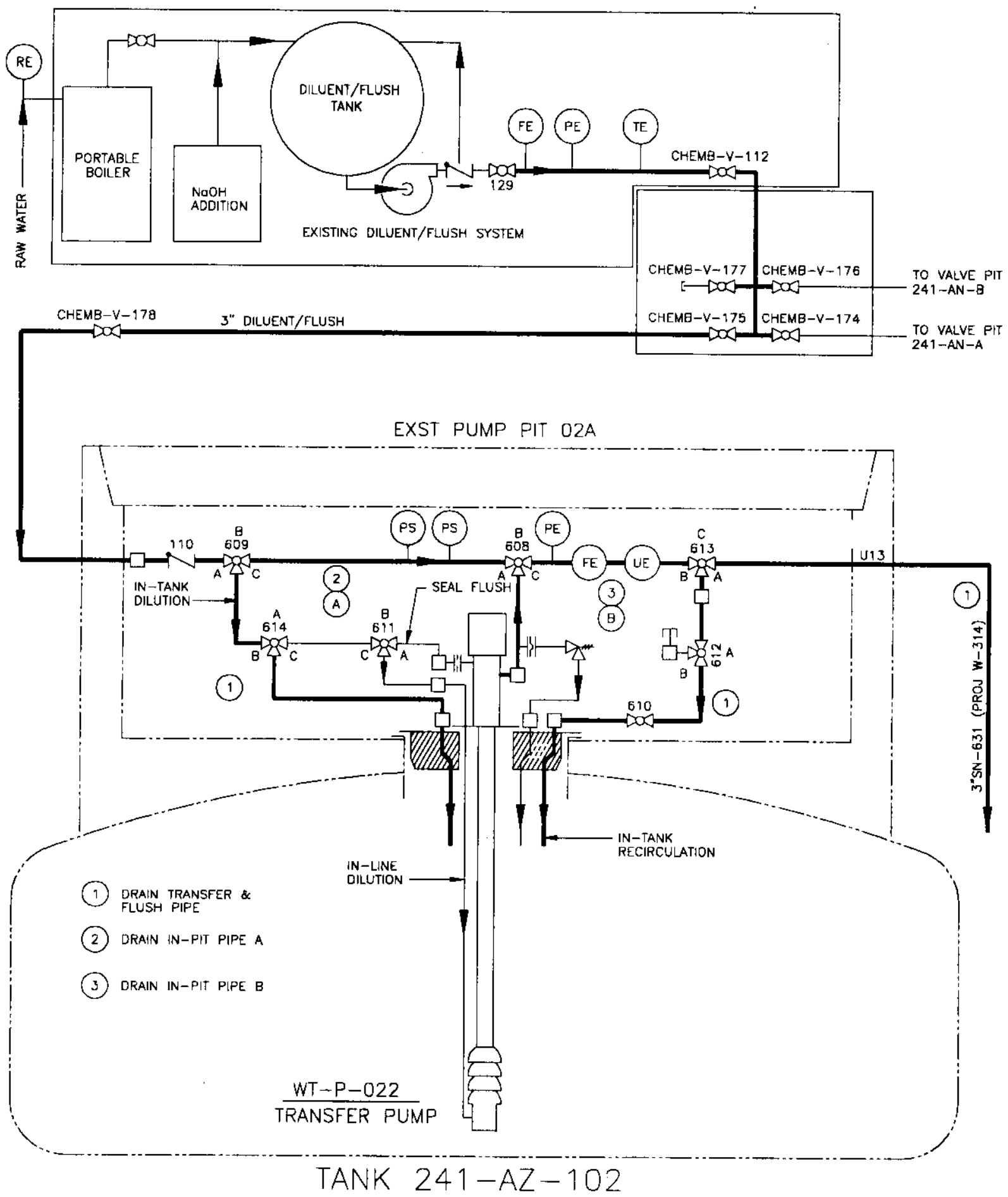

Post Flush Drain (PFD) Mode Flowpath

Figure XI-6 

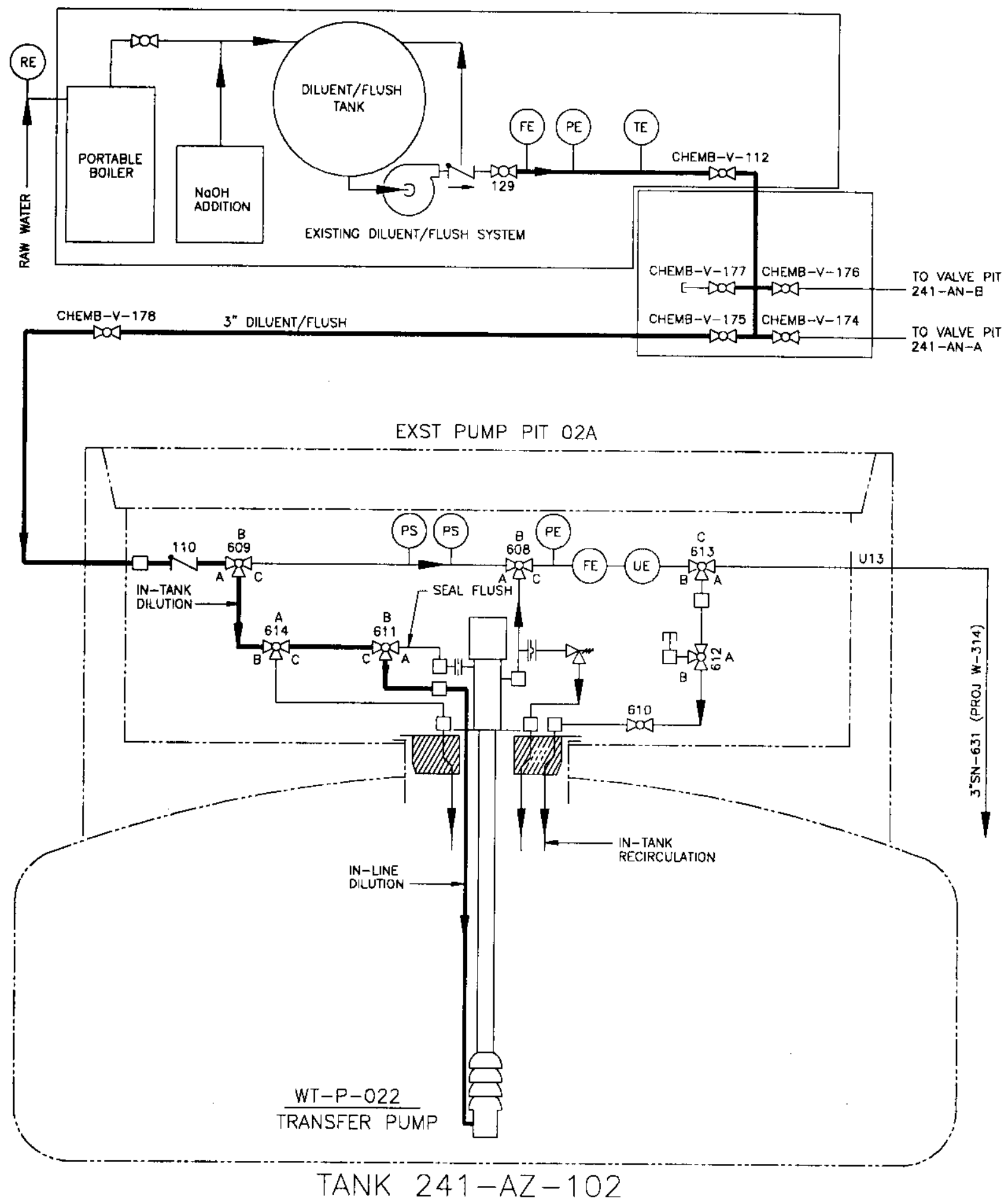

In-Line Dilution (ILD) Mode Flowpath

Figure XI-7 


\begin{tabular}{|c|c|c|c|c|c|c|c|c|c|c|c|c|c|c|c|c|c|c|c|c|c|c|c|}
\hline & $\tau^{-7 \forall n ~}$ & & ग|: & & & & & & & & & & 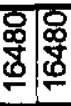 & 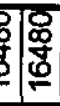 & & 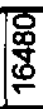 & & 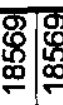 & & & & & | \\
\hline 萢 & OGSO LON & & & & & & & & & & & & & & & & & & & & & & \\
\hline$n$ & dOLS'OLIN/ $220^{-} d^{-} 1 M^{-} Z V$ & & & & & $\sigma$ & - & $-r$ & $-r$ & T & & -1 & $-r$ & -5 & - & - & - & - & & & & - & - \\
\hline \pm & $\exists 78 \mathrm{~N} \mathrm{~N}^{-} \mathrm{O} O \perp \mathrm{N}^{-} Z 20^{-} \mathrm{d}^{-} \mathrm{L} \mathrm{M}^{-} Z \mathrm{~V}$ & & & & $r$ & & & & & & & & & & & & & & - & - & - & & \\
\hline$m$ & 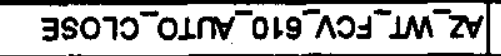 & & & & & & & & & & & & & & & & & & & & & & \\
\hline$\sim$ & 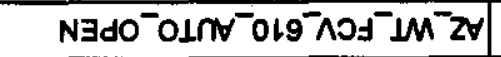 & & & & - & & - & - & -7 & - & & & & & & & - & $-r$ & & & & & \\
\hline$F$ & agsn LON & & & & & & & & & & & & & & & & & & & & & & \\
\hline 오 & OJSO LON & & & & & & & & & & & & & & & & & & & & & & \\
\hline$\sigma$ & 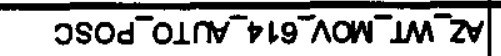 & & & & & & & & & & & & & & & & & & & & & & \\
\hline$\infty$ & gsodolnd $619^{-} \wedge N^{-} 1 M^{-} Z$ & & - & $r \mid r$ & $r$ & & & & & & & & & & & & - & $-r$ & & & & & \\
\hline$\Lambda$ & $\forall S^{\prime} O d^{-} O 1 n \pi^{-}+19^{-1} \wedge O N^{-} \perp M^{-} Z \forall$ & & & & & & - & - & $-r$ & - & & & -- & - & 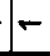 & - & & & - & - & - & & \\
\hline$\infty$ & 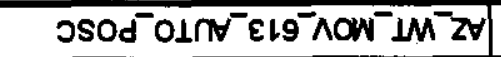 & & & & & & & & & & - & & $-r$ & $-1-$ & . & t & & & & & & & \\
\hline$\infty$ & 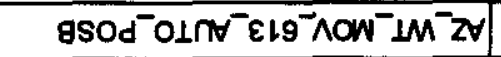 & & & & - & & - & - & $-r$ & - & & & & & & & & & & & & & \\
\hline+ & 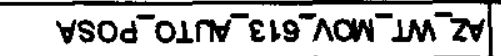 & & & & & & & & & & & & & & & & - & $-r$ & & & & & \\
\hline$m$ & osodolny $219^{-} \wedge \mathrm{N}^{-} 1 \mathrm{M}^{-} 2 \theta$ & & & & & & & & & & & & & & & & & & & & & & \\
\hline$N$ & 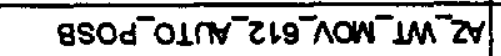 & & & & & & & & & & & & & & & & & & & & & & \\
\hline 䙲- & $\forall S O d^{-} O 1 N^{-} 219^{-} \wedge N^{-} 1 M^{-} Z \forall$ & & & & F & & - & - & $-[-$ & - & & & & & & & - & $r$ & & & & & \\
\hline & $b^{-} \mathrm{N}$ & & & ल্লিম & 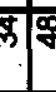 & & 面 & & & $\mathbb{8}$ & 勇 & & 员席 & 可 & & 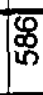 & क्ल & (f) & & & 站 & $\bar{N}$ & N \\
\hline 岁: & 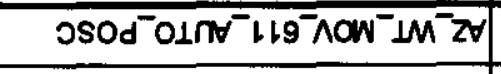 & & & & & & & & & & - & & & & & & & & $F$ & - & $r$ & & \\
\hline 으 & 8SOd'OLNA $119^{-} \wedge N^{-} 1 M^{-} Z V$ & & & & & & - & - & $-\}$ & - & & & $-r$ & - & 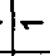 & - & & & & & & & \\
\hline$\sigma$ & $\forall S O d^{-} O \perp n \nabla^{-} L 19^{-} \wedge O N^{-} \angle M^{-} Z V$ & & & & & & & & & & & & & & & & & & & & & & \\
\hline$\infty$ & 0SOd OIN $609^{-} \wedge O N^{-} \perp M^{-} Z V$ & & & & & & & & & & & & & & & & & -1 & & & & & \\
\hline$\sim$ & gSOd $01 n^{-} 609^{-} \wedge N^{-} \perp M^{-} Z V$ & & & & & & & & -5 & - & & & & - & - & - & & & & & & & \\
\hline$\infty$ & $\forall S O d^{-} O 1 n V^{-} 609^{-} \wedge W^{-} \mathrm{LN}^{-} \mathrm{ZV}$ & & - & -1 & $-F$ & & - & $F$ & & & - & & -5 & - & & & - & & $F$ & - & - & & \\
\hline in & 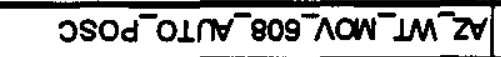 & & & & $r$ & & & & & & - & & & & & & & 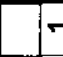 & $-F$ & 7 & - & & . \\
\hline$\nabla$ & gSOd'OLnN $809^{-} \wedge \mathrm{NW}^{-} 1 \mathrm{M}^{-} \mathrm{ZV}$ & & & & & & & & F & - & & & & & - & - & & & & & & & \\
\hline$m$ & $\forall S O d^{-} 0104^{-} 809^{-} \wedge \mathrm{OW}^{-} \perp \mathrm{M}^{-} \mathrm{Z}$ & & & & & & - & - & - & & & & $-\sigma$ & - & & & - & - & & & & & \\
\hline$N$ & 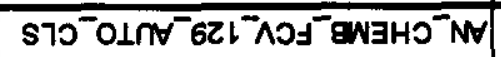 & & - & & $F$ & & $\sigma$ & & & - & & & - & & & - & - & -7 & - & & - & - & $\sigma$ \\
\hline \begin{tabular}{|l|l|}
0 & - \\
\end{tabular} & 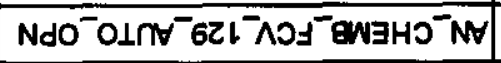 & & & - & & & & - & -5 & & & & - & - & - & & & & & - & & & \\
\hline & 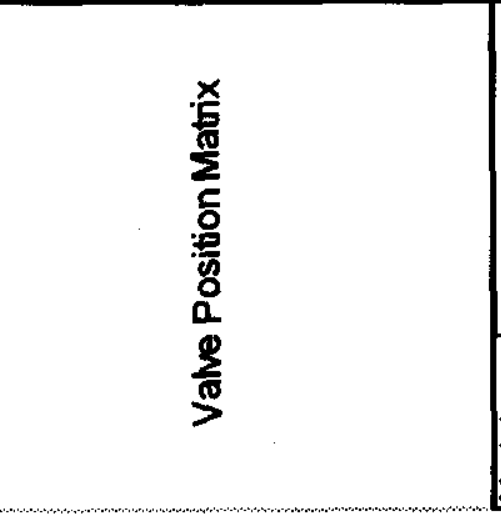 & 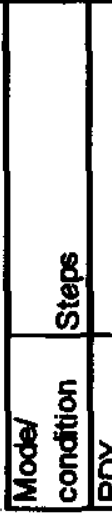 & 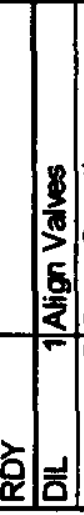 & 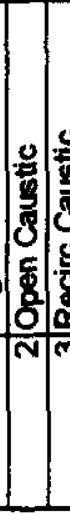 & 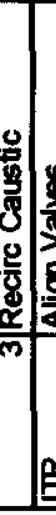 & 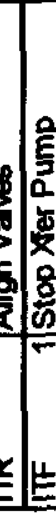 & & 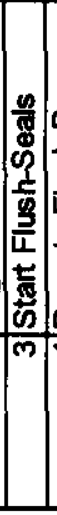 & 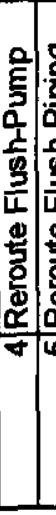 & 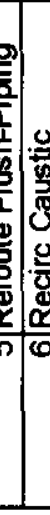 & 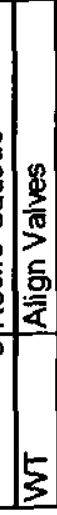 & 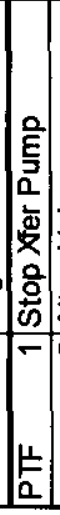 & 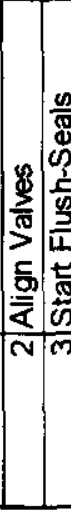 & 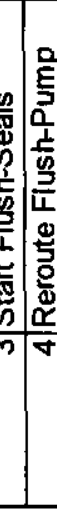 & 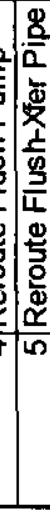 & 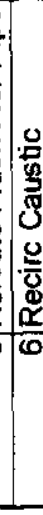 & 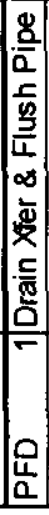 & 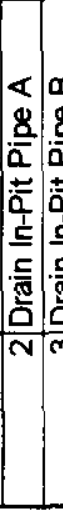 & 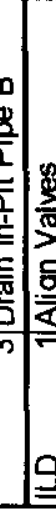 & 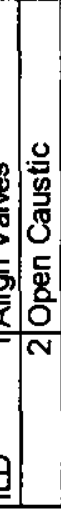 & \begin{tabular}{|c|}
0 \\
0 \\
3 \\
0 \\
0 \\
0 \\
0 \\
0 \\
$\frac{\pi}{m}$ \\
$m$
\end{tabular} & 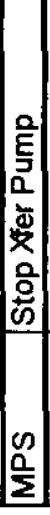 & 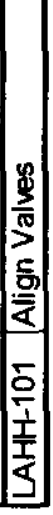 \\
\hline
\end{tabular}


RCS Description of Operation for DST 241-AZ-102

HNF-3695, Revision 0

XII. APPENDICES

APPENDIX A - KEYBOARD ASSIGNMENTS

APPENDIX B - PARAMETERS FOR TRENDING, ALARMS, CONTROLS AND INDICATIONS

APPENDIX C - CAUSTIC SUPPLY SYSTEM

APPENDIX D - HMI SCREENS 
RCS Description of Operation for DST 241-AZ-102

HNF-3695, Revision 0

APPENDIX A - KEYBOARD ASSIGNMENTS

\begin{tabular}{|c|c|l|}
\hline $\begin{array}{c}\text { Function } \\
\text { Key }\end{array}$ & Label & \multicolumn{1}{|c|}{ Description } \\
\hline F1 & HELP & Displays the HELP Screen. \\
\hline F2 & MENU & Displays the screen selection Pop-Up Window menu. \\
\hline F3 & LOG ON & Displays the Title Screen and Log-On Prompt. \\
\hline F4 & (Not Used) & \\
\hline F5 & ALARMS & Displays the Current Alarms page. \\
\hline F6 & SUMMARY & Displays the Alarm Summary page. \\
\hline F7 & HARDWARE & Displays the Hardware Alarms page. \\
\hline F8 & (Not Used) & \\
\hline F9 & LAST PAGE & Displays the previous page. \\
\hline F10 & (Not Used) & \\
\hline F11 & (Not Used) & \\
\hline F12 & LOG OFF & Displays the Title Screen and Allows Log Off of current user. \\
\hline END & CLOSE & Closes active Pop-Up Window \\
\hline ESC & Shutdown & Shuts down the Control System (With proper access level.) \\
\hline Print & Print Screen & Prints the current screen to the default printer. \\
\hline Screen & & \\
\hline
\end{tabular}




\section{APPENDIX B - PARAMETERS FOR TRENDING, ALARMS, CONTROLS AND INDICATIONS}

This appendix lists the tag names that will be used in the control of the retrieval process for AZ-102.

These tag names are not modifiable and therefore will be used in the program to substitute for the P\&ID alarm designations, with the exception of wired limit switches, such as TAH-273 (Temperature High Alarm), where the actual alarm tag name will be used.

\section{Table Fields Description: P\&ID H-14- \\ Tagname \\ Trend}

Description

Range

Alarm Setpoints

Unit
P\&ID drawing and sheet number

Name for an item

" $Y$ " to indicate that trending is pre-programmed for this item (all analog values can be trended)

Literal description of the tagname

The possible range in engineering units of the item

Empty fields indicate alarm setpoint is not needed

Engineering units of the item

Note:

The following tag names for analog and discrete I/O were derived from the P\&ID drawings H-14-102971 Rev. 0. If there is any modification to the P\&IDs, it may affect this list.

This is a list of actual $1 / 0$ points needed for the control system. Note that all 3-way valves are instrumented for three positions even though some 3-way valves will use only two positions. $1 / O$ points to and from the mixer pumps, turntables, and transfer pump VFDs, and caustic injection pump, and boiler control systems will be obtained directly from the pumps' or control systems' PLCs through Modbus Plus connections.

The position of each transfer switch is transmitted to the RCS computer. Based on the position of each transfer switch, the computer determines and displays the proper EIN associated with each instrument signal as it is switched from one pump (or turntable) to the "other" pump or turntable. In addition, the pump or turntable not selected will be "grayed out" on the graphic screen, indicating to the operator that the device is not available for service, and the selected device will be highlighted, indicating that it is available for service. Clicking on the grayed out devices will have no effect on the device; that is, it cannot be turned on or off or otherwise controlled if it is grayed out. 


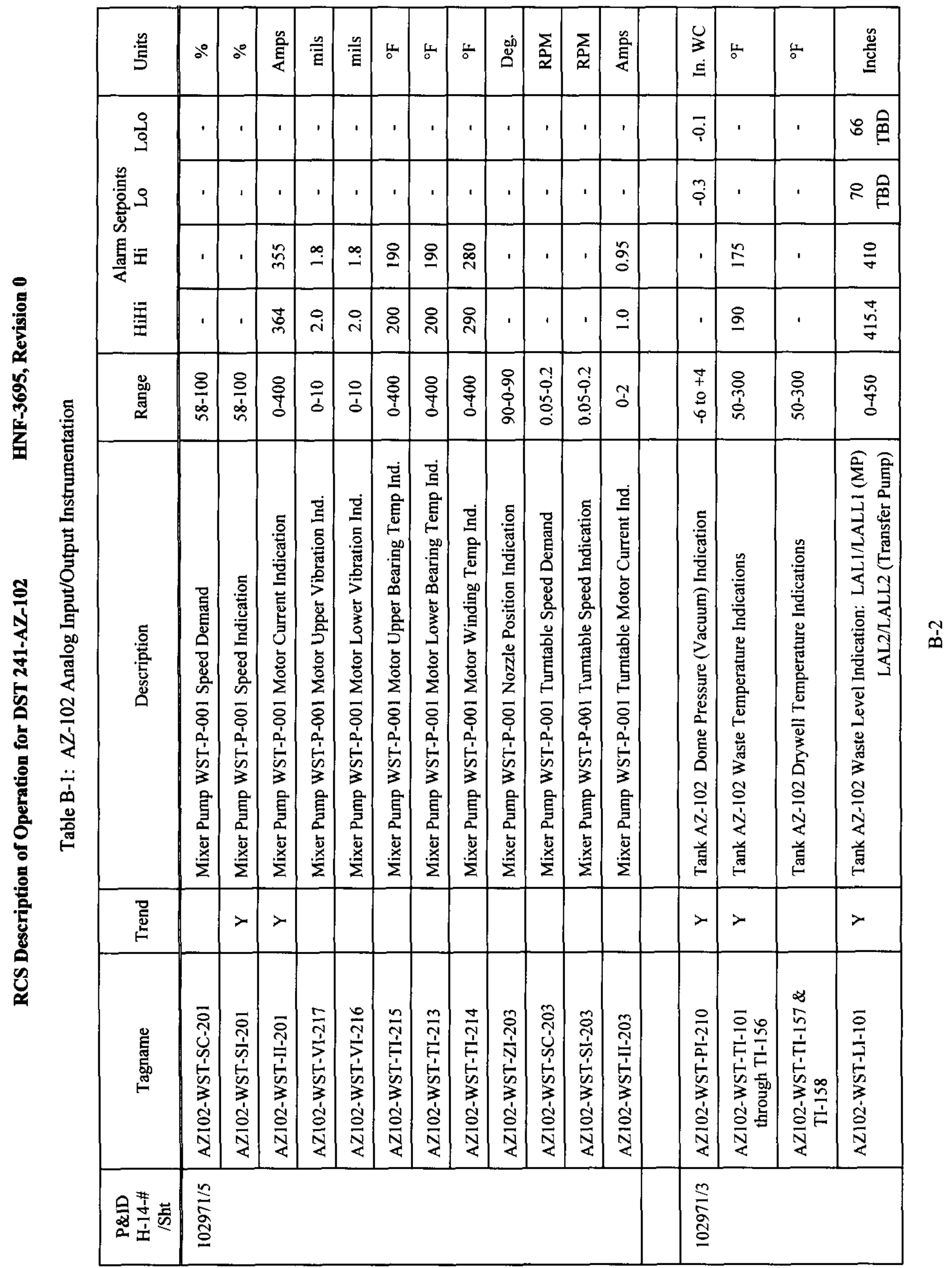




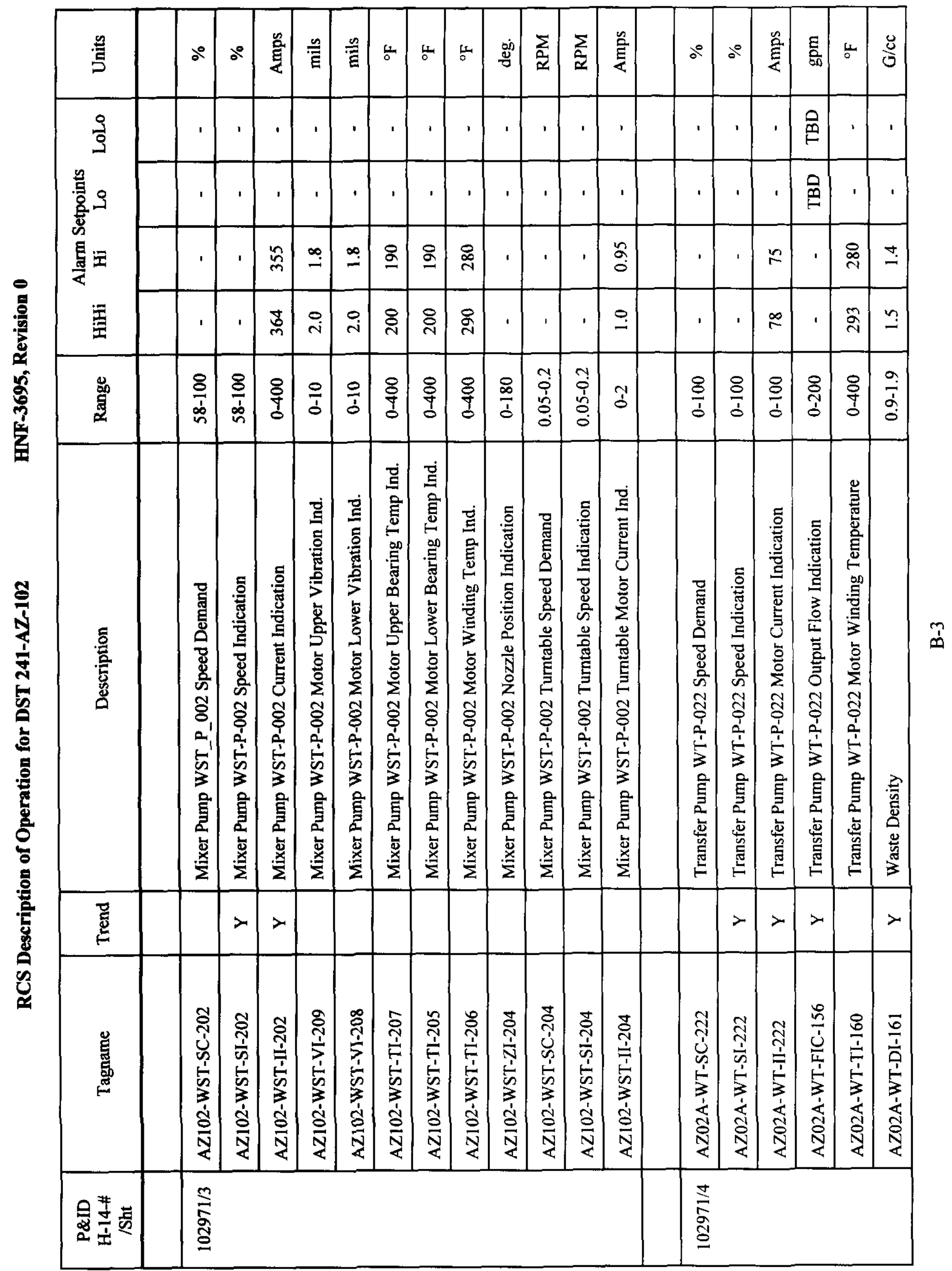




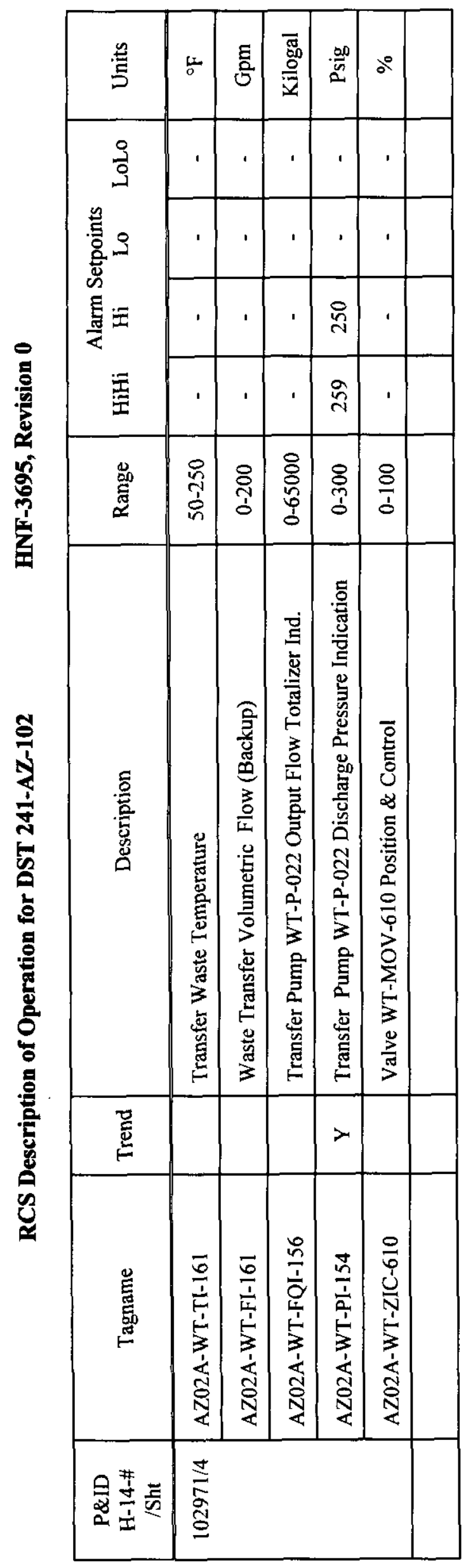




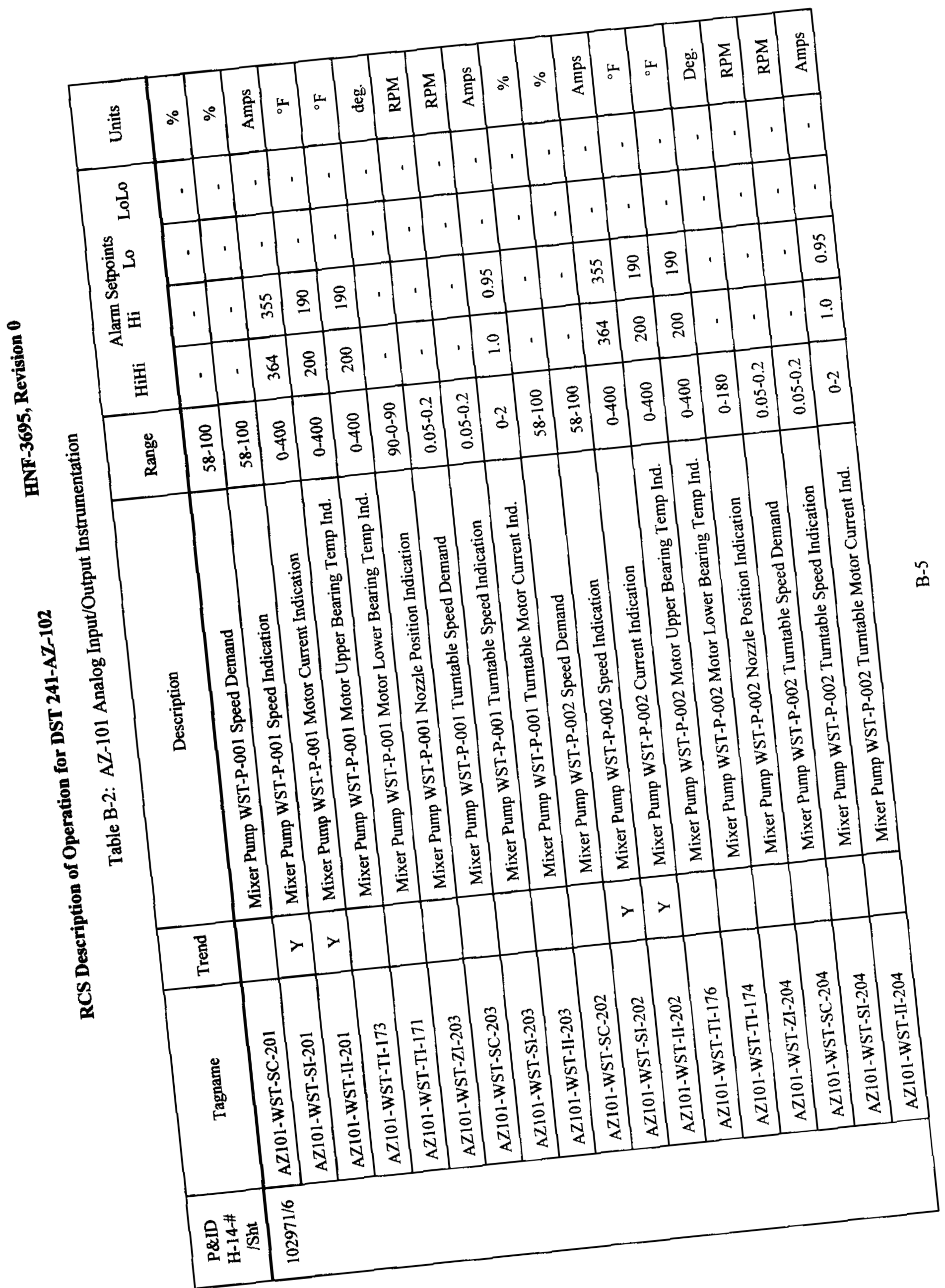




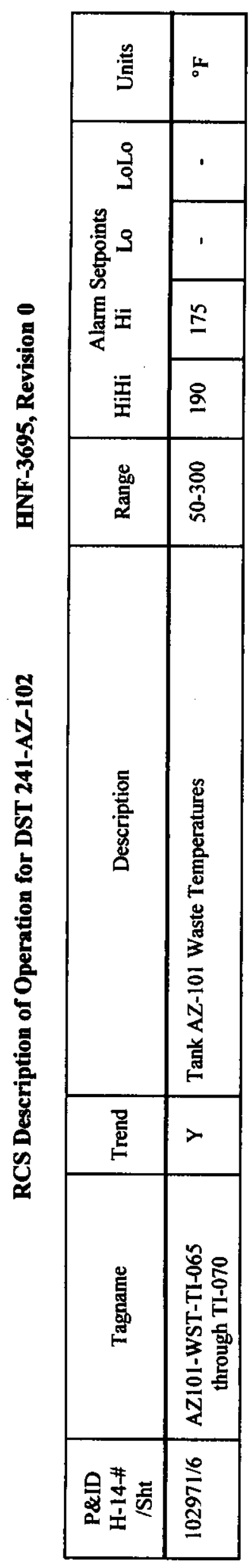

ตٌ 
Table B-3: AZ-102 Discrete Input/Output Instrumentation

\begin{tabular}{|c|c|c|c|}
\hline $\begin{array}{c}\text { P\&ID } \\
\text { H-14-\# } \\
\text { /Sht }\end{array}$ & Tagname & Description & Setpoint \\
\hline \multirow[t]{14}{*}{$102971 / 5$} & AZ102-WST-YL-201A & Mixer Pump WST-P-001 Local/Remote Indication & - \\
\hline & AZ102-WST-SS-201 & Mixer Pump WST-P-001 Auto/Manual/Off Command & - \\
\hline & AZ102-WST-YL-201B & Mixer Pump WST-P-001 Auto/Manual/Off Indication & - \\
\hline & AZ102-WST-HS-201A & Mixer Pump WST-P-001 Start/Stop Command & - \\
\hline & AZ102-WST-YL-201C & Mixer Pump WST-P-001 On/Off Indication & - \\
\hline & AZ102-WST-YL-203A & $\begin{array}{l}\text { Mixer Pump WST-P-001 Turntable Local/Remote } \\
\text { Indication }\end{array}$ & - \\
\hline & AZ102-WST-SS-203 & $\begin{array}{l}\text { Mixer Pump WST-P-001 Turntable Auto/Manual/Off } \\
\text { Command }\end{array}$ & - \\
\hline & AZ102-WST-YL-203B & $\begin{array}{l}\text { Mixer Pump WST-P-001 Turntable Auto/Manual/Off } \\
\text { Indication }\end{array}$ & - \\
\hline & AZ102-WST-HS-203A & Mixer Pump WST-P-001 Turntable Start/Stop Command & - \\
\hline & AZ102-WST-YL-203C & Mixer Pump WST-P-001 Turntable On/Off Indication & - \\
\hline & AZ102-WST-HS-203B & Mixer Pump WST-P-001 Turntable CW/CCW Command & - \\
\hline & AZ102-WST-ZL-203D & Mixer Pump WST-P-001 Turntable CW/CCW Indication & - \\
\hline & AZ102-WST-ZI-201 & Mixer Pump WST-P-001 VFD Transfer Switch Position & - \\
\hline & AZ102-WST-ZI-203E & $\begin{array}{l}\text { Mixer Pump WST-P-001 Turntable VFD Transfer Switch } \\
\text { Position }\end{array}$ & - \\
\hline \multirow[t]{7}{*}{$102971 / 3$} & AZ102-WST-YL-202A & Mixer Pump WST-P-002 Local/Remote Indication & - \\
\hline & AZ102-WST-SS-202 & Mixer Pump WST-P-002 Auto/Off/Manual Command & - \\
\hline & AZ102-WST-YL-202B & Mixer Pump WST-P-002 Auto/Off/Manual Indication & - \\
\hline & AZ102-WST-HS-202A & Mixer Pump WST-P-002 Start/Stop Command & - \\
\hline & AZ102-WST-YL-202C & Mixer Pump WST-P-002 On/Off Indication & - \\
\hline & AZ102-WST-YL-204A & $\begin{array}{l}\text { Mixer Pump WST-P-002 Turntable Local/Remote } \\
\text { Indication }\end{array}$ & - \\
\hline & AZ102-WST-SS-204 & $\begin{array}{l}\text { Mixer Pump WST-P-002 Turntable Auto/Off/Manual } \\
\text { Command }\end{array}$ & - \\
\hline
\end{tabular}




\begin{tabular}{|c|c|c|c|}
\hline $\begin{array}{c}\text { P\&ID } \\
\text { H-14-\# } \\
\text { /Sht }\end{array}$ & Tagname & Description & Setpoint \\
\hline \multirow[t]{8}{*}{$102971 / 3$} & AZ1 02-WST-YL-204B & $\begin{array}{l}\text { Mixer Pump WST-P-002 Turntable Auto/Off/Manual } \\
\text { Indication }\end{array}$ & - \\
\hline & AZ102-WST-HS-204A & Mixer Pump WST-P-002 Turntable Start/Stop Command & - \\
\hline & AZ102-WST-YL-204C & Mixer Pump WST-P-002 Turntable On/Off Indication & - \\
\hline & AZ102-WST-HS-204B & Mixer Pump WST-P-002 Turntable CW/CCW Command & - \\
\hline & AZ102-WST-ZL-204D & Mixer Pump WST-P-002 Turntable CW/CCW Indication & - \\
\hline & AZ102 WST-ZI-202 & Mixer Pump WST-P-002 VFD Transfer Switch Position & - \\
\hline & AZ102-WST-ZI-204E & $\begin{array}{l}\text { Mixer Pump WST-P-002 Turntable VFD Transfer Switch } \\
\text { Position }\end{array}$ & - \\
\hline & AZ102-WST-XA-212 & Control System Loss of 120 Vac Power to UPS & - \\
\hline \multirow[t]{16}{*}{$102971 / 4$} & AZ02A-WT-YL-222A & Transfer Pump WT-P-022 Local/Remote Indication & - \\
\hline & AZ02A-WT-SS-222 & Transfer Pump WT-P-022 Auto/Manual/Off Command & - \\
\hline & AZ02A-WT-YL-222B & Transfer Pump WT-P-022 Auto/Manual/Off Indication & - \\
\hline & AZ02A-WT-HS-222A & Transfer Pump WT-P-022 Start/Stop Command & - \\
\hline & AZ02A-WT-YL-222C & Transfer Pump WT-P-022 On/Off Indication & - \\
\hline & AZ02A-WT-ZI-222 & Transfer Pump WT-P-022 VFD Transfer Switch Position & - \\
\hline & AZ02A-WT-ZC-608 & MOV-608 Positions A,B,\&C Commands & - \\
\hline & AZ02A-WT-ZS-608 & MOV-608 Positions A,B,\&C Indications & - \\
\hline & AZ02A-WT-ZC-609 & MOV-609 Positions A,B,\&C Commands & - \\
\hline & AZ02A-WT-ZS-609 & MOV-609 Positions A,B,\&C Indications & - \\
\hline & AZ02A-WT-ZC-611 & MOV-611 Positions A,B,\&C Commands & - \\
\hline & AZ02A-WT-ZS-611 & MOV-611 Positions A,B,\&C Indications & - \\
\hline & AZ02A-WT-ZC-612 & MOV-612 Positions A\&B Commands & - \\
\hline & AZ02A-WT-ZS-612 & MOV-612 Positions A\&B Indications & - \\
\hline & AZ02A-WT-ZC-613 & MOV-613 Positions A,B,\&C Commands & - \\
\hline & AZ02A-WT-ZS-613 & MOV-613 Positions A,B,\&C Indications & - \\
\hline
\end{tabular}




\begin{tabular}{|c|l|l|c|}
\hline $\begin{array}{c}\text { P\&ID } \\
\text { H-14-\# } \\
\text { /Sht }\end{array}$ & \multicolumn{1}{|c|}{ Tagname } & \multicolumn{1}{|c|}{ Description } & Setpoint \\
\hline \multirow{5}{*}{$102971 / 4$} & AZ02A-WT-ZC-614 & MOV-614 Positions A,B,\&C Commands & - \\
\cline { 2 - 5 } & AZ02A-WT-ZS-614 & MOV-614 Positions A,B,\&C Indications & - \\
\cline { 2 - 5 } & AZ02A-WT-ZIC-610 & FCV-610 Indication/Commands & - \\
\cline { 2 - 5 } & AZ02A-WT-ZS-610 & FCV-610 Open/Closed Indications & - \\
\cline { 2 - 5 } & AZ02A-WT-LDA-159 & MPS Event & 15 psig \\
\cline { 2 - 5 } & AZ02A-WT-XA-100 & High pressure in Flush jumper H-14-102978 & TBD \\
\cline { 2 - 5 } & AZ02A-WT-PAL-161 & Transfer Pump WT-P-022 Seal Gas Low Pressure & TBD \\
\cline { 2 - 5 } & AZ02A-WT-FAH-160 & Transfer Pump WT-P-022 Seal Gas High Flow & 15 psig \\
\cline { 2 - 5 } & AZ02A-WT-PAH-252 & Waste Transfer Pipe Rupture Disk PSE-101 Actuation & TBD \\
\cline { 2 - 5 } & AZ241-CHEMB-ZI-178 & CHEMB-V-178 Open/Closed Indication & TBD \\
\hline
\end{tabular}


Table B-4, AZ-101 Discrete Input/Output Instrumentation

\begin{tabular}{|c|c|c|c|}
\hline $\begin{array}{c}\text { P\&ID } \\
\text { H-14-\# } \\
\text { /Sht }\end{array}$ & Tagname & Description & Setpoint \\
\hline \multirow[t]{16}{*}{$102971 / 6$} & AZ101-WST-YL-201A & Mixer Pump WST-P-001 Local/Remote Indication & - \\
\hline & AZ101-WST-SS-201 & Mixer Pump WST-P-001 Auto/Manual/Off Command & - \\
\hline & AZ101-WST-YL-201B & Mixer Pump WST-P-001 Auto/Manual/Off Indication & - \\
\hline & AZ101-WST-HS-201A & Mixer Pump WST-P-001 Start/Stop Command & - \\
\hline & AZ101-WST-YL-201C & Mixer Pump WST-P-001 On/Off Indication & - \\
\hline & AZ101-WST-YL-203A & $\begin{array}{l}\text { Mixer Pump WST-P-001 Turntable Local/Remote } \\
\text { Indication }\end{array}$ & - \\
\hline & AZ101-WST-SS-203 & $\begin{array}{l}\text { Mixer Pump WST-P-001 Turntable Auto/Manual/Off } \\
\text { Command }\end{array}$ & - \\
\hline & AZ101-WST-YL-203B & $\begin{array}{l}\text { Mixer Pump WST-P-001 Turntable Auto/Manual/Off } \\
\text { Indication }\end{array}$ & - \\
\hline & AZ101-WST-HS-203A & Mixer Pump WST-P-001 Turntable Start/Stop Command & - \\
\hline & AZ101-WST-YL-203C & Mixer Pump WST-P-001 Turntable On/Off Indication & - \\
\hline & AZ101-WST-HS-203B & Mixer Pump WST-P-001 Turntable CW/CCW Command & - \\
\hline & AZ101-WST-ZL-103D & Mixer Pump WST-P-001 Turntable CW/CCW Indication & - \\
\hline & AZ101-WST-ZI-201 & Mixer Pump WST-P-001 VFD Transfer Switch Position & - \\
\hline & AZ101-WST-ZI-203E & $\begin{array}{l}\text { Mixer Pump WST-P-001 Turntable VFD Transfer Switch } \\
\text { Position }\end{array}$ & - \\
\hline & AZ101-WST-VAH-116 & $\begin{array}{l}\text { Mixer Pump WST-P-001 Lower Motor Bearing Vibration } \\
\text { High }\end{array}$ & - \\
\hline & AZ101-WST-VAH-117 & $\begin{array}{l}\text { Mixer Pump WST-P-001 Upper Motor Bearing Vibration } \\
\text { High }\end{array}$ & - \\
\hline \multirow[t]{5}{*}{$102971 / 6$} & AZ101-WST-YL-202A & Mixer Pump WST-P-002 Local/Remote Indication & - \\
\hline & AZ101-WST-SS-202 & Mixer Pump WST-P-002 Auto/Off/Manual Command & - \\
\hline & AZ101-WST-YL-202B & Mixer Pump WST-P-002 Auto/Off/Manual Indication & - \\
\hline & AZ101-WST-HS-202A & Mixer Pump WST-P-002 Start/Stop Command & - \\
\hline & AZ101-WST-YL-202C & Mixer Pump WST-P-002 On/Off Indication & - \\
\hline
\end{tabular}




\begin{tabular}{|c|c|c|c|}
\hline $\begin{array}{c}\text { P\&ID } \\
\text { H-14-\# } \\
\text { /Sht }\end{array}$ & Tagname & Description & Setpoint \\
\hline \multirow[t]{11}{*}{$102971 / 6$} & AZ101-WST-YL-204A & Mixer Pump WST-P-002 Turntable Local/Remote Ind. & - \\
\hline & AZ101-WST-SS-204 & $\begin{array}{l}\text { Mixer Pump WST-P-002 Turntable Auto/Off/Manual } \\
\text { Command }\end{array}$ & - \\
\hline & AZ101-WST-YL-204B & $\begin{array}{l}\text { Mixer Pump WST-P-002 Turntable Auto/Off/Manual } \\
\text { Indication }\end{array}$ & - \\
\hline & AZ101-WST-HS-204A & Mixer Pump WST-P-002 Turntable Start/Stop Command & - \\
\hline & AZ101-WST-YL-204C & Mixer Pump WST-P-002 Turntable On/Off Indication & - \\
\hline & AZ101-WST-HS-204B & Mixer Pump WST-P-002 Turntable CW/CCW Command & - \\
\hline & AZ101-WST-ZL-104D & Mixer Pump WST-P-002 Turntable CW/CCW Indication & - \\
\hline & AZ101 WST-ZI-202 & Mixer Pump WST-P-002 VFD Transfer Switch Position & - \\
\hline & AZ101-WST-ZI-204E & $\begin{array}{l}\text { Mixer Pump WST-P-002 Turntable VFD Transfer Switch } \\
\text { Position }\end{array}$ & - \\
\hline & AZ101-WST-VAH-108 & $\begin{array}{l}\text { Mixer Pump WST-P-002 Lower Motor Bearing Vibration } \\
\text { High }\end{array}$ & - \\
\hline & AZ101-WST-VAH-109 & $\begin{array}{l}\text { Mixer Pump WST-P-002 Upper Motor Bearing Vibration } \\
\text { High }\end{array}$ & - \\
\hline \multirow[t]{3}{*}{$102971 / 5$} & AZ801A-RW-PAL-750 & Mixer Pump WST-P-001 Upper Seal Water Low Pressure & 50 psig \\
\hline & AZ801A-RW-PAL-751 & Mixer Pump WST-P-002 Upper Seal Water Low Pressure & $50 \mathrm{psig}$ \\
\hline & AZ801A-RW-PDAH-750 & Mixer Pump Seal Water Filter High Differential Pressure & TBD \\
\hline
\end{tabular}




\section{APPENDIX C - CAUSTIC SUPPLY SYSTEM}

This is a generic description of how the shared CSS provided by Project W-211 operates for flushing and dilution of AZ-102. Equipment numbers (EINs) shown on Figure C-1 were chosen to facilitate this description of operation, and do not represent the actual EINs that are Tank Farm specific. The controller blocks and logic statements shown on Figure C-1 are implemented by the RCS computer through the use of Citect\& interactive graphic screens, and Modiconß PLC logic, implemented through Control Plus@ladder logic. For more detailed information on the programming aspects of this system, refer to the Programmers Guide, document HNF-3761 and the Description of Operation, document HNF-3514.

From the overall RCS perspective, the CSS can be started any time that outlet flow control valve FCV-1 is closed, and can continue to operate in the recirculation mode with no outside restrictions. However, some system components such as the caustic supply truck connections, and boiler operation must have been put in service locally by operators. The RCS will be used to remotely control the CSS once the boiler has been locally started and a caustic supply truck connected.

The CSS can be operated in either the MANUAL or AUTOMATIC mode.

In the MANUAL mode, all parameters can be set separately, and the only interlocks in effect are high tank level, which closes the incoming water valve and stops the injection pump, and low tank level, which stops the diluent/flush pump from cavitating. The normal interlocks such as high and low temperatures, high and low $\mathrm{pH}$, etc., are not in effect. In the MANUAL mode, caustic solution does not have to be added to the hot water. The operator can add any amount of caustic desired, including none. This feature allows the operator to deliver any $\mathrm{pH}$ level from hot raw water (about $\mathrm{pH} 7.3$ ), up to the maximum of $\mathrm{pH} 14$.

In the AUTOMATIC mode, the RCS will control the boiler temperature setpoint, the flush tank level, and the caustic/water injection ratio, and implement the interlock logic described herein. The total diluent flow rate will be controlled by the automatic positioning of the outlet flow control valve (FCV-1). Closing the outlet flow control valve will result in automatic adjustment of recirculation flow through FT-2 to satisfy the constant speed pump curve.

General:

The CSS will provide a source of caustic solution (diluent), or hot water, for dilution of the waste, flushing the waste transport piping, or providing hot water to clear the pump inlets of accumulated/solidified waste after extended shutdowns. An oil-fired boiler will heat the incoming water to a pre-set temperature, and the in-tank heater will maintain the tank temperature until the diluent is used. The caustic injection pump will inject $\mathrm{NaOH}$ into the heated water to obtain a pH between 11 and 14 . The diluent/flush pump will deliver the prepared diluent from the 5,000 gallon flush tank, through a route established by the RCS, to its end-point use (i.e., dilute or flush). Startup will be under administrative control, and because the tank may be in a different status prior to each use (e.g., full \& hot, cold \& empty, etc.), procedures will be developed to address the various startup scenarios. In general, the boiler will be started manually, and once boiler steam is within an acceptable range, inlet water/caustic flow to the $5,000 \mathrm{gal}$. tank will be initiated from the OIS.

The diluent flow to the waste storage tank will be totalized by the RCS computer in two ways, one will be a non-resettable accumulator to indicate total lifetime liquid flow through the system, and the second will be an operator-resettable accumulator that is set for each campaign, and automatically terminates flow when a preset value is reached. These (and similar) parameters are saved in an archival data base, so all activities (such as resets, alarm acknowledges, etc.) can be retrieved for future review. 


\section{Automatic Control (Refer to Figure C-1)}

The RCS will have been pre-loaded with a look-up table (See Figure C-1) of caustic flow rates (Fc) vs water flow rates ( $\mathrm{Fw}$ ) to achieve any one of five $\mathrm{pH}$ levels at any one of five flow rates (Fo). If a $\mathrm{pH}$ or flow rate not in the table is required, the system can be operated in the manual mode, where all parameters are adjustable, with no restrictions except equipment protection interlocks.

To startup the CSS for an upcoming campaign, the operator will enter desired values of diluent $\mathrm{pH}$, tank level, and diluent flow rate, in the SETUP screen on the RCS. The setup values will be interpreted by the RCS, using the proportioning matrix on Figure C-1, to establish setpoints that will deliver the desired total flow and $\mathrm{pH}$. The operator will then activate the CSS. Upon activation, the RCS will deliver the Fc setpoint to the $\mathrm{NaOH}$ pump, the Fw setpoint to flow controller (FC-2), the tank level setpoint to the tank level summing junction, and the 5000 gallon tank will begin to fill at the flow rate selected $(70$, $95,105,120$, or $140 \mathrm{gpm})$.

When the tank level approaches the level setpoint, the outlet flow control valve (FCV-1) will begin to open. The actual tank level signal will be compared with the tank level setpoint in the summing junction, and an error signal will be delivered to the flow setpoint summing junction, which will adjust the flow control valve to maintain desired tank level. Because the proportioning matrix is designed to deliver the correct total flow, only minor automatic adjustment of FCV-1 to accommodate slow changes in flush tank level is expected. In the AUTOMATIC mode, $\mathrm{Fc}, \mathrm{Fw}$, and Fo are constant values, but Fo is augmented in the summing junction by the tank level error signal.

When a software flow totalizer reaches the value previously entered on the CSS SETUP screen, the RCS will set Fc, Fw, and Fo to zero, stop the injection pump, and close the tank isolation valve (MOV-1) and the tank outlet flow control valve (FCV-1). As more experience is obtained, the operator could anticipate the approaching end of the dilute campaign, and begin manually reducing the tank level setpoint. This would leave the tank nearly empty when the totalizer stopped the process.

\section{Batch Mode}

The caustic system will be able to be operated in a "batch" mode, where the required volume of diluent is less than one tank full $(5,000 \mathrm{gal})$. In the batch mode, the operator will set the required tank level (volume), the tank will fill as described above, but the inlet flow will be terminated by closing MOV-1 when the tank level reaches the pre-set level. In the batch mode, the inlet isolation valve (MOV-1) will remain closed as the contents of the tank are pumped out through the outlet flow control valve (FCV-1) to support the mission profile.

Modes that require diluent useage also require a "CSS Ready" signal from the CSS to the RCS to allow the selected mode to be "Activated." The criteria for "CSS Ready" are different for the Batch or Continuous modes of the CSS as follows:

In the following conditions, all criteria are logically "ANDed" in the RCS software unless otherwise noted. 


\section{CSS READY:}

1. If Batch Mode $=O N$ :

FCV-1 is closed

Diluent/Flush Pump is ON

TI-1 $=$ setpoint $\pm 5^{\circ} \mathrm{F}$

AI-1 $=$ setpoint $\pm 5 \%$

LI-1 = setpoint $\pm 5^{\prime \prime}$

LC- 1 is in Manual

FI-2 > $100 \mathrm{gpm}$

CSS valves lined-up for applicable tank

2. If Continuous Mode $=\mathrm{ON}$ :

FCV-1 is closed

Diluent/Flush Pump is ON

TI-1 $=$ setpoint $\pm 5^{\circ} \mathrm{F}$

AI-1 $=$ setpoint $\pm 1 \%$

LI-1 = setpoint $\pm 5^{\prime \prime}$

Boiler is "READY"

FI-2 > $100 \mathrm{gpm}$

$\mathrm{NaOH}$ Pump is $\mathrm{ON}$

FC-1 is in Auto (with flow setpoint)

Boiler Fuel Level $>$ Minimum (Administrative Control, no automatic logic)

Boiler Temp $=$ Setpoint $\pm 5^{\circ} \mathrm{F}$

Boiler Pressure $=$ Setpoint $\pm 5^{\circ} \mathrm{F}$

CSS valves lined-up for applicable tank

Setpoints are values entered into the SETUP screen, and are mission-dependent. 


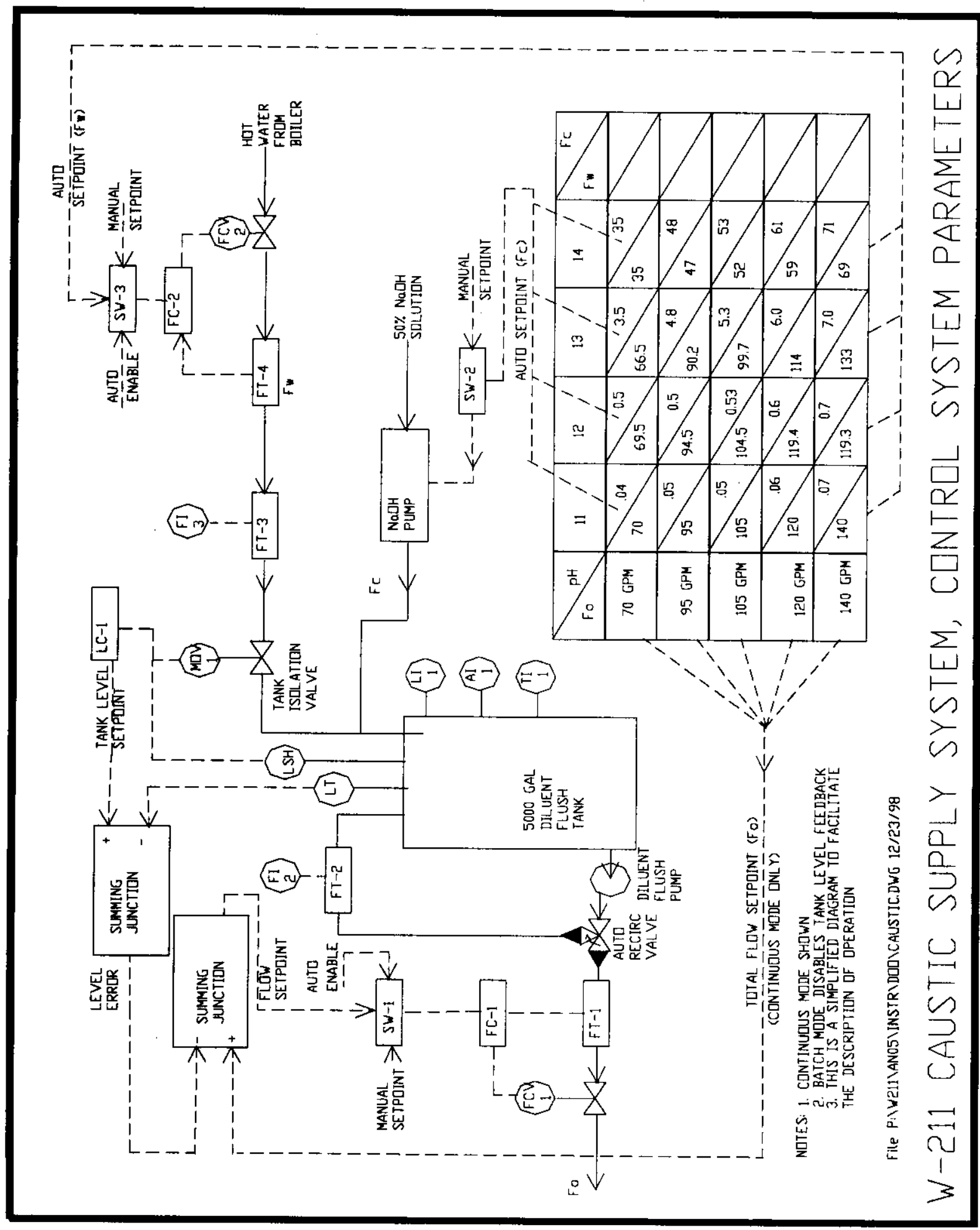




\section{APPENDIX D - HMI SCREENS}

FIGURE D-1: INITIAL TANK RETRIEVAL SYSTEMS RCS FOR DST 241-AZ-102

FIGURE D-2: RETRIEVAL SYSTEM OVERVIEW

FIGURE D-3: SCREEN LIST

FIGURE D-4: TYPICAL RETRIEVAL SETUP

FIGURE D-5: ALARM SUMMARY

FIGURE D-6: MODE LIST

FIGURE D-7: PLC STATUS

FIGURE D-8: BYPASSABLE INTERLOCK TABLE

FIGURE D-9: TYPICAL TANK OVERVIEW

FIGURE D-10: TYPICAL MIXER PUMP FACEPLATE

FIGURE D-11: TYPICAL TRANSFER PUMP FACEPLATE

FIGURE D-12: MIXER PUMP SPEED VS. POSITION PROFILE

FIGURE D-13: TEMPERATURE PROFILE FACEPLATE

FIGURE D-14: TYPICAL ALARM SETPOINT FACEPLATE

FIGURE D-15: FLOW CONTROL VALVE FACEPLATE

FIGURE D-16: 2-WAY MOV FACEPLATE

FIGURE D-17: 3-WAY MOV FACEPLATE

FIGURE D-18: AZ-102 ACTIVE INTERLOCK TABLE

FIGURE D-19: TRENDING SCREEN

FIGURE D-20: UTILITIES 


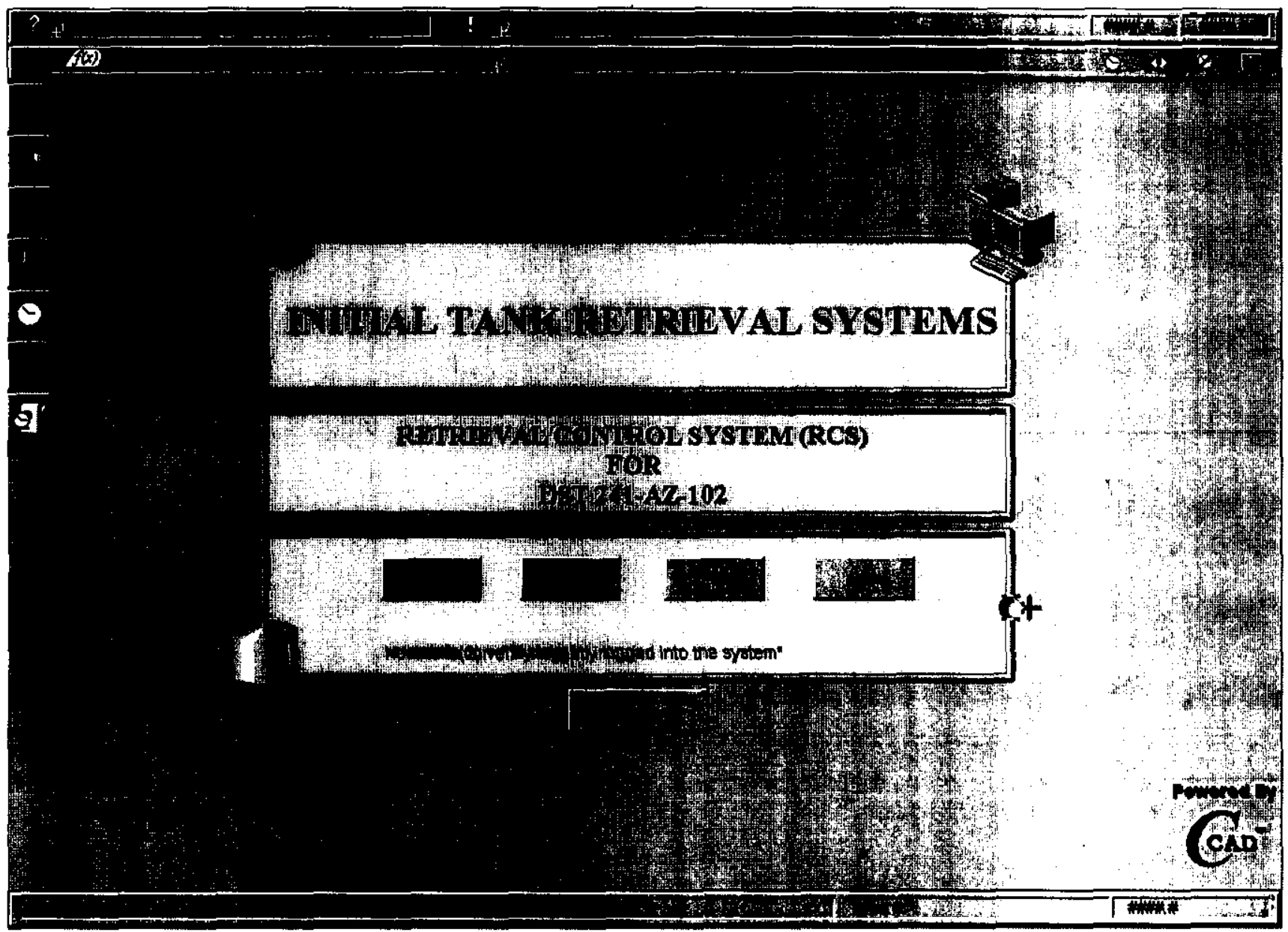

Figure D-1 


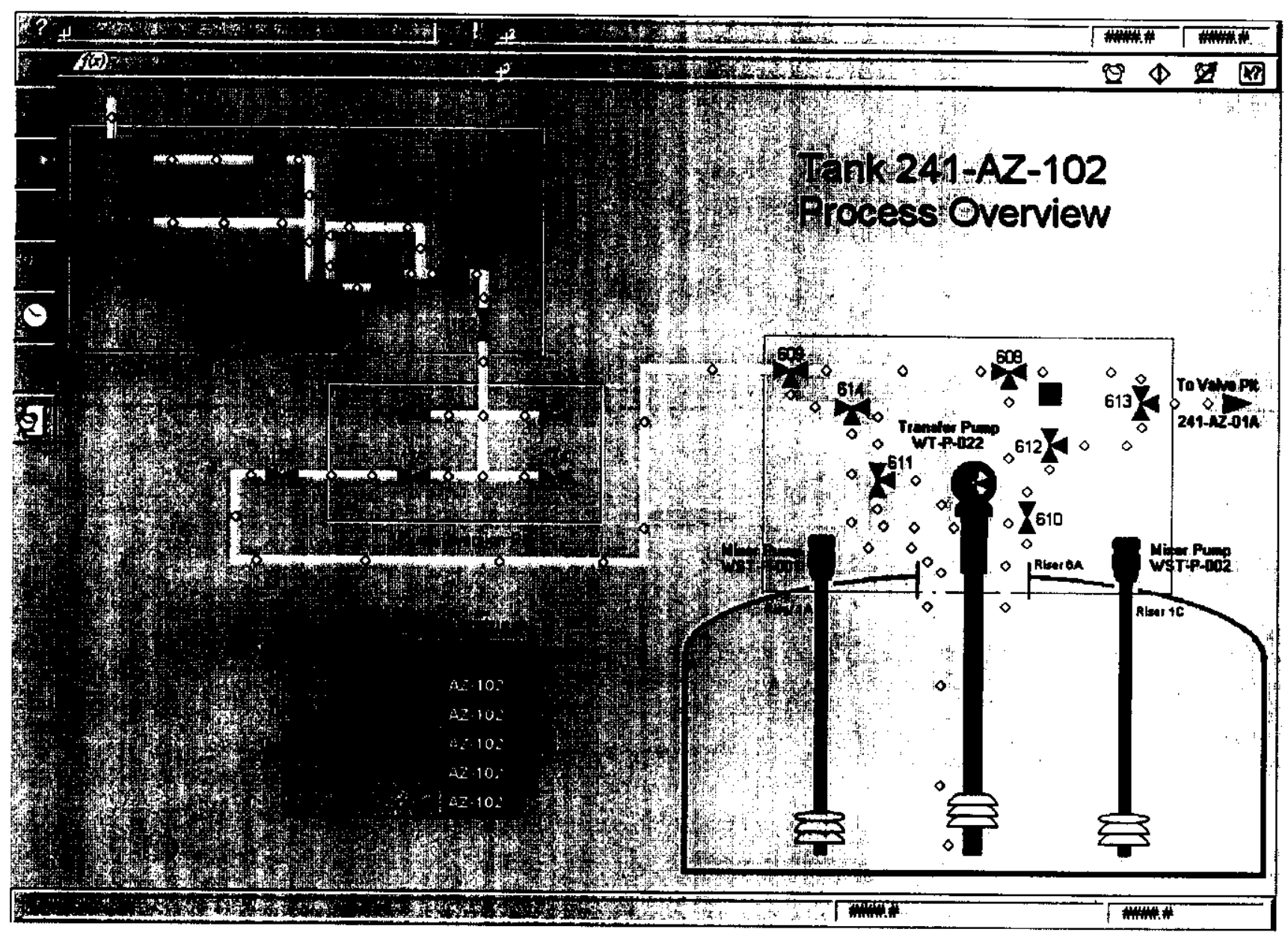

Figure D-2 


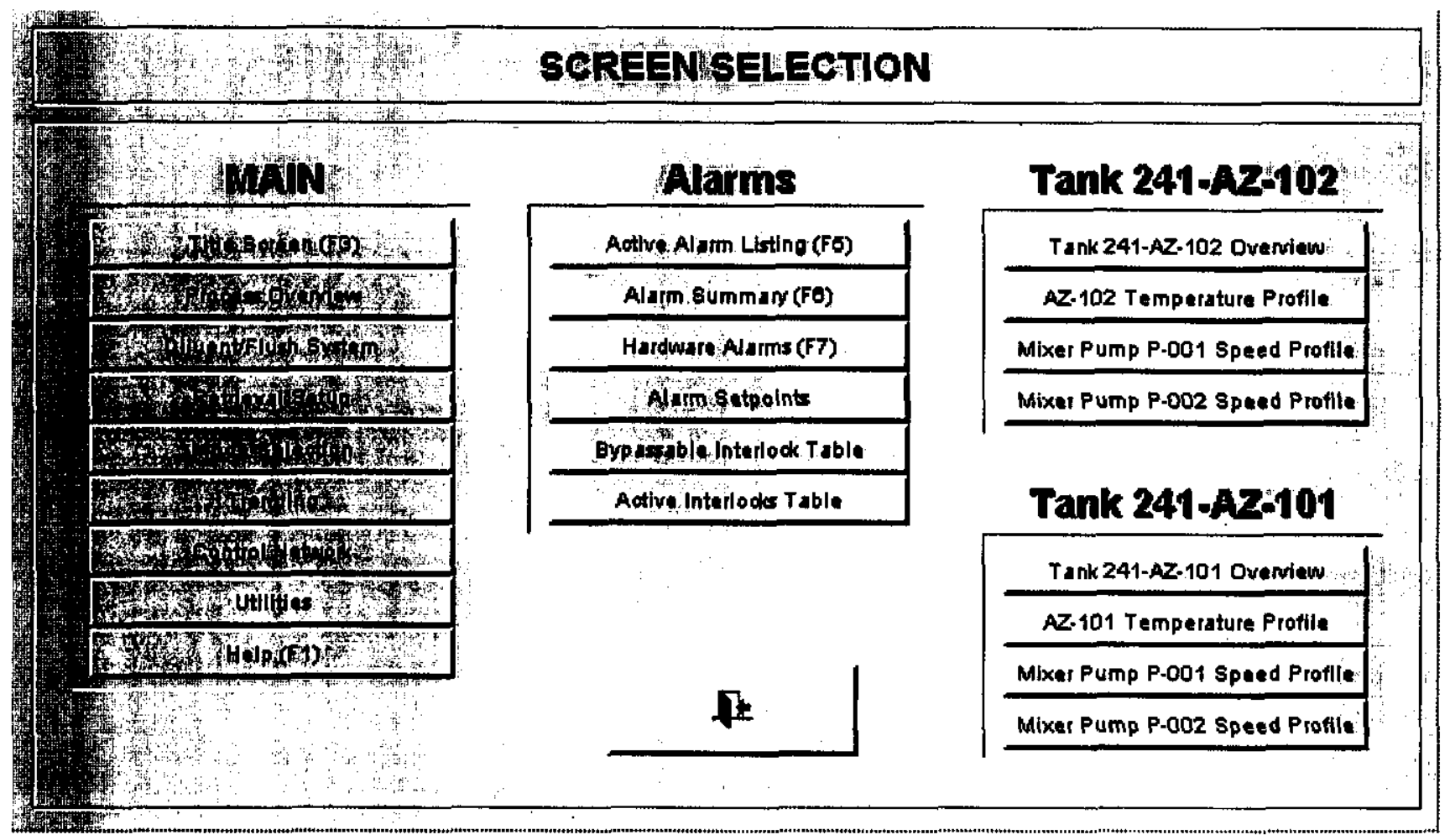

Figure D-3 


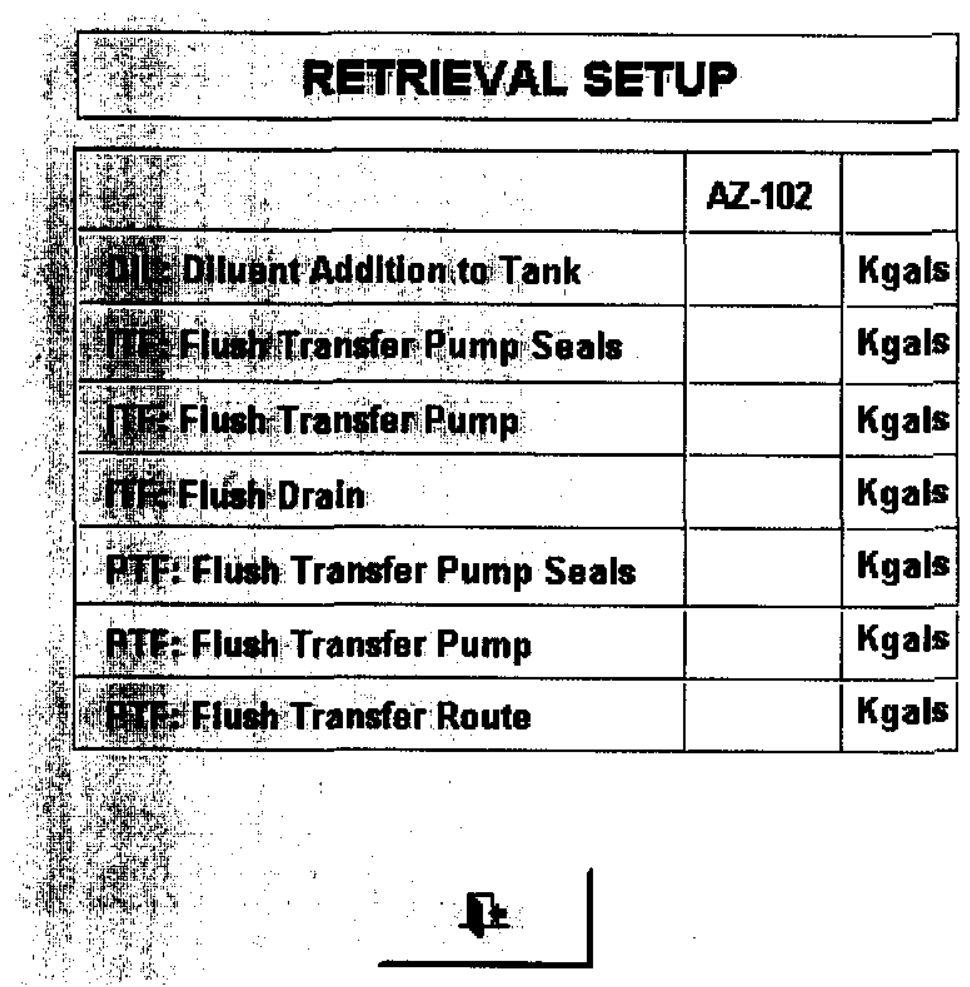

Figure D-4 


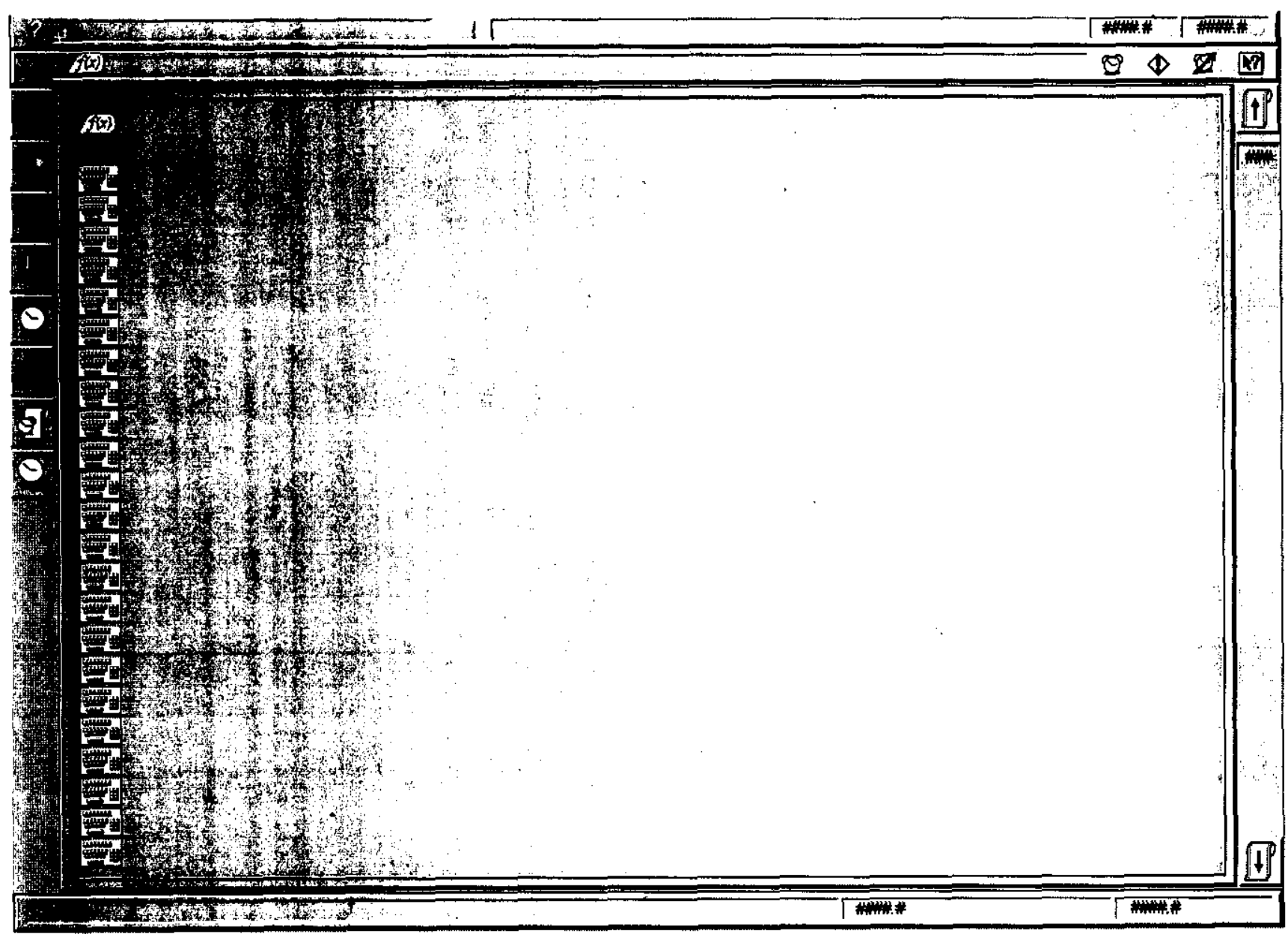

Figure D-5 


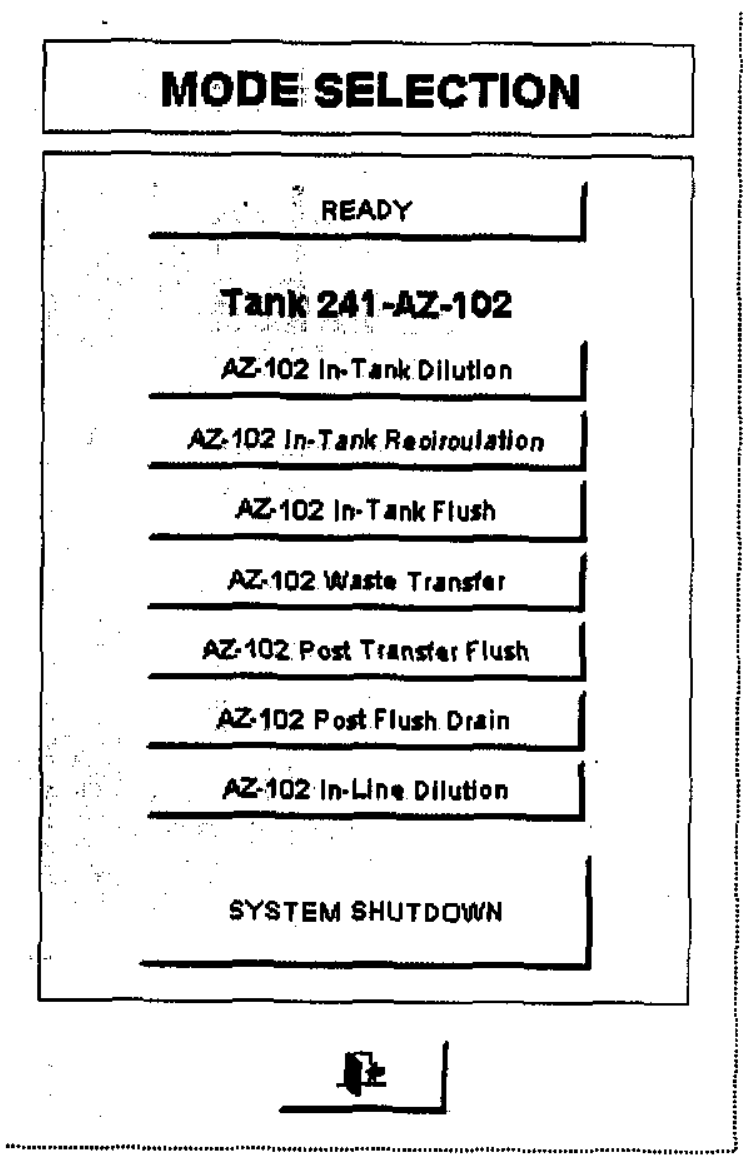

Figure D-6 


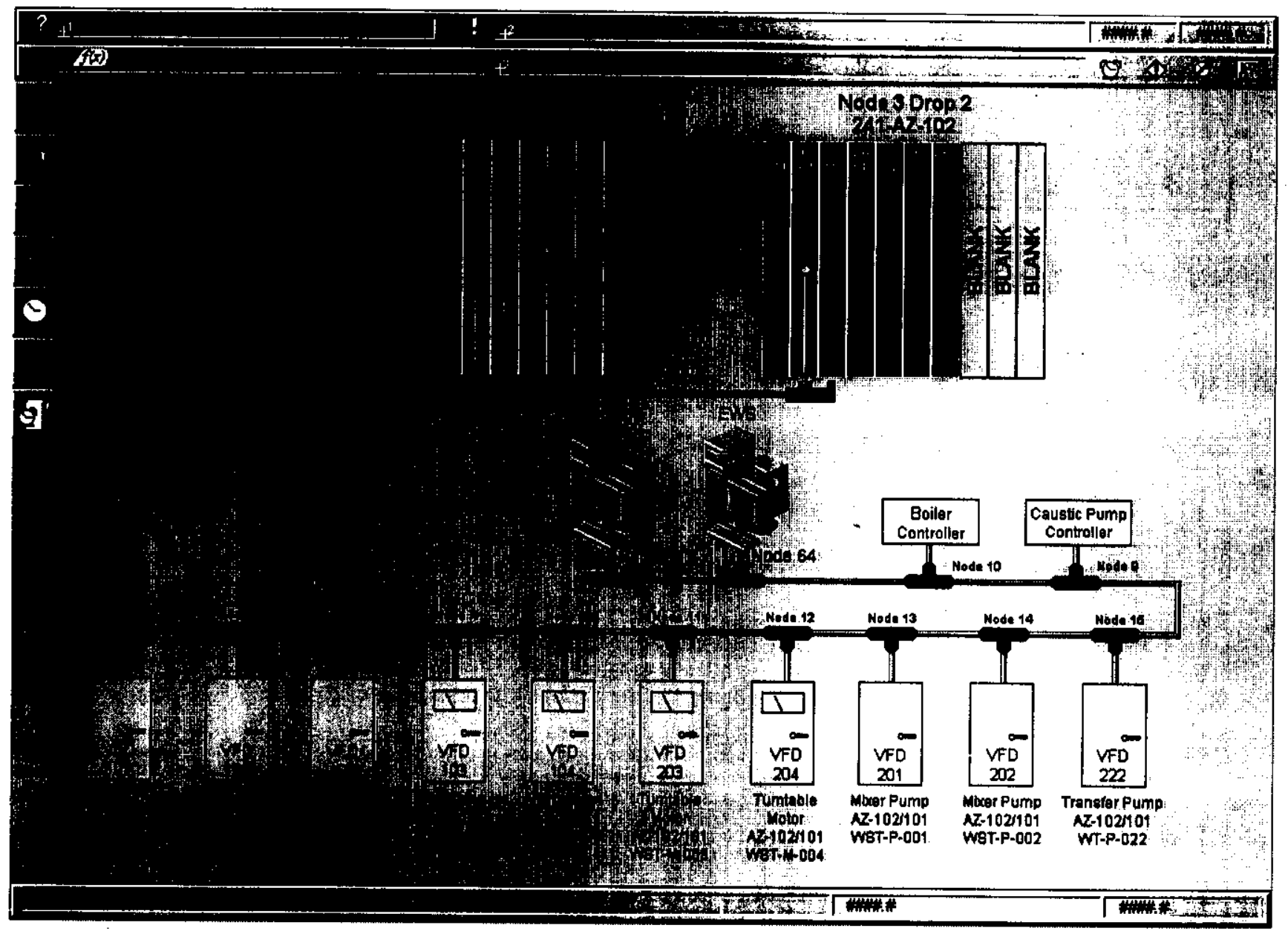

Figure D-7 


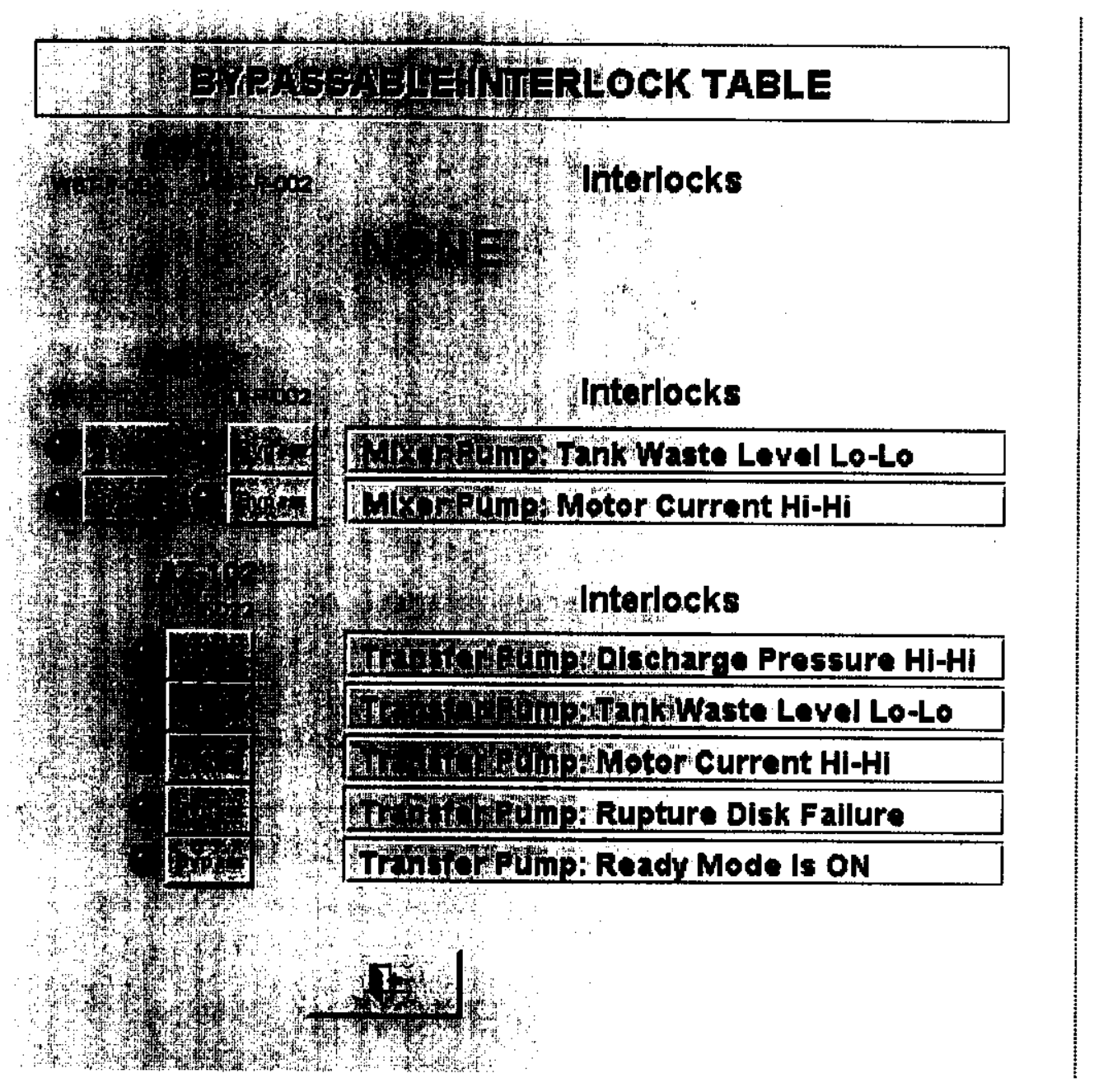

Figure D-8 


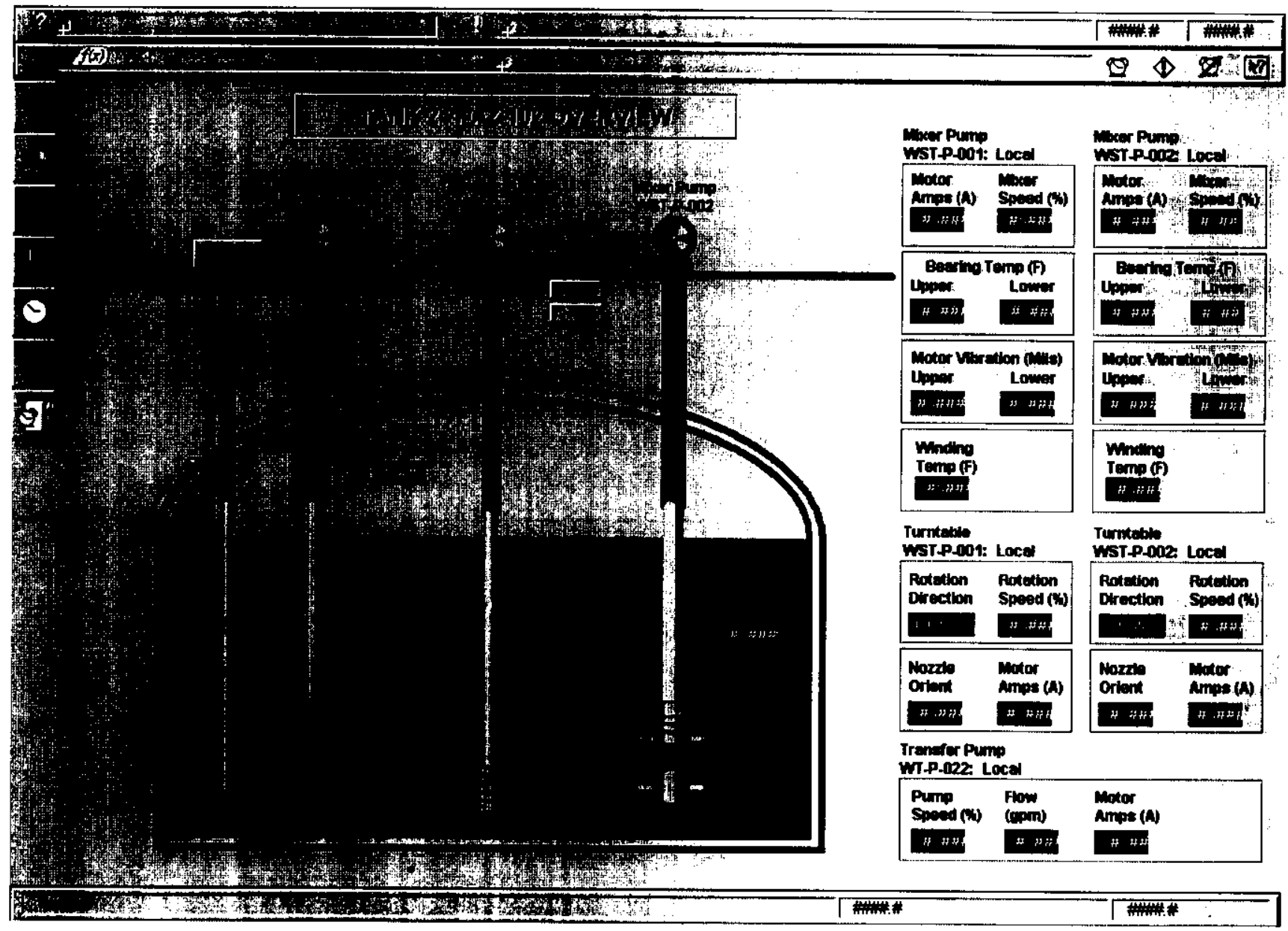

Figure D-9 


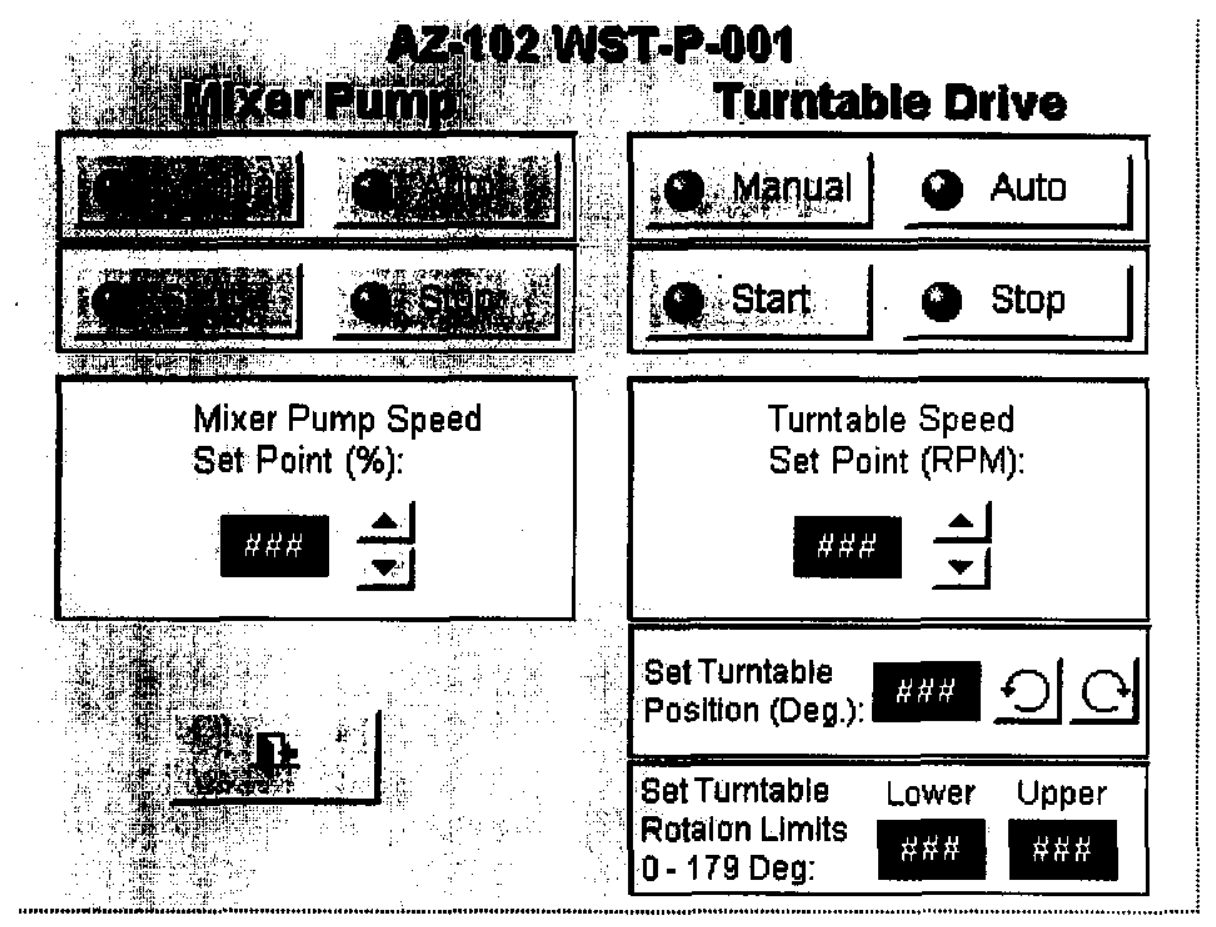

Figure D-10 


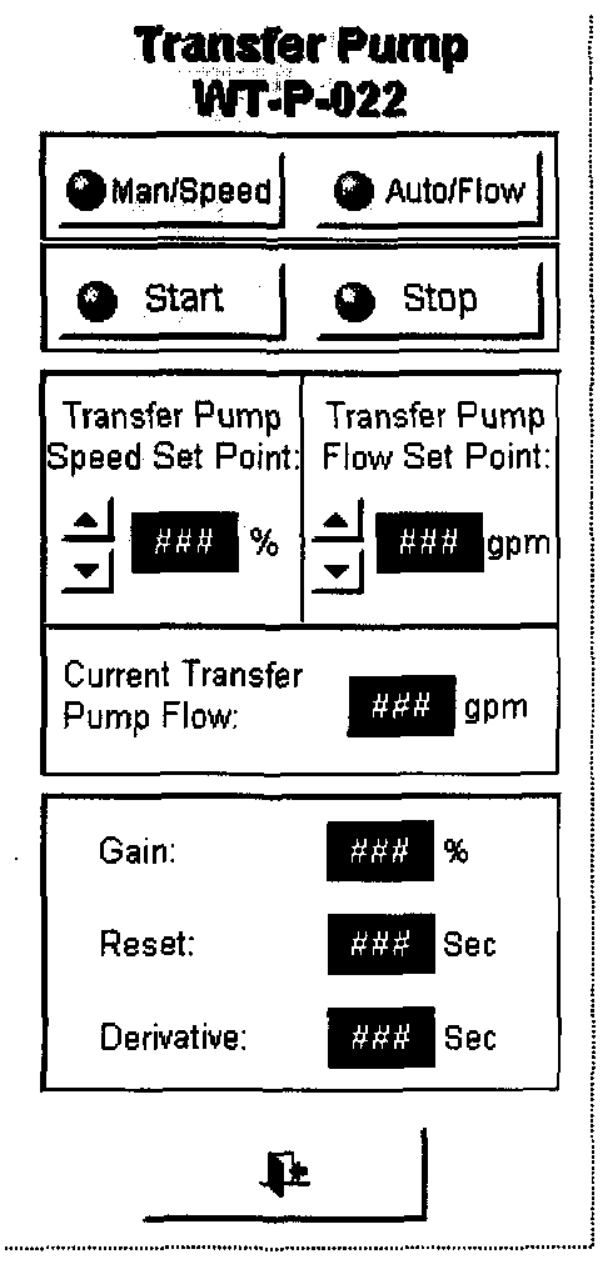

Figure D-11 


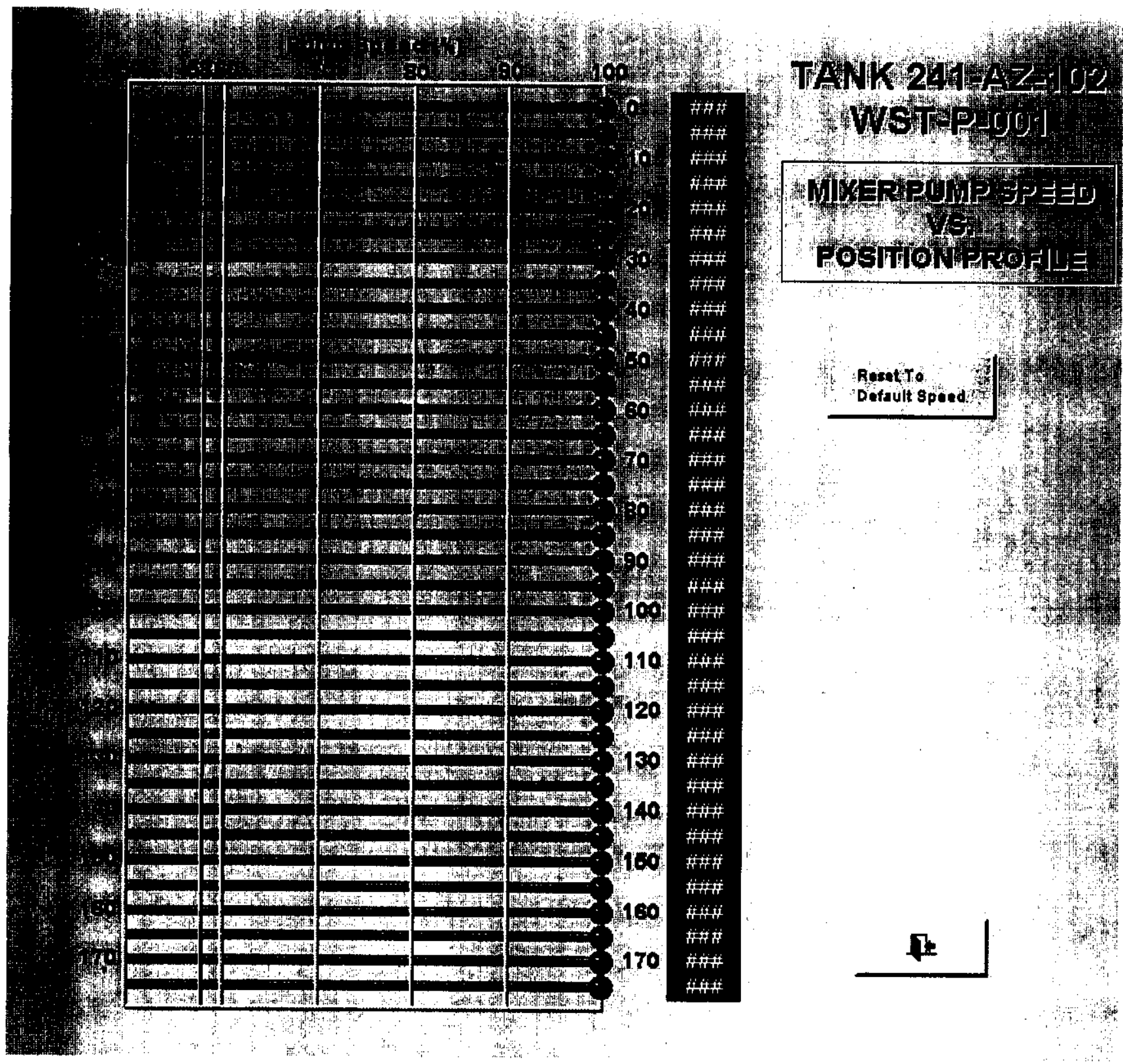

Figure D-12 


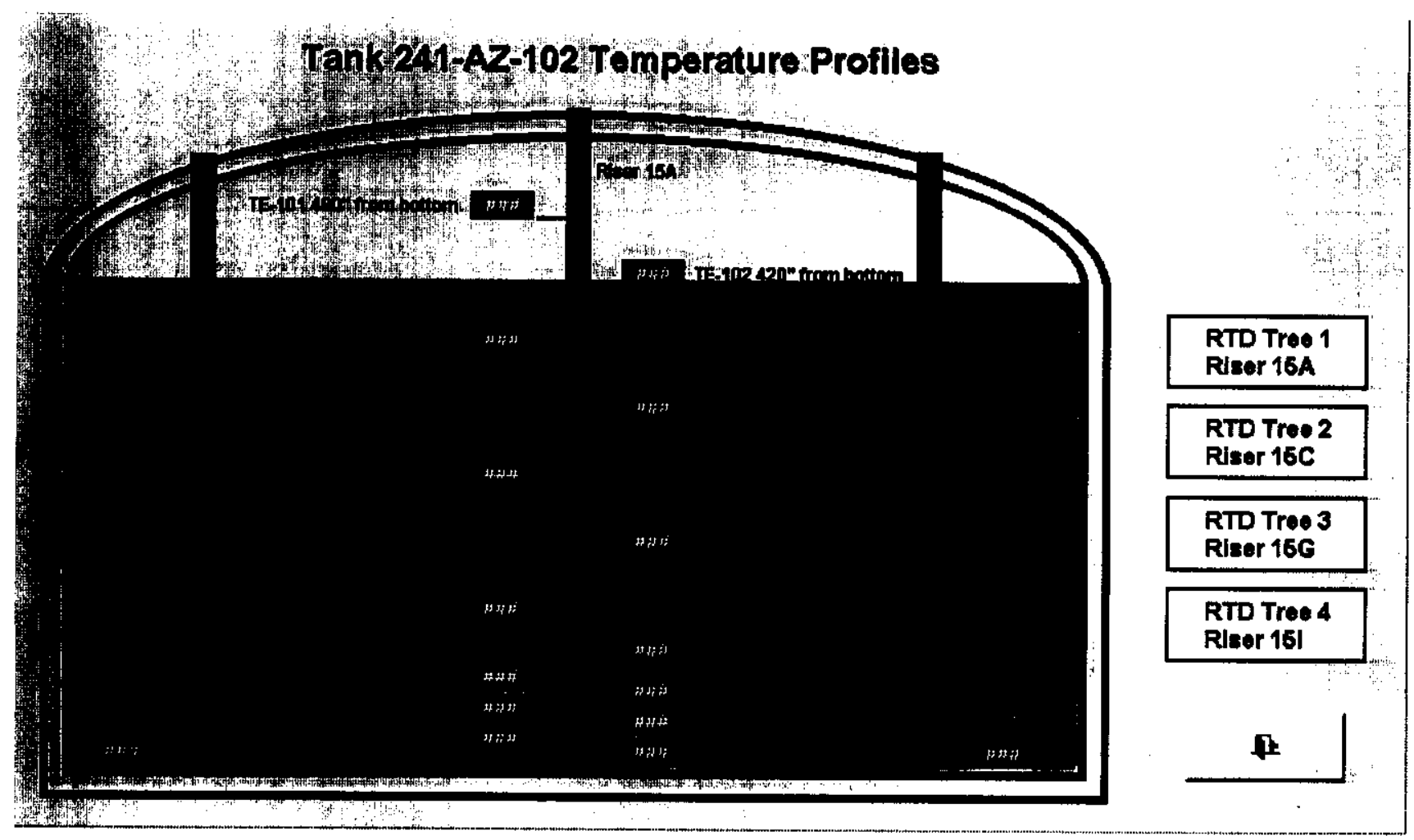

Figure D-13

D-14 


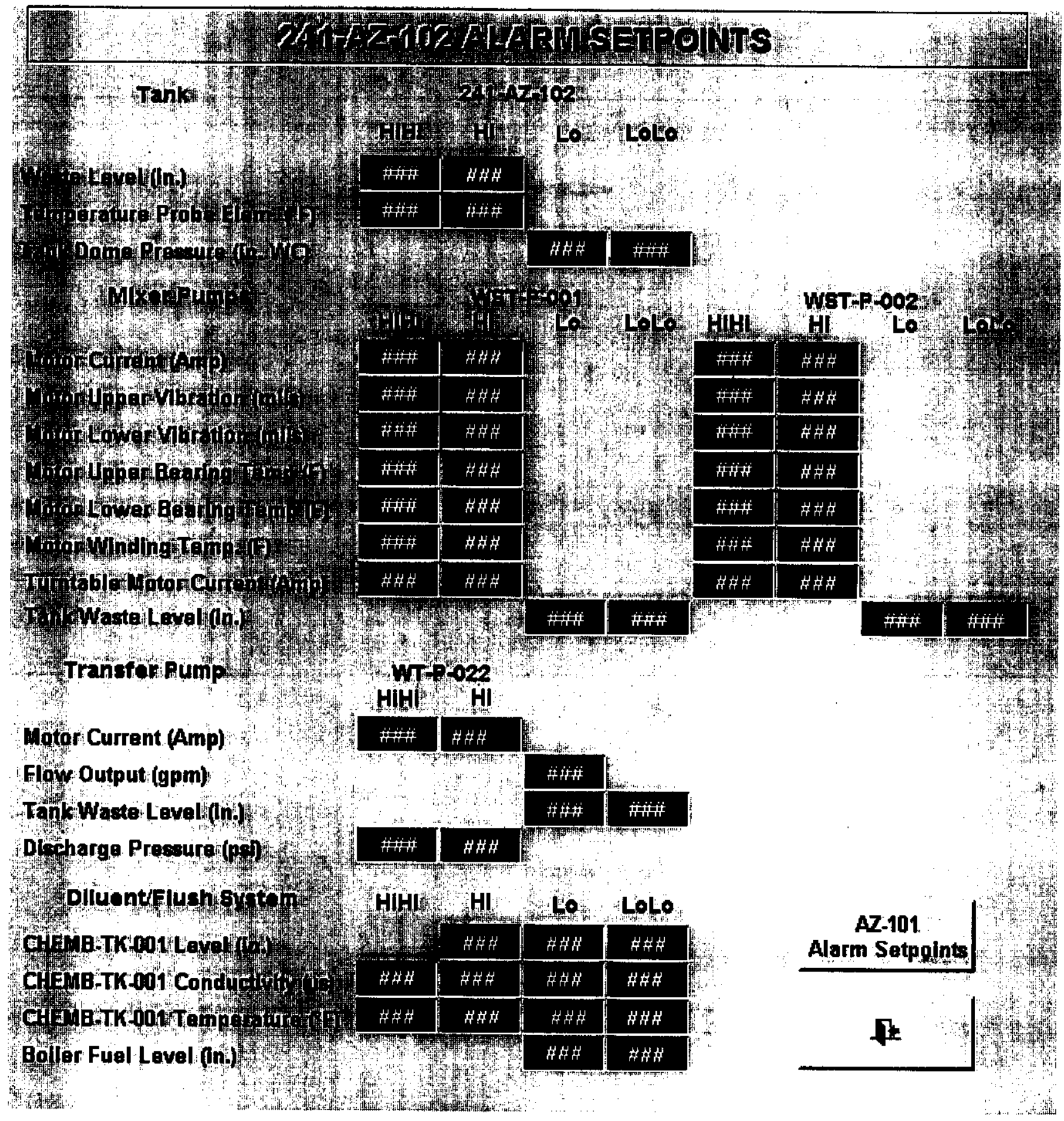

Figure D-14 


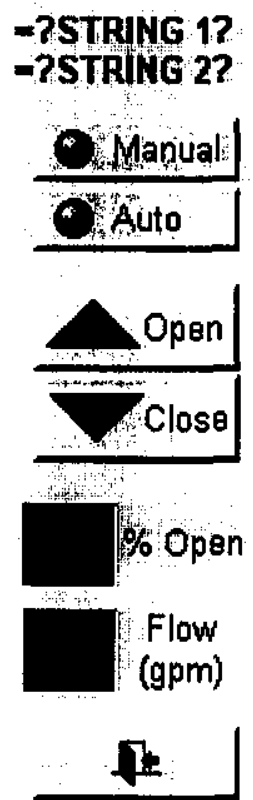

Figure D-15 
-?STRING $1 ?$

=?STRING 2 ?

\begin{tabular}{c} 
OManual \\
OAuto \\
\hline Open \\
\hline$\square$ Close \\
\hline 1
\end{tabular}

Figure D-16 


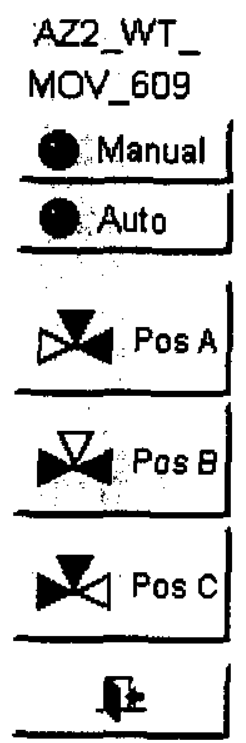

Figure D-17 


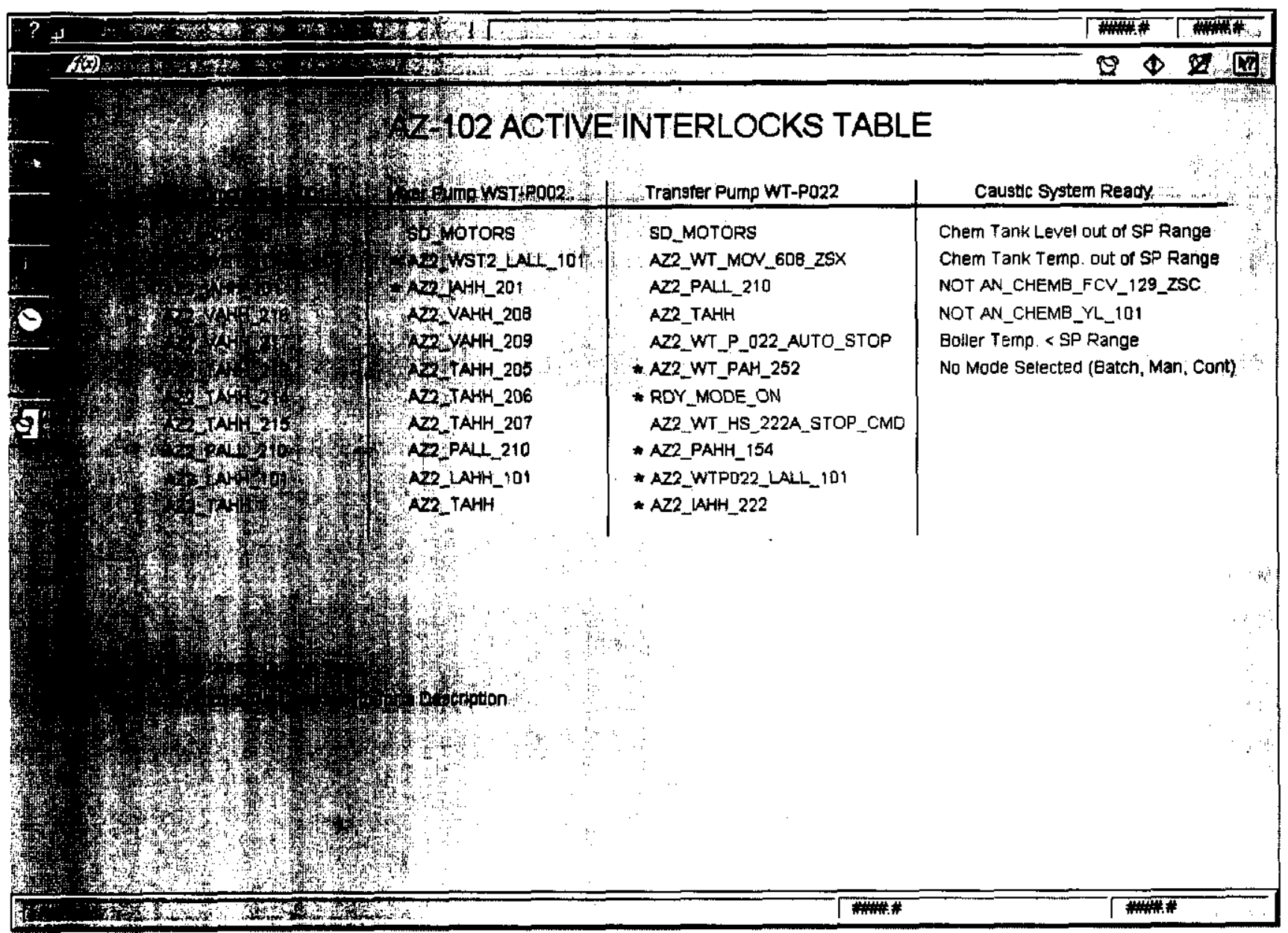

Figure D-18 


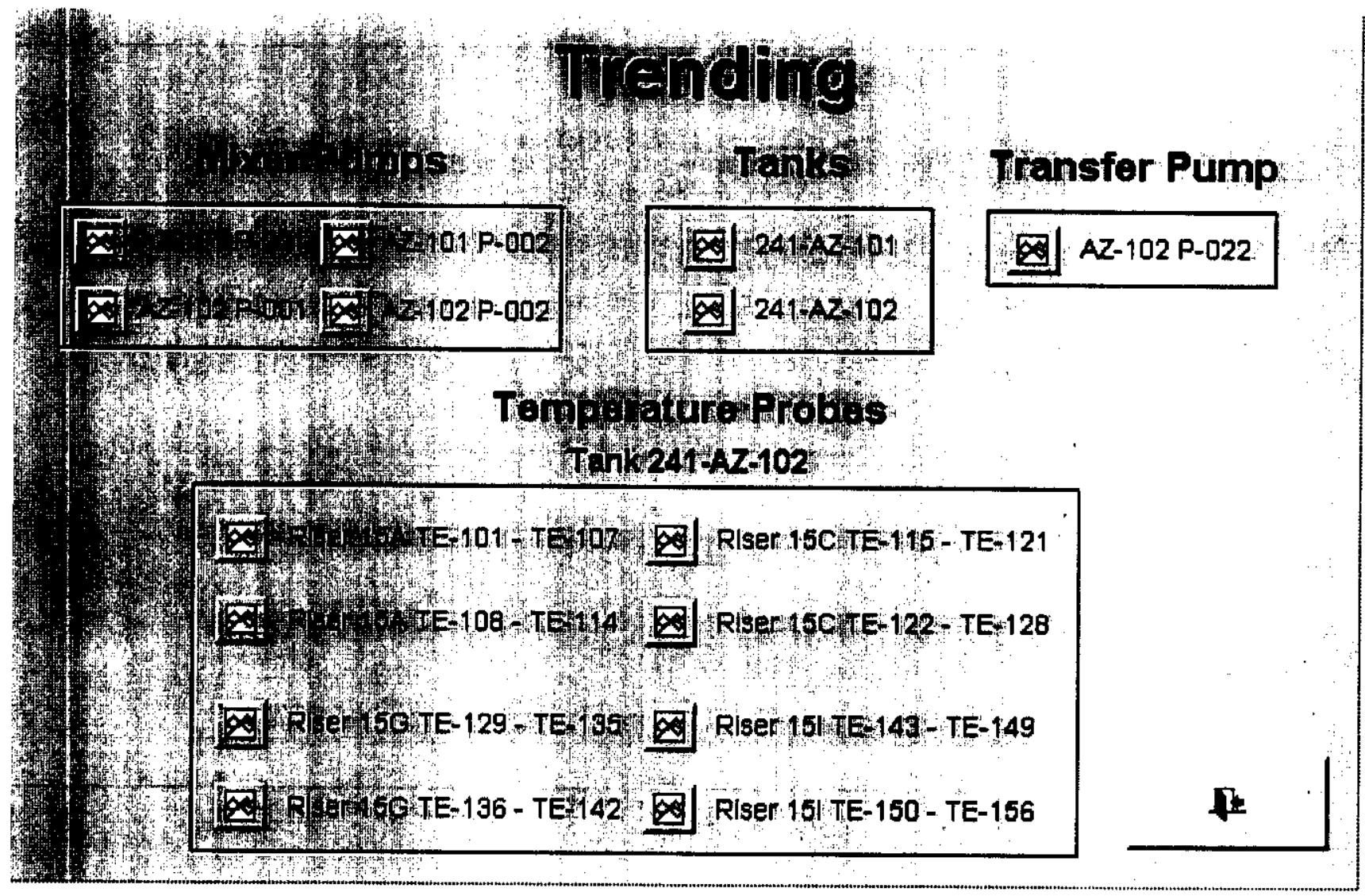

Figure D-19 


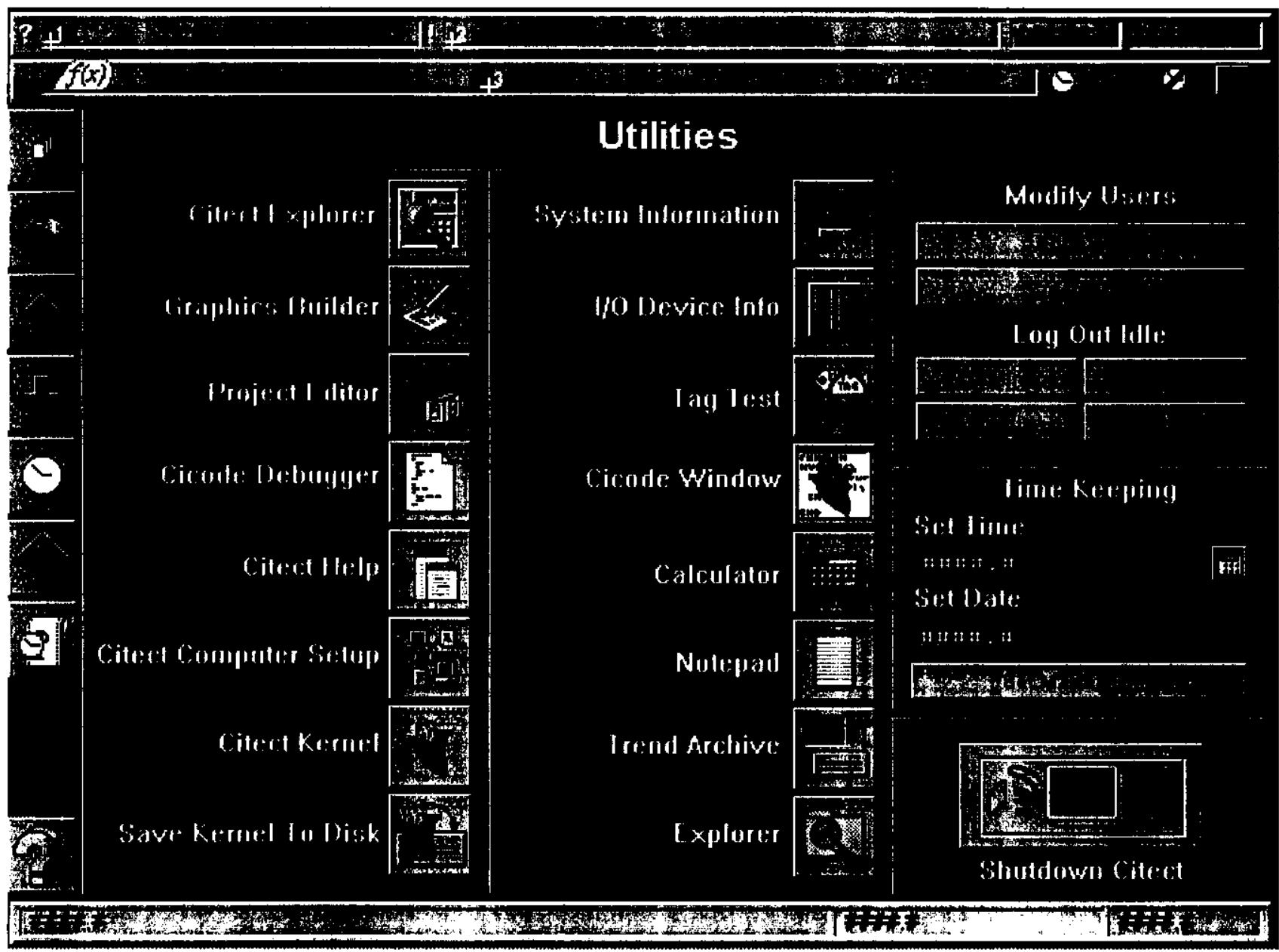

Figure D-20 